Prepared for the U.S. Department of Energy under Contract DE-AC05-76RL01830

\title{
THE WIDE-AREA ENERGY STORAGE AND MANAGEMENT SYSTEM PHASE II Final Report - Flywheel Field Tests
}
N Lu
F Rudolph
C Loutan
YV Makarov
S Murthy
S Chowdhury
MR Weimar
J Arseneaux

August 2010

\section{Pacific Northwest}

NATIONAL LABORATORY

Proudly Operated by Battelle Since 1965 


\title{
DISCLAIMER
}

This report was prepared as an account of work sponsored by an agency of the United States Government. Neither the United States Government nor any agency thereof, nor Battelle Memorial Institute, nor any of their employees, makes any warranty, express or implied, or assumes any legal liability or responsibility for the accuracy, completeness, or usefulness of any information, apparatus, product, or process disclosed, or represents that its use would not infringe privately owned rights. Reference herein to any specific commercial product, process, or service by trade name, trademark, manufacturer, or otherwise does not necessarily constitute or imply its endorsement, recommendation, or favoring by the United States Government or any agency thereof, or Battelle Memorial Institute. The views and opinions of authors expressed herein do not necessarily state or reflect those of the United States Government or any agency thereof.

\author{
PACIFIC NORTHWEST NATIONAL LABORATORY \\ operated by \\ BATTELLE \\ for the \\ UNITED STATES DEPARTMENT OF ENERGY \\ under Contract DE-AC05-76RL01830
}

Printed in the United States of America
Available to DOE and DOE contractors from the Office of Scientific and Technical Information, P.O. Box 62, Oak Ridge, TN 37831-0062; ph: (865) 576-8401 fax: $(865) 576-5728$
email: reports@adonis.osti.gov

Available to the public from the National Technical Information Service, U.S. Department of Commerce, 5285 Port Royal Rd., Springfield, VA 22161 ph: (800) 553-6847 fax: $(703) 605-6900$ email: orders@ntis.fedworld.gov online ordering: http://www.ntis.gov/ordering.htm

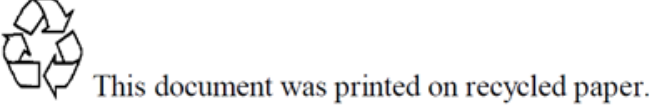


PNNL-19669

\section{THE WIDE-AREA ENERGY MANAGEMENT SYSTEM Phase II Final Report - Flywheel Field Tests}

Ning Lu, PhD, Project Manager

Yuri V. Makarov, Ph.D.: Chief Scientist - Power Systems, Principal Investigator Mark R. Weimar, Ph.D.: Chief Economist

Pacific Northwest National Laboratory

Frank J. Rudolph, $\mathrm{PhD}$

Shashikala N. Murthy, MS

Jim Arseneaux, MS

Beacon Power Corporation

Clyde Loutan, Senior Advisor

Sirajul Chowdhury, Sr. EMS Engineering Specialist

California Independent system Operator

August 2010

Prepared for

the Bonneville Power Administration

and the California Energy Commission

under Contract DE-AC05-76RL01830

Related Services

Pacific Northwest National Laboratory

Richland, Washington 99352 


\section{Acknowledgements}

This work was funded by the Bonneville Power Administration and the California Energy Commission and managed by the California Institute for Energy and Environment. This report was prepared with support from the California Independent System Operator.

The authors would like to thank Mike Gravely, Pedro Gomez, and Jamie Patterson, California Energy Commission; Terry Oliver, John H Pease Jr., Bart McManus, Nancy Parker, Juergen Bermejo, and Eric King, Bonneville Power Administration; and Merwin Brown, Larry Miller, and Jim Cole, California Institute for Energy and Environment; and Jim Price, California Independent System Operator, for providing the project team with organizational support, advice, and guidance essential to this work.

The authors would also like to thank Ross T. Guttromson, Carl H. Imhoff, Evan O. Jones, Mark P. Morgan, Suresh Baskaran, and Sheena L. Kanyid, Pacific Northwest National Laboratory, for supporting this work.

The authors would like to express their sincere thanks to Jian Ma, Pacific Northwest National Laboratory, for providing a technical review for the report.

The authors would like to express their sincere thanks to Wayne Cosby, Pacific Northwest National Laboratory, for providing an editorial review for the report. 


\section{Abstract}

The higher penetration of intermittent generation resources (including wind and solar generation) in the Bonneville Power Administration (BPA) and California Independent System Operator (CAISO) balancing authorities (BAs) raises the issue of requiring expensive additional fast grid balancing services in response to additional intermittency and fast up and down power ramps in the electric power system.

The overall goal of the wide-area energy management system (WAEMS) project is to develop the principles, algorithms, market integration rules, a functional design, and technical specifications for an energy storage system to cope with uncertainties and unexpected rapid changes in renewable generation power output. The resulting WAEMS system will store excess energy, control dispatchable load and distributed generation, and use inter-area exchange of the excess energy between the CAISO and BPA BAs. A further goal is to provide a cost-benefit analysis and develop a business model for an investment-based practical deployment of such a system.

A major goal of the WAEMS project is to minimize the balancing effort by developing a centralized control system that operates energy storage devices in conjunction with conventional generators to provide fast balancing services that can be shared among balancing authorities. The idea is based on coordination of traditional services (provided by conventional generation) and energy storage.

In Phase II of the project described in this report, a prototype WAEMS configuration consisting of a hydro electric plant and a flywheel energy storage was field tested using actual area-control-error and regulation signals provided by BPA and CAISO. The results were used to evaluate the performance and economics of the flywheel-hydro regulation service.

The performance evaluation shows an excellent performance of the WAEMS control algorithm, which separates the faster regulation effort provided by the energy storage from the slower one provided by a conventional regulating unit. The WAEMS combined service is not strictly constrained by energy storage limits because the hydro plant supports the desired flywheel's energy level. In addition, the WAEMS combined service has the same fast-response characteristic (within 6 seconds) as that provided by the flywheel energy storage alone. Furthermore, the WAEMS control algorithm reduces wear and tear on the hydro unit and allows the hydro unit to operate closer to its preferred operating point.

The breakeven price for flywheel energy storage to provide bi-directional service (1 MW regulation-up and $1 \mathrm{MW}$ regulation-down) is $\$ 20.37 / \pm \mathrm{MW}$. Because the average bi-directional regulation price of the CAISO balancing authority is $\$ 11.95 / \pm \mathrm{MW}$ (Jan.-July, 2010) and that of 
the BPA balancing authority is $\$ 9.38 / \pm \mathrm{MW}(2010)$, regulation service provided by a standalone flywheel energy storage will not be economical unless the regulation price will be increased or the fast regulation service will be paid at a higher rate.

Assuming that the minimum regulation price of regulation provided a hydro power plant is $\$ 4 / \pm \mathrm{MW}$, the breakeven price of the combined flywheel-hydro regulation service would be $\$ 12.19 / \pm \mathrm{MW}$; therefore, the flywheel-hydro regulation service breakeven price is found to be slightly higher than the average CAISO (\$11.95/ $\pm \mathrm{MW})$ and BPA $(\$ 9.38 / \pm \mathrm{MW})$ regulation prices. Because regulation prices are increasing when more renewable generation resources are integrated into the power grids, the flywheel-hydro regulation service is expected to become economical in the CAISO and BPA balancing authorities soon.

From the results, we conclude that the opportunities for flywheels or other energy storage devices lie in the following areas:

- To avoid performance problems associated with their finite energy storage capacity, provide regulation services for system operators which would agree to manage the flywheels' energy level, or participate in alternative schemes helping to co-optimize fast acting storage devices and conventional generators to provide high-quality combined regulation services.

- Operate energy storage devices in conjunction with conventional generators to improve their response time, reduce their wear and tear, and provide compatible services that do not require modifications of the existing automatic generation control and market systems.

- To increase the capacity payment, explore opportunities for sharing regulation services among two or more balancing authorities.

- Investigate methods and tariff changes so that the fast responsive and flexible resources can be compensated for additional services such as frequency response, fast ramping, voltage and reactive power support, or damping of transmission line oscillations to prevent grid angular instability.

Keywords: energy storage, flywheel, regulation services, balancing services, economic analysis, performance evaluation, wind integration, ancillary services.

\section{Please use the following citation for this report:}

Lu, Ning, Yuri V. Makarov, Mark R. Weimar, Frank J. Rudolph, Shashikala N. Murthy, Jim Arseneaux, Clyde Loutan, and Sirajul Chowdhury. 2010. Wide-area Energy Management System, Phase II Final Report-Flywheel Field Tests, California Energy Commission. Publication number: PNNL-19669. 


\title{
Acronyms
}

\author{
ACE area control error \\ AGC automatic generation control \\ APEL Advanced Process Engineering Laboratory \\ BA balancing authority \\ BP base-point \\ BPA Bonneville Power Administration \\ CAISO California Independent System Operator Corporation \\ CEC California Energy Commission \\ CIEE California Institute for Energy and Environment \\ DOE U.S. Department of Energy \\ DOT dispatch operating target \\ EMS energy management system \\ ESD energy storage device \\ FERC Federal Energy Regulatory Commission \\ ISO Independent System Operator \\ $\mathrm{NaS} \quad$ sodium sulfur \\ NPV net present value \\ NYISO New York Independent System Operator \\ O\&M operations and maintenance \\ PDF probability density function \\ PJM Pennsylvania-New Jersey-Maryland Interconnection \\ PNNL Pacific Northwest National Laboratory \\ SOC state of charge \\ WAEMS wide-area energy management system
}




\section{Table of Contents}

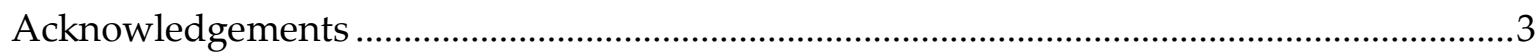

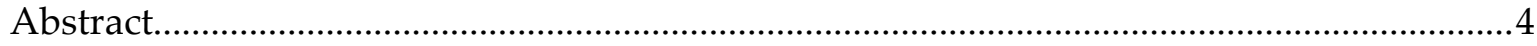

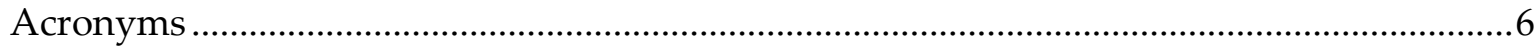

Executive Summary ……………………………………………………………....13

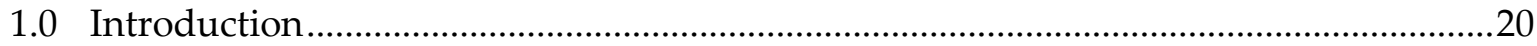

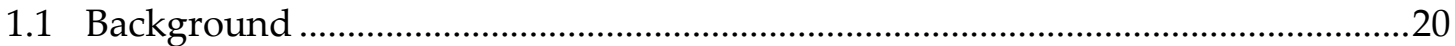

1.1.1 An Introduction to the Wide-area Energy Management System ................20

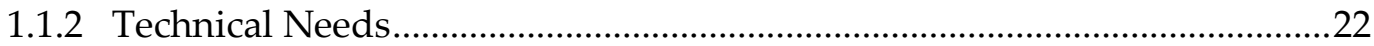

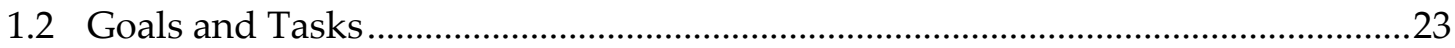

1.3 The Beacon Power Flywheel Technology [6]........................................................24

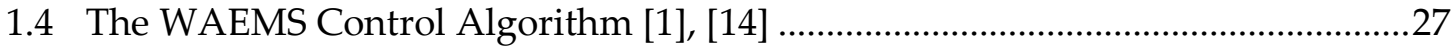

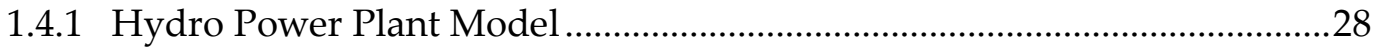

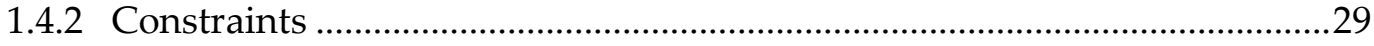

1.4.3 Objective Function.......................................................................................

1.4.4 Resulting Minimization Problem ...................................................................32

2.0 Flywheel Field Experiments.......................................................................................34

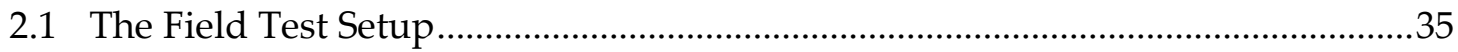

2.2 Field Test Signals Preparation …………………………………………………......

2.2.1 The Characteristics of the CAISO ACE Signal ...............................................38

2.2.2 The Characteristics of the BPA ACE Signal....................................................4

2.2.3 The Characteristics of the Aggregated CAISO and BPA ACE Signal..........44

2.2.4 The Characteristics of the Base-point Adjustment Signal of a Hydro Plant in BPA Balancing Authorities ...........................................................................4

2.2.5 The Characteristics of the Regulation Signal of a Hydro Plant in the CAISO Balancing Authorities........................................................................46

2.2.6 The Characteristics of the Future BPA, CAISO, and Aggregated (BPA+CAISO) ACE Signals............................................................................4

2.2.7 The Test Signals Normalization ……………………………………….....4

3.0 Flywheel Performance Evaluation ……………………………………………......49

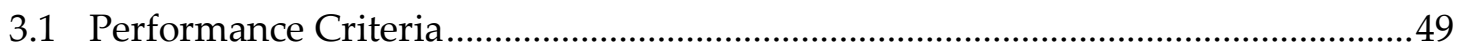

3.2 Field Test 1: CAISO and BPA ACE Signal Sharing …………………………........51

3.3 Field Test 2: The BPA Base-point Adjustment Signal .............................................56 
3.4 Field Test 3: Flywheel Responses to the CAISO Regulation Signal Sent to a

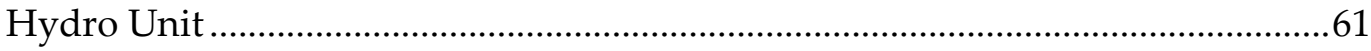

3.5 Field Test 4: The Future Aggregated ACE Signal ..................................................64

3.6 Field Test 5: The Future BPA ACE Signal .............................................................6

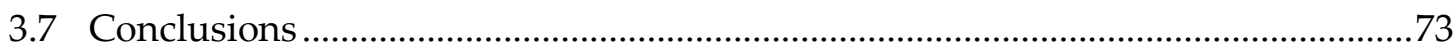

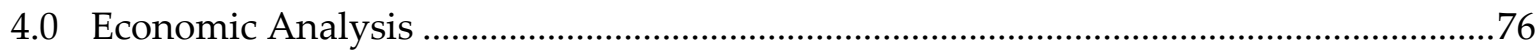

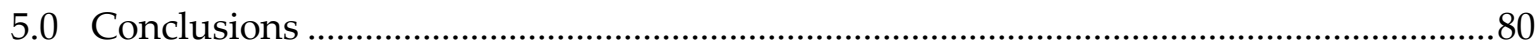

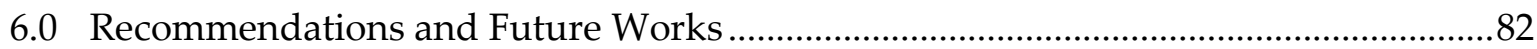

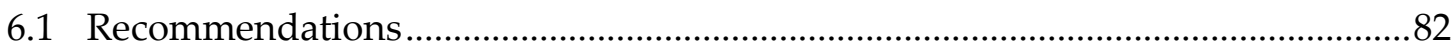

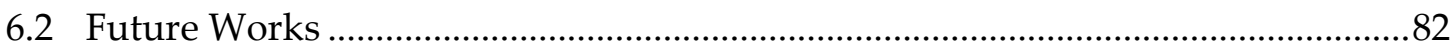

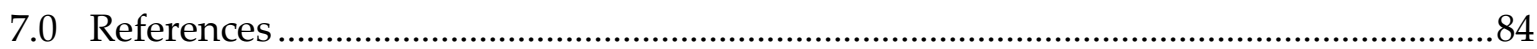




\section{List of Tables}

Table 1: Flywheel energy storage characteristics...............................................................25

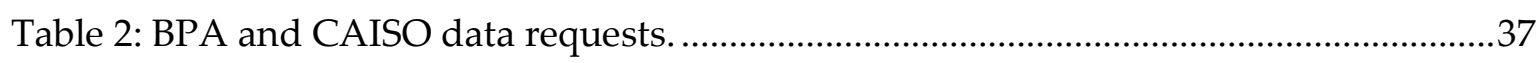

Table 3: Test signal sent to Beacon Power. …........................................................................37

Table 4: The regulation energy savings by ACE sharing. …...............................................45

Table 5: The performance of the three cases........................................................................52

Table 6: The performance of the three cases......................................................................57

Table 7: The performance of the three cases.....................................................................66

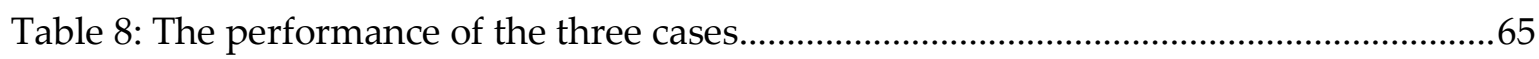

Table 9: The performance of the three cases........................................................................69

Table 10: The flywheel performance of the five test cases. .................................................75

Table 11: The inputs of the model.........................................................................................77

Table 12: Modeling results of the fixed flywheel lifetimes...................................................77

Table 13: The 2010 CAISO regulation prices (Region CAISO_EXP) ....................................79 


\section{List of Figures}

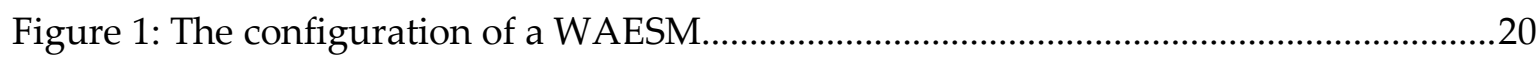

Figure 2: Artist's rendering of Beacon's 20-MW flywheel plant. ........................................25

Figure 3: A 1-MW outdoor flywheel storage facility. ........................................................26

Figure 4: The lifetime plots of the flywheel versus the NaS battery...................................26

Figure 5: The flow chart of the control algorithm. ............................................................27

Figure 6: Block diagram of the hydro power plant model.................................................28

Figure 7: Hydro power plant model response to step signals..............................................28

Figure 8: The plot of the flywheel energy deviation loss function........................................31

Figure 9: Loss function of the hydro power plant...............................................................32

Figure 10: The combined regulation service provided by the flywheel and a hydro power

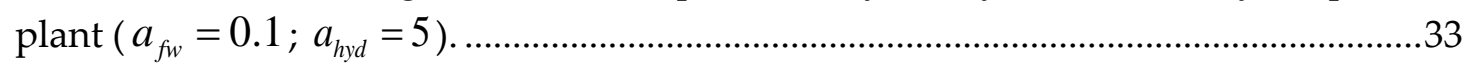

Figure 11: The flywheel energy profile (flywheel index $a_{f w}$ from 0.1 to $1 ; a_{\text {hyd }}=1$ )...........33

Figure 12: The experimental framework. …..........................................................................34

Figure 13: Assembling the 25-kWh, 100-kW flywheel used for the field test.......................35

Figure 14: An example of input regulation signals and flywheel responses recorded in

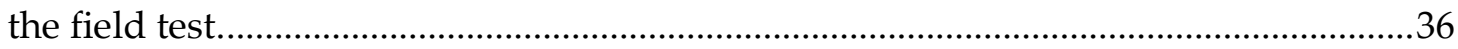

Figure 15: An example flywheel capacity levels recorded in the field test..........................36

Figure 16: The block diagram of ACE and regulation signal calculation. ............................38

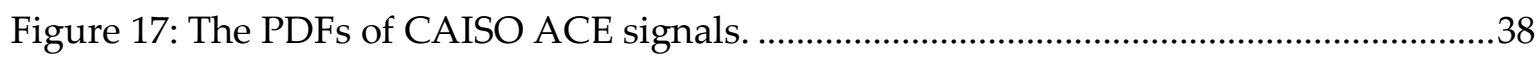

Figure 18: The CAISO ACE signal and its PDF (April 13-18, 2010) .....................................39

Figure 19: The CAISO total generation, total wind generation, and ACE signal (April 13-

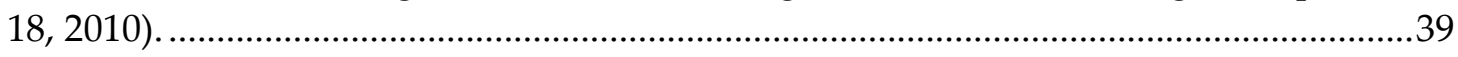

Figure 20: The wind generation composition (Total wind generation divided by total

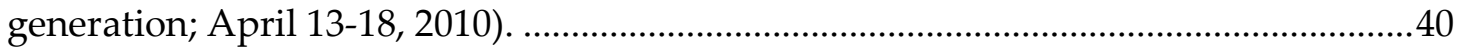

Figure 21: The real-time ancillary service requirements and average prices (April 13-18,

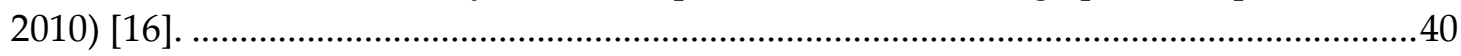

Figure 22: CAISO ancillary service average prices for April 2009 [17] ...............................42

Figure 23: The BPA ACE signal and its PDF (April 13-18, 2010).........................................43

Figure 24: The BPA total load, total wind generation, and ACE signal (April 13-18, 2010)

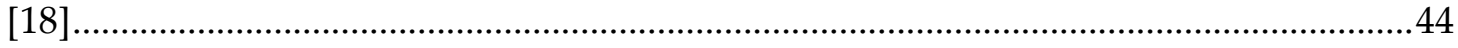

Figure 25: The BPA total load and wind generation composition (April 13-18, 2010)........44

Figure 26: The BPA+CAISO ACE signal and its PDF (April 13-18, 2010)...........................45 
Figure 27: The base-point adjustment signal and its PDF for a BPA hydro unit (April 13-

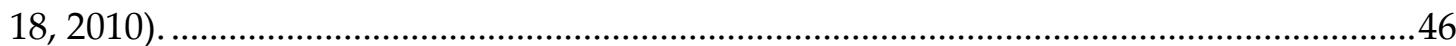

Figure 28: The regulation signal of a BPA hydro unit (April 13, 0:00 - 10:00 am)..............46

Figure 29: The regulation signals sent to a hydro unit in a CAISO control area. .................47

Figure 30: The CAISO ACE signal and its PDF (Scenario 2013) ..........................................47

Figure 31: The BPA ACE signal and its PDF (Scenario 2013).............................................48

Figure 32: The BPA+CAISO ACE signal and its PDF (Scenario 2013)................................48

Figure 33: The test signals and the output signals. (a) A zoom-in view, (b) hours 0 to 168.53

Figure 34: The test signals and the output signals (flywheel without energy

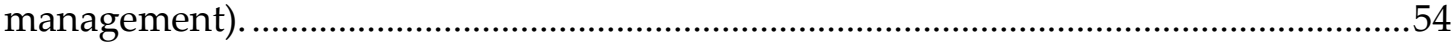

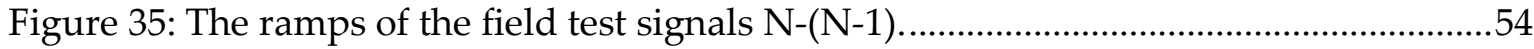

Figure 36: The ramps of the regulation signals sent to the hydro power plant ...................55

Figure 37: The cumulated mileages of different cases.........................................................55

Figure 38: The test signals and the output signals. (a) A zoom-in view, (b) hours 0 to 168.58

Figure 39: The test signals and the output signals (flywheel without energy

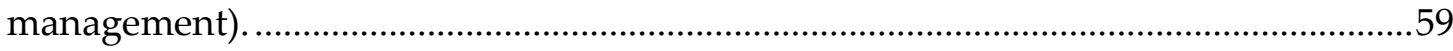

Figure 40: The ramps of the field test signals N-(N-1) (hours 1 to 140)..............................60

Figure 41: The ramps of the regulation signals sent to the hydro power plant ..................60

Figure 42: The cumulated mileages of different cases.........................................................60

Figure 43: The test signals and the output signals. (a) A zoom-in view, (b) hours 0 to 153.62

Figure 44: The test signals and the output signals (flywheel without energy

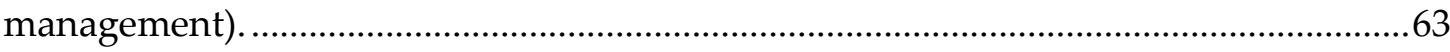

Figure 45: The ramps of the field test signals N-(N-1) (hours 1 to 153)...............................63

Figure 46: The ramps of the regulation signals sent to the hydro power plant..................64

Figure 47: The cumulated mileages of different cases.......................................................64

Figure 48: The test signals and the output signals. (a) A zoom-in view, (b) hours 0 to 103.66 Figure 49: The test signals and the output signals (flywheel without energy

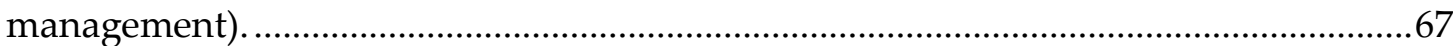

Figure 50: The ramps of the field test signals N-(N-1) (hours 1 to 103)...............................67

Figure 51: The ramps of the regulation signals sent to the hydro power plant ..................68

Figure 52: The cumulated mileages of different cases.........................................................68

Figure 53: The test signals and the output signals. (a) A zoom-in view, (b) hours 0 to 103.70

Figure 54: The test signals and the output signals (flywheel without energy

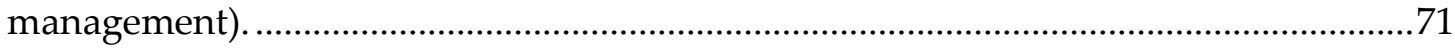

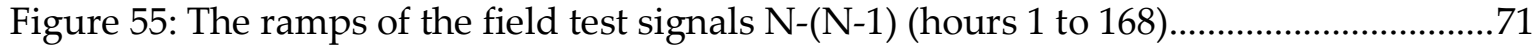


Figure 56: The ramps of the regulation signals sent to the hydro power plant ...................72

Figure 57: The cumulated mileages of different cases.........................................................72 


\section{Executive Summary}

This research was conducted by the Pacific Northwest National Laboratory (PNNL), which is operated for the U.S. Department of Energy (DOE) by Battelle under Contract DE-AC05-76RL01830, for the Bonneville Power Administration (BPA), the California Energy Commission (CEC), and the California Institute for Energy and Environment (CIEE).

\section{Objectives}

A major operational issue associated with high renewable energy penetration $(20 \%$ or even $33 \%$ ) is that balancing requirements are expected to increase significantly. The balancing requirements include the capacity, ramping, and other requirements needed to move conventional generation to follow the collective variations of power system loads and intermittent generation resources, such as wind or solar generation. The balancing services include the intra-hour load following and minute-by-minute regulation services; both are expensive.

The overall goal of the wide-area energy management system (WAEMS) project is to develop the principles, algorithms, market integration rules, a functional design, and technical specifications for an energy storage system to cope with uncertainties and unexpected rapid changes in renewable generation power output. The resulting WAEMS system will store excess energy, control dispatchable load and distributed generation, and use inter-area exchange of the excess energy between the CAISO and BPA BAs. A further goal is to provide a cost-benefit analysis and develop a business model for an investment-based practical deployment of such a system.

A major goal of the WAEMS project is to minimize the balancing effort by developing a centralized control system that operates energy storage devices in conjunction with conventional generators to provide fast balancing services that can be shared among balancing authorities. The idea is based on coordination of traditional services (provided by conventional generation) and energy storage. In Phase II of the project described in this report, a prototype WAEMS configuration consisting of a hydro electric plant and a flywheel energy storage was field tested using actual area-control-error and regulation signals provided by BPA and CAISO. The results were used to evaluate the performance and economics of the flywheel-hydro regulation service.

The idea is based on coordination of traditional services (provided by conventional generation) and energy storage. An evaluation of different energy storage technologies was conducted in Phase I of the WAEMS project. The flywheel energy storage has been selected as an emerging technology that is technically ready to provide fast regulation service. A prototype WAEMS configuration (see Figure E1), consisting of a hydro electric plant and a flywheel 
energy storage, was controlled using area-control-error (ACE) signals. The modeling results showed an excellent performance of the WAEMS control algorithm, which separates the faster regulation effort provided by the energy storage from the slower one provided by a conventional regulating unit.

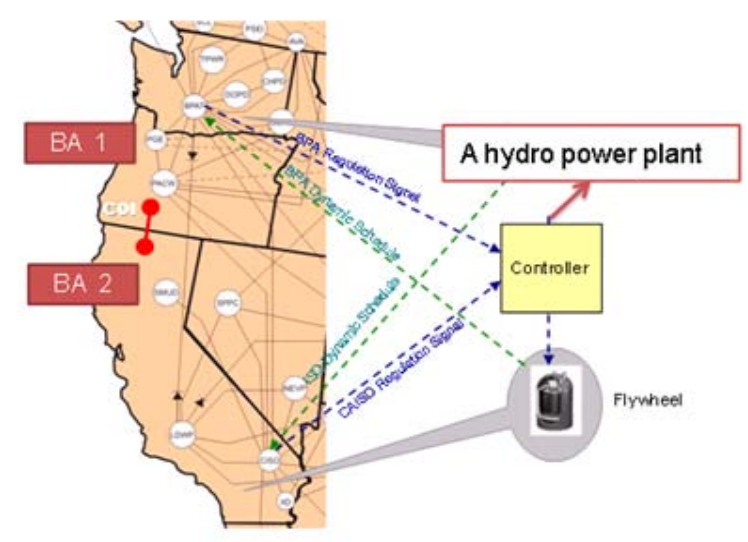

Figure E1: The configuration of a WAESM.

\section{Scope}

This report presents: 1) a methodology of sharing regulation services between balancing authorities helping to minimize the overall balancing effort, 2) an algorithm to allocate the regulation signal between the flywheel energy storage and a hydro power plant to minimize the wear and tear of the hydro power plant and to prevent the flywheel storage form performance problems related to its finite energy capacity, 3) results of the hydro-flywheel field tests (conducted by the Beacon Power Corporation), and 4) a performance evaluation and an economic analysis of the combined hydro-flywheel regulation service.

The following tasks were accomplished in Phase II:

- Experiments representing existing renewable penetration have been conducted using regulation and ACE signals obtained from BPA and CAISO.

- Experiments representing future renewable penetration have been conducted using modeled ACE signals forecasted by CAISO and BPA. (CAISO, forecasted regulation signals reflecting $20 \%$ renewables in 2013; BPA, forecasted regulation signals for 2013.)

- Performance evaluation and economic analysis have been conducted based on experiment results of the existing and future renewable penetration for each regulation resource.

\section{Approach}

PNNL acquired 4-second ACE and regulation signals from BPA and CAISO, which were used as test signals in scenarios representing the existing level of wind generation penetration. 
Simulated ACE signals representing 2013 wind penetration scenarios were used for 20\% renewable penetration scenarios.

The test signal was normalized to fit $\pm 40 \mathrm{MW}$ range and then fed into the WAEMS controller, which allocated the signal to the flywheel energy storage (within $\pm 20 \mathrm{MW}$ ) and the hydro plant model (within $\pm 20 \mathrm{MW}$ ), so that the flywheel energy storage provided the fast regulating component while the hydro plant provided the slow one. The hydro power plant was also used to help the flywheel energy storage to maintain a desired level of the stored energy. In this project, we have not conducted field tests on a real hydro plant. The hydro power outputs were simulated outputs. The \pm 20 flywheel signal was further scaled down to $\pm 100 \mathrm{~kW}$ to operate the $25-\mathrm{kWh}, 100-\mathrm{kW}$ flywheel provided for the test by Beacon Power Corporation. All field tests were conducted at the Beacon Power facility located in Tyngsboro, MA. The field tests lasted for 8 weeks (March through April, 2010.)

The performance and economic evaluations were performed by PNNL. Fade time, mileage, and utilization rate were used as performance metrics. The fade time refers to the time during which the flywheel can no longer fully respond to the regulation signal due to the energy limitations. (When a flywheel is fully charged or discharged, it cannot respond to the regulation signal.) The mileage is the sum of the power output changes, which reflects the total movements of a regulating unit within a period. The ramp-up mileage is the sum of all incremental movements and the ramp-down mileage is the sum of all decremental movements. The utilization rate is obtained as the mean absolute value of the flywheel's output, varying in response to the regulation signal, divided by its rated power.

Breakeven prices were used to evaluate the minimum market entry costs. The calculation of the breakeven prices has accounted for the installation cost, the operation and maintenance cost, the rate of return, and discount rates, as well as a few other economic parameters related with the flywheel energy storage. The pay-by-capacity payment method was studied for the regulation service. Pay-by-capacity service means that a unit is paid by the capacity that it bids into the market regardless of the actual energy that it provides to the grid.

\section{Summary of Findings}

The main findings can be summarized as follows:

- The WAEMS algorithm successfully allocated the fast component of the regulation signal to the flywheel and the slow one to the hydro power plant.

- The flywheel followed the regulation signal within 6 seconds.

- The WAEMS combined service had the same fast-response characteristic as that provided by the flywheel energy storage alone, which was in the 6-second range. 
- The WAEMS combined service was not strictly constrained by energy storage limits because the hydro plant supported the desired flywheels' energy level.

- The WAEMS control algorithm provided a higher utilization rate and minimized fade time.

- The WAEMS control algorithm reduced wear and tear on the hydro unit and allowed it to operate closer to the most preferred economical operating point. (A reduction in megawatt response or lesser mileage means less wear and tear for the hydro unit.)

- The breakeven price for the bi-directional ${ }^{1}$ regulation service provided by flywheel energy storage is $\$ 20.37 / \pm \mathrm{MW}$.

- The evaluation of the breakeven price for the hydro regulation service is not in the scope of this project; therefore, the price was not calculated. Based on the average regulation prices published at the CAISO website (see Figure E3), the lowest prices are $\$ 2 / \mathrm{MW}$ for regulation-up and $\$ 2 / \mathrm{MW}$ for regulation-down service. Therefore, the bi-directional service is paid $\$ 4 / \pm \mathrm{MW}$. Thus, the weighted breakeven price is calculated as

$$
(20.37+4) / 2=12.19 \$ / \pm M W
$$

for the bi-directional service provided by the flywheel-hydro hybrid energy storage.

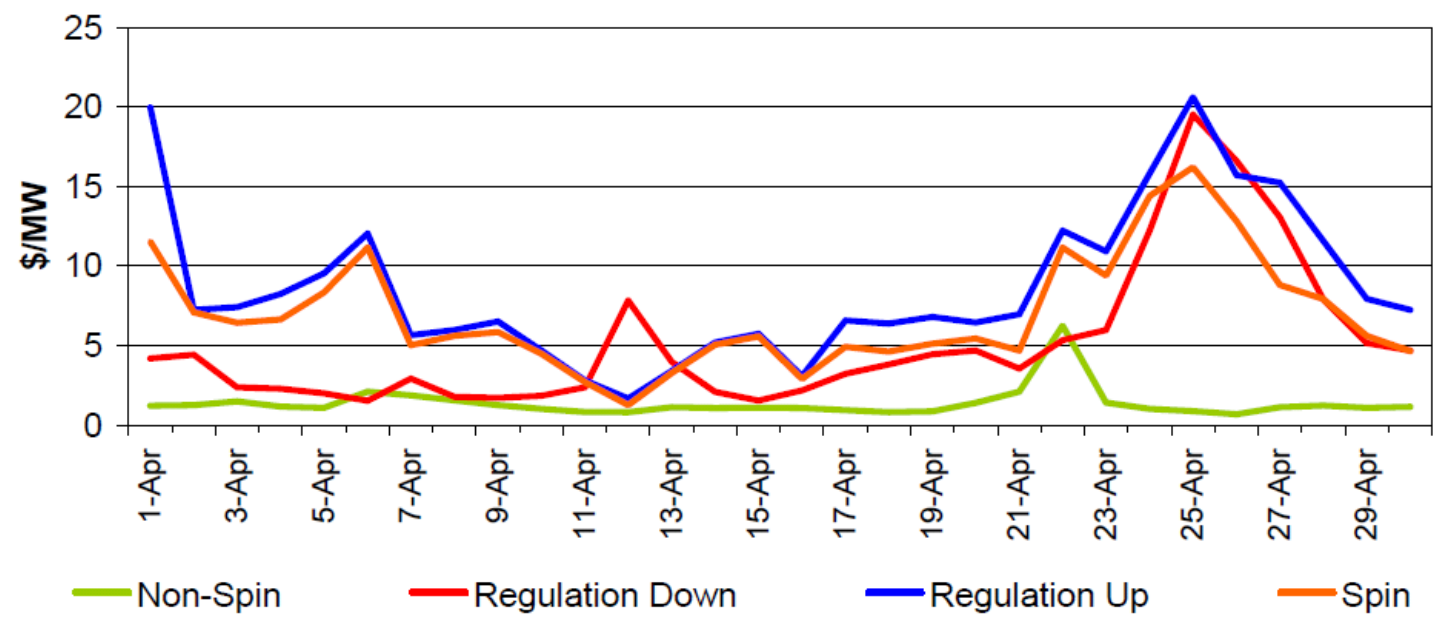

Figure E3: The CAISO average regulation prices for April 2009 (available online: http://www.caiso.com/17ed/17ed90c231ac0.html)

Note that flywheel energy storage can be operated in one of two ways to mitigate the flywheels' finite energy capacity: 1) receive a specially generated well-balanced regulation

\footnotetext{
${ }^{1}$ The bi-directional regulation service of \pm 1 MW includes 1 MW regulation-up and 1 MW regulation-down.
} 
signal from the ISO, or 2) use an energy management system, such as the WAEMS, so it can respond to the same regulation signal as that sent to conventional generators.

The New York ISO (NYISO) and the Midwest ISO implemented the Approach 1, which is a stand-alone application for the flywheel energy storage. The proposed WAEMS belongs to the second approach, which is a more flexible, effective, and economical operating scheme. By operating the flywheel energy storage combined with a hydro plant or some other generation resource, the combined service takes advantage of both the resources. This not only reduces the wear and tear of the conventional regulating resources, but also helps the flywheel energy storage to stay within its energy limits. The initial results have demonstrated an improved performance of the flywheel energy storage in terms of the utilization and the breakeven price.

\section{Economics}

In the BPA balancing authority, the average regulation price in 2010 is $\$ 6.75 / \mathrm{kW}$-month ${ }^{2}$ for $\pm 1 \mathrm{~kW}$ bi-directional regulation service. The payment for $1 \mathrm{MW}$ bi-directional regulation service is calculated as

$$
6.75 \times 1000 /(30 \times 24)=9.38 \$ / \pm M W
$$

In the CAISO balancing authority (Region CAISO_EXP), the average day-ahead regulation price from January to July 2010 is $\$ 5.38 / \mathrm{MW}$ for regulation-down and $\$ 6.57 / \mathrm{MW}$ for regulationup, as shown in Table E1. The payment of $1 \mathrm{MW}$ bi-directional regulation service is calculated as

$$
5.38+6.57=11.95 \$ / \pm \mathrm{MW}
$$

Table E1: The 2010 CAISO regulation prices (Region CAISO_EXP) ${ }^{3}$

\begin{tabular}{|l|c|c|c|}
\hline $\mathbf{2 0 1 0}$ & $\begin{array}{c}\text { Average } \\
\text { Regulation-down } \\
(\mathbf{1} \mathbf{~ M W )}\end{array}$ & $\begin{array}{c}\text { Average } \\
\text { Regulation-up } \\
(\mathbf{1} \mathbf{M W})\end{array}$ & $\begin{array}{c}\text { Average } \\
\text { Bi-directional Regulation } \\
( \pm 1 \mathrm{MW})\end{array}$ \\
\hline Jan & $\$ 4.38$ & $\$ 4.99$ & $\$ 9.37$ \\
\hline Feb & $\$ 4.27$ & $\$ 4.75$ & $\$ 9.02$ \\
\hline March & $\$ 4.39$ & $\$ 5.00$ & $\$ 9.39$ \\
\hline April & $\$ 3.90$ & $\$ 5.22$ & $\$ 9.12$ \\
\hline May & $\$ 5.71$ & $\$ 8.33$ & $\$ 14.04$ \\
\hline June & $\$ 9.16$ & $\$ 11.60$ & $\$ 20.76$ \\
\hline July & $\$ 5.83$ & $\$ 6.10$ & $\$ 11.93$ \\
\hline Average & $\$ 5.38$ & $\$ 6.57$ & $\$ 11.95$ \\
\hline
\end{tabular}

\footnotetext{
${ }^{2}$ Please refer to the "Bonneville Power Administration Transmission Services 2010 Transmission and Ancillary Service Rate Schedules”. It is available online at http://www.transmission.bpa.gov/Business/Rates/documents/ 2010_Rate_Schedules_10_01_09.pdf).

${ }^{3}$ CAISO regulation prices are available online at http://oasis.caiso.com.
} 
The breakeven price for flywheel energy storage to provide bi-directional service (1 MW regulation-up and $1 \mathrm{MW}$ regulation-down) is $\$ 20.37 / \pm \mathrm{MW}$. Because the average bi-directional regulation price of the CAISO balancing authority is $\$ 11.95 / \pm \mathrm{MW}$ (Jan.-July, 2010) and that of the BPA balancing authority is $\$ 9.38 / \pm \mathrm{MW}(2010)$, regulation service provided by a standalone flywheel energy storage will not be economical unless the regulation price will be increased or the fast regulation service will be paid at a higher rate.

Assuming that the minimum regulation price of regulation provided a hydro power plant is $\$ 4 / \pm \mathrm{MW}$, the breakeven price of the combined flywheel-hydro regulation service would be $\$ 12.19 / \pm \mathrm{MW}$; therefore, the flywheel-hydro regulation service breakeven price is found to be slightly higher than the average CAISO (\$11.95/ $\pm \mathrm{MW})$ and BPA $(\$ 9.38 / \pm \mathrm{MW})$ regulation prices. Because regulation prices are increasing when more renewable generation resources are integrated into the power grids, the flywheel-hydro regulation service is expected to become economical in the CAISO and BPA balancing authorities soon.

\section{Benefits}

The combined hydro-flywheel energy management system will benefit CAISO and BPA by:

- providing additional means of mitigating the variability introduced by renewable resources,

- reducing the wear and tear of the hydro units,

- reducing the regulation requirements for BPA and CAISO balancing authorities by sharing the regulation services between them,

- providing combined service that has the same fast-response characteristic as that provided by flywheel energy storage alone, and

- maintaining desired energy levels for energy storage devices.

\section{Recommendations}

From Phase I and II results, we conclude that the opportunities for flywheels or other energy storage devices lie in the following areas:

- To avoid performance problems associated with their finite energy storage capacity, provide regulation services for system operators which would agree to manage the flywheels' energy level, or participate in alternative schemes helping to co-optimize fast acting storage devices and conventional generators to provide high-quality combined regulation services.

- Operate energy storage devices in conjunction with conventional generators to improve their response time, reduce their wear and tear, and provide compatible services that do not require modifications of the existing automatic generation control and market systems. 
- To increase the capacity payment, explore opportunities for sharing regulation services among two or more balancing authorities.

- Investigate methods and tariff changes so that the fast responsive and flexible resources can be compensated for additional services such as frequency response, fast ramping, voltage and reactive power support, or damping of transmission line oscillations to prevent grid angular instability.

\section{Future Work}

Based on the Phase II results, it is recommended that the next phase of the WAEMS project focus on research leading to (1) practical deployment of the WAEMS that provides balancing services (including both load-following and regulation services) to the CAISO and BPA balancing authorities and (2) commercialization of the control algorithms developed in Phases 1 and 2 of the WAEMS project.

A near-term goal should be commercialization of a shared storage system between CAISO and BPA. A longer term goal should be development of methodologies for operating both fast and slow resources and sharing these resources over multiple control areas to facilitate the renewable integration and operate the power grids reliably and economically.

The next steps are to

- enhance the WAEMS controller so that it is more robust and can provide load following services;

- field test more energy storage technology options, such as Li-ion battery energy storage; and

- $\quad$ assist BPA and CAISO to deploy a WAEMS system between BPA (offer a hydropower plant) and CAISO (offer an energy storage device).

Another potential area of future research is the development of an energy storage evaluation toolbox that incorporates the models, algorithms, methodologies, and standardized testing signals developed or obtained in previous WAEMS tasks. This toolbox would help users find optimal configurations and assess the performance and economics of different energy storage solutions, enabling them to answer the following questions:

- Are the selected ESDs capable of providing the required services as expected?

- How much fast-regulating ESD capacity is needed for a given regulation/load-following signal?

- What is the cost of the service?

This research will provide information for power grid operators to make decisions on building an energy storage portfolio that best meets the wind-integration requirements and is most economical to implement. 


\subsection{Introduction}

This research was conducted by the Pacific Northwest National Laboratory (PNNL), which is operated for the U.S. Department of Energy (DOE) by Battelle under Contract DE-AC0576RL01830, for the Bonneville Power Administration (BPA), the California Institute for Energy and Environment (CIEE), and the California Energy Commission (CEC). This section introduces the background, objectives, benefits, and tasks of Phase II of the wide-area energy management system (WAMES) project.

\subsection{Background}

The WAEMS project has three phases. Phase I (completed in 2008) was funded by BPA and supported by the California Independent System Operator (CAISO) and Beacon Power Corporation with in-kind inputs. Phase I was proof of the concept. The tasks included energy storage technology evaluation, initial WAEMS configuration design and control algorithm development, and cost-benefit analysis. Phase II was co-funded by BPA and CEC and supported by CAISO and Beacon Power Corporation with in-kind support. Phase II focused on flywheel field tests for regulation service, economic analysis, and performance evaluation. The tasks included preparing signals from field tests, implementing control algorithms, field testing flywheels, analyzing economics, and evaluating performance.

\subsubsection{An Introduction to the Wide-area Energy Management System}

As shown in Figure 1, a WAEMS is a centralized control system that operates energy storage devices (ESDs) located in different places to provide energy and ancillary services that can be shared among balancing authorities (BAs). In Phase II, we considered the hydro electric plant plus flywheel (hydro + flywheel) option selected in Phase I.

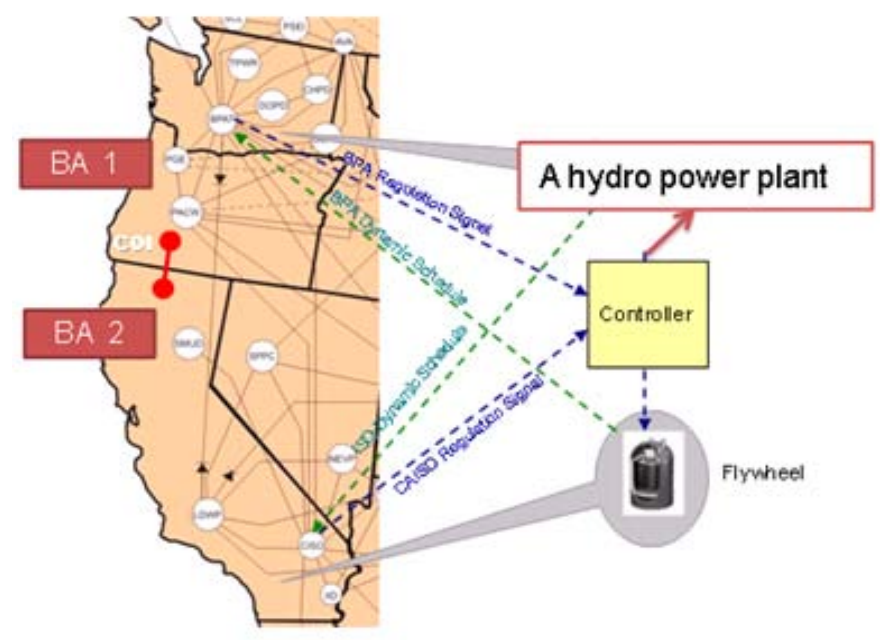

Figure 1: The configuration of a WAESM. 
The WAEMS design criteria included:

- Ability to provide wide-area regulation service

- Efficiency (reduced regulation requirement)

- Compatibility (minimum changes of the existing automatic generation control (AGC) and market systems)

- Minimum cost for BPA and CAISO

- Minimum technical difficulty of implementation

- Minimizing the impact on congestion, and

- Ability to mimic the behavior of a conventional unit on regulation and coordinate the control functions of participating energy storage devices.

The selected technical characteristics are listed as follows:

- Flywheel + hydro configuration was selected

- Vertical configuration based on centralized controls provided by BAs was chosen

- Inputs were identified as BPA's and CAISO's area control error (ACE) or "conventional regulating unit" signals, and

- Dynamic schedules were proposed to distribute the regulation to the participating BAs.

Control algorithm design considerations were as follows:

- The total MW output of the WAEMS should equal the total MW request from both balancing authorities

- A flywheel/battery provides fast regulation service

- A hydro unit provides slow regulation service

- A hydro unit is used to maintain the desired state of charge (SOC) on the flywheel

- The hydro power plant operates as close as practical to the most efficient output point, and

- Dynamic schedules are used to "distribute" the flywheel's and hydro's outputs among the balancing authorities.

The objectives of WAEMS are to:

- Help balance the intermittent resources by recycling excess energy, controlling dispatchable load and distributed generation, and exchanging excess energy between the BPA and CAISO balancing authorities.

- Develop principles, algorithms, market integration rules, functional design, and technical specification for WAEMS.

- Provide a cost-benefit analysis and business model for an investment-based practical deployment of the system. 
The WAEMS benefits the participating BAs by managing grid-connected intermittent energy and directly addressing the following CAISO and BPA areas of interest:

- Renewable integration:

o Provide fast-ramping balancing services that could potentially reduce the regulation and load-following requirement by up to $30 \%$.

o Reduce the wear and tear of traditional regulation units.

- Transmission services:

o The WAEMS can operate without creating congestion problems on critical transmission paths.

- Market and operational design solutions:

o Support further integration of renewable energy resources.

o Make energy storage options more economical and efficient.

\subsubsection{Technical Needs}

This research addresses the goals and technology needs identified by CAISO and BPA in renewable energy integration and optimization of the hydro and wind resources operations.

A major operational issue associated with high renewable energy penetration $(20 \%$ or even $33 \%$ ) is that ramp rates and magnitudes of the regulation and load-following requirements are expected to increase significantly. Phase I and other CEC studies [1]-[5] have shown that fastramping balancing services could potentially reduce the regulation and load-following requirement by up to $30 \%$. Therefore, it is important for BPA and CAISO to seek additional fast load-following and regulation resources to meet challenges of the high penetration of wind in BPA and CAISO balancing authorities.

The fast regulation and load-following services are currently provided mainly by hydro power plants or gas turbines. To meet the increasing ramp and capacity requirements, the regulating hydro plant may not be able to operate close to its preferred operating point, resulting in low efficiencies. In addition, faster load-following service puts higher mechanical stress on hydro turbines, increasing the wear and tear cost. Furthermore, due to environmental and efficiency constraints, the range within which a hydro unit can operate varies with the season and water availability. Therefore, BPA and CAISO need to consider alternative load-following and regulation resources that are economical and meet performance requirements.

California has set a goal of renewable energy resources providing $20 \%$ of its electricity supply by 2012 and has a policy preference to increase that target to 33\% by 2020. Moving towards achieving these goals, CAISO has an urgent need to mitigate the variability and fastramp requirements that occur at higher penetration levels of intermittent resources, the majority of which are wind and solar power. Because CAISO does not have as abundant hydro generation 
resources as BPA does, it is even more critical for CAISO than BPA to obtain additional fast loadfollowing and regulation resources.

ESDs are an important part of key initiatives to integrate more renewable generation resources into the electric power grid. Traditionally, ESDs such as battery banks are considered to be used as backup or used to level wind or solar outputs and shave or shift peak loads. Now providing balancing services, including load-following and regulation, becomes potential revenue streams for ESDs. For instance, two 20-MW flywheel facilities are being installed in New York Independent System Operator (NYISO) and Pennsylvania-New Jersey-Maryland Interconnection (PJM) balancing authorities for providing regulation services. Flywheels, NaS and Li-ion batteries, and ultra capacitors are energy storage systems having a very fast response rate but relatively limited energy storage capabilities. In Phase II, Beacon Power flywheel field tests have been carried out to test a hybrid system consisting of a hydro power unit and a flywheel unit to provide a combined high-quality regulation service.

\subsection{Goals and Tasks}

The goal of this research is to investigate the technical characteristics and economics of the flywheel used for combined regulation services in the electricity market operated by CAISO and in BPA system. The tasks related to flywheel field tests addressed in Phase II are as follows:

Task 2: Design and Monitor the Flywheel Field Experiments for Existing Renewable Penetration:

- Design field experiments with the flywheel energy storage.

- Implement changes/adjustments of the flywheel energy storage, if required.

- Prepare sets of simulated control signals to control the flywheel device for regulation and frequency response using the actual data provided by BPA and independent system operators (ISOs).

- Monitor the experiments for the existing penetration levels.

- Depending on availability of resources and affordability of experiments, conduct studies with transactive commercial building controllers at PNNL's buildings in Richland and the Advanced Process Engineering Laboratory (APEL) Building Micro Turbine in Richland. ${ }^{4}$

Task 3: Design and Monitor the Flywheel Field Experiments for Future Scenarios

- In cooperation with BPA and the ISO engineers (or with BPA and the ISO wind generation forecasting service providers), prepare sets of look-ahead data for higher

\footnotetext{
${ }^{4}$ Note that we did not conduct experiments with transactive commercial building controllers at PNNL's buildings because of funding limitations.
} 
penetration levels of wind energy in these systems (future scenarios). Design experiments to simulate these future scenarios on the flywheel utilized in Task 2.

- Monitor the experiments for the future scenarios.

Task 4: Calculate and analyze performance characteristics (performance metrics) of the flywheel experiments (existing renewable penetration and the future scenarios) for each regulation resource.

- Analyze, compare, and systemize the experimental results.

- Provide a summary of results and recommendations to BPA/CEC/CIEE on continuation of the project.

\subsection{The Beacon Power Flywheel Technology [6]}

The Beacon's flywheel is a mechanical battery designed for a minimum 20-year life, with virtually no maintenance required for the mechanical portion of the flywheel system over its lifetime. Of critical importance in performing frequency regulation with energy storage-based systems is their cyclic life capability. Beacon's experience to date in the New England ISO shows that 6,000 or more effective full charge/discharge cycles per year are required. The system is capable of over 150,000 full charge/discharge cycles at a constant full power charge/discharge rate, with zero degradation in energy storage capacity over time. For the frequency regulation application, flywheel mechanical efficiency is over 97 percent, and total system round-trip charge/discharge efficiency is 85 percent.

At the heart of Beacon's Smart Energy 25 flywheel is a patented high-strength carbon-fiber composite rim, supported by a metal hub and shaft, with a motor/generator on the shaft. Together the rim, hub, shaft, and motor/generator assembly form the rotor. To nearly eliminate friction, the rotor is sealed in a strong vacuum chamber and levitated magnetically.

The rotor spins between 8,000 and 16,000 rpm. When absorbing energy, the flywheel's motor acts like a load and draws power from the grid to accelerate the rotor to higher speed. When discharging, the motor switches into generator mode, and the inertial energy of the rotor drives the generator, creating electricity that is injected back into the grid as the rotor slows down. At 16,000 rpm, a single Smart Energy 25 flywheel can deliver 25 kilowatt-hours (kWh) of extractable energy at a 100-kW power level for 15 minutes. Multiple flywheels are connected in

parallel to provide any desired megawatt-level power capacity. A 20-MW energy storage plant consists of 200 such flywheels.

Figure 2 shows an artist's conception of a 20 MW flywheel plant. The plant consists of 200 Smart Energy 25 flywheels housed below ground in concrete cylinders (blue covers seen above), along with 20 steel containers ( 1 per MW) placed on concrete pads. The containers house electronics and communications equipment. 


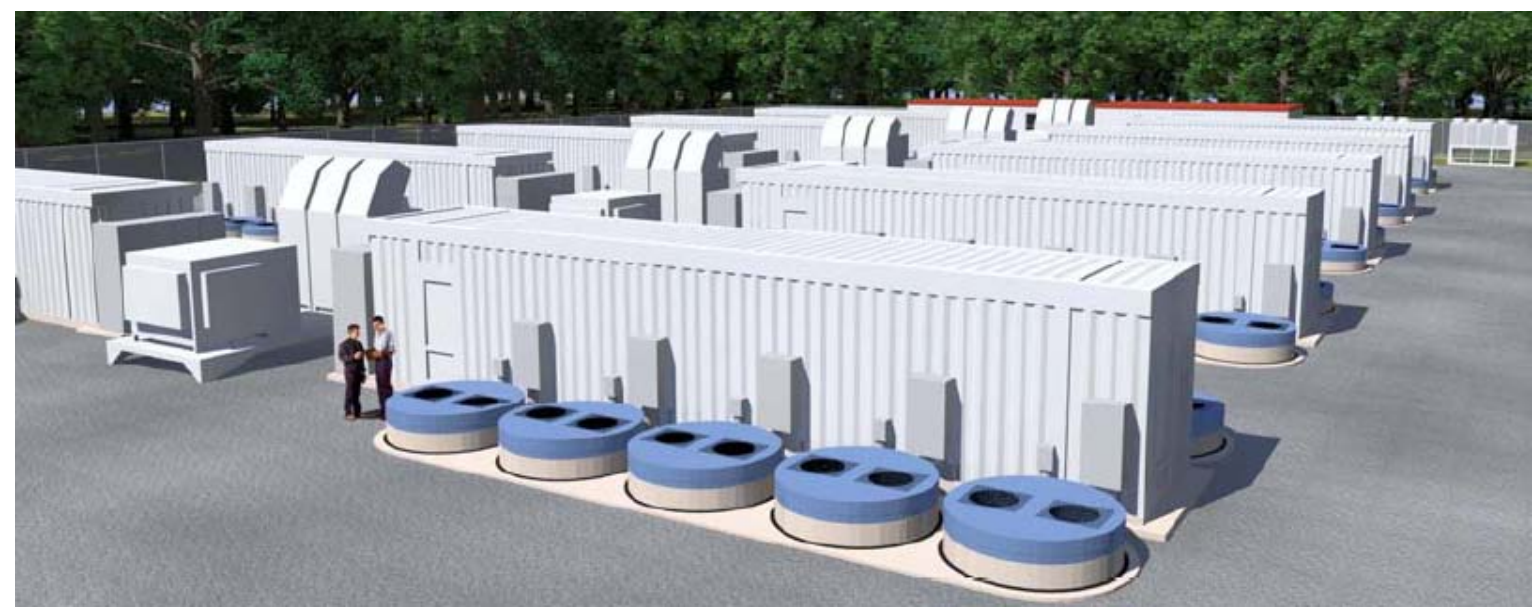

Figure 2: Artist's rendering of Beacon's 20-MW flywheel plant.

The characteristics of a 5-MWh and 20-MW flywheel energy storage are summarized in Table 1. Figure 3 shows a picture of a 1-MW outdoor flywheel facility. The benefits of the flywheel are its fast ramping capability, efficiency, and long-term durability. The flywheel can respond to regulation up or down signals within 6 seconds. Its round-trip efficiency is from 80 to $85 \%$. Unlike batteries, the flywheel has no performance (energy or power capacity) degradation as a function of cycles or time. As shown in Figure 4, the flywheel lifetime in terms of cycles is much longer than the sodium sulfur ( $\mathrm{NaS})$ battery [7], [8], exceeding the number of cycles expected in the 20-year lifetime of the regulation plant.

To provide the regulation service, a flywheel can run either by itself or jointly with a hydro unit (as proposed in this project) to reduce the hydro plant's wear and tear, improve its efficiency, and manage the flywheel energy level. In the joint-hydro mode, both the flywheel and hydro plant take a share of the incoming regulation signal such that the hydro power plant will have minimum wear and tear while preventing the flywheel from fading.

Table 1: Flywheel energy storage characteristics

\begin{tabular}{|c|c|c|}
\hline \multicolumn{2}{|c|}{ Flywheel Characteristics } & Assumptions \\
\hline & Flywheel Capacity (MWh) & 5 \\
\hline \multirow{2}{*}{ Flywheel Power (MW) } & 20 \\
\hline \multirow{3}{*}{ General } & Flywheel Life (year) & 20 \\
\cline { 2 - 3 } & Self Discharging & N/A \\
\cline { 2 - 3 } & Lifetime (cycles at 100\% DOD) & 150000 \\
\hline \multirow{3}{*}{ Cost } & One-way Efficiency & $90 \%$ \\
\cline { 2 - 3 } & Capital Cost (\$/kWh) & 5000 \\
\cline { 2 - 3 } & Start-up Cost $(\$)$ & Not included in the study \\
\cline { 2 - 3 } & Shut-down Cost (\$) & 3\% of capital cost \\
\hline
\end{tabular}




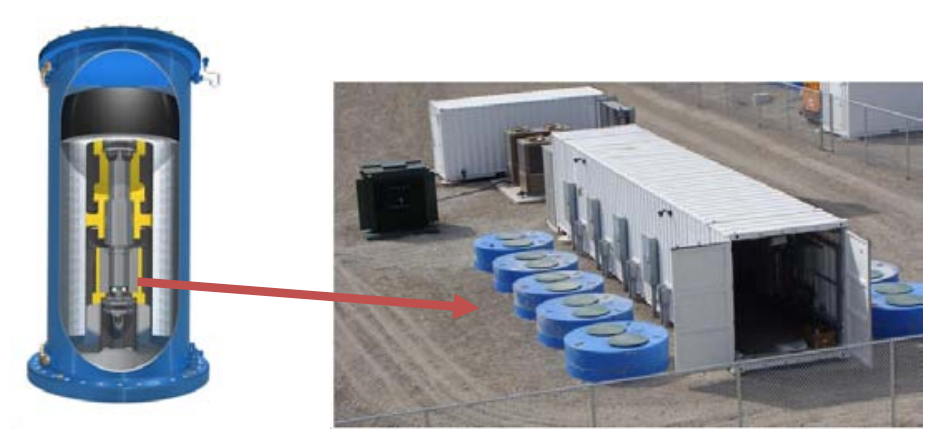

Figure 3: A 1-MW outdoor flywheel storage facility.

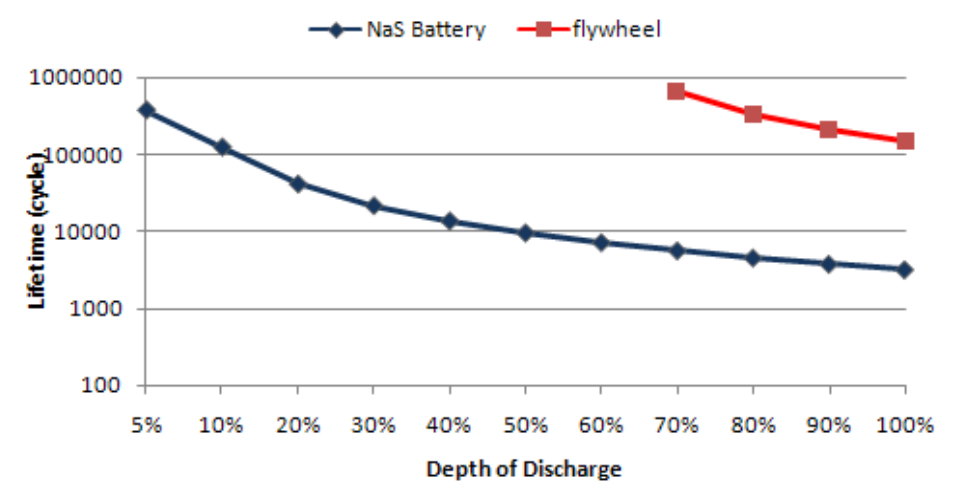

Figure 4: The lifetime plots of the flywheel versus the NaS battery.

Tariffs have been defined and accepted by the Federal Energy Regulatory Commission (FERC) in NYISO and Midwest ISO to co-optimize energy resources with fast response energy storage regulation resources. The impact of these tariffs will be to manage energy levels in the flywheels and prevent fade time ${ }^{5}$ while providing regulation on an economical basis. A variation on this approach would be to co-optimize regulation by the flywheel together with a hydro plant, which is expected to provide additional cost and performance benefits. This approach is investigated in this report and was compared with the flywheel providing the regulation service by itself.

Previous flywheel evaluation studies assessed flywheel storage characteristics and the economics involved. Makarov et al. evaluated and compared available energy storage options and identified the top three technologies that can meet regulation-service needs [1]. The cost/benefit study for the flywheel was conducted based on net present value (NPV) [9] analysis, assuming that the flywheel provides regulation service at a specified utilization factor. Walawalkar and Apt evaluated the economics of flywheels for regulation services in the electricity markets operated by NYISO and the PJM Interconnection [10]. The previous studies all assumed fixed utilization factors with energy management to address fade time. For more detailed information, refer to [6], [11], and [12].

\footnotetext{
${ }^{5}$ Fade time refers to a period of time during which the flywheel can no longer fully respond to the regulation signal. For example, when a flywheel is fully charged or discharged, it can no longer respond to the regulation signal.
} 
This research incorporated realistic CAISO regulation signals with flywheel responses to these signals for the flywheel alone and with the flywheel combined with the hydro power plant model. In addition, the breakeven costs for the flywheel supplying regulation services were compared for different payment methods and operational mechanisms to find the best implementation options. (The breakeven point [13] for a product is the point where total revenue received equals the total costs of the product.)

\subsection{The WAEMS Control Algorithm [1], [14]}

This Section describes the WAEMS algorithm used to allocate the control signals between the flywheel and hydro power plant. The algorithm was developed by PNNL in Phase I. In Phase II, Beacon Power implemented the algorithm on the Beacon master controller (controlling all the flywheels on an asset) with PNNL's assistance. Note that all the materials provided in this chapter can be found in Section 6 of the Phase I report.

The control algorithm is illustrated in Figure 5. The control algorithm distributes the regulation signal between the flywheel's energy storage and the hydro power plant based on their current states and system constraints. Flywheel and hydro power plant outputs must vary to match the regulation signal. Dynamic scheduling distributes a part of the output into the neighboring control area.

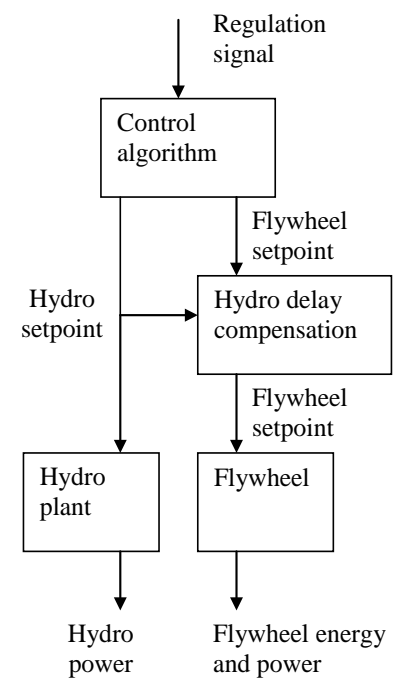

Figure 5: The flow chart of the control algorithm.

The hydro power plant delay compensation model recalculates the steady-state set-points from the control algorithm to a new set-point for the flywheel, which compensates for the response time in the hydro plant such that the aggregated response to the input signal is much faster than that of the hydro plant alone. 


\subsubsection{Hydro Power Plant Model}

A hydro power plant model has been developed to simulate the hydro power plant's response to regulation signals. The block diagram of this model is given in Figure 6.

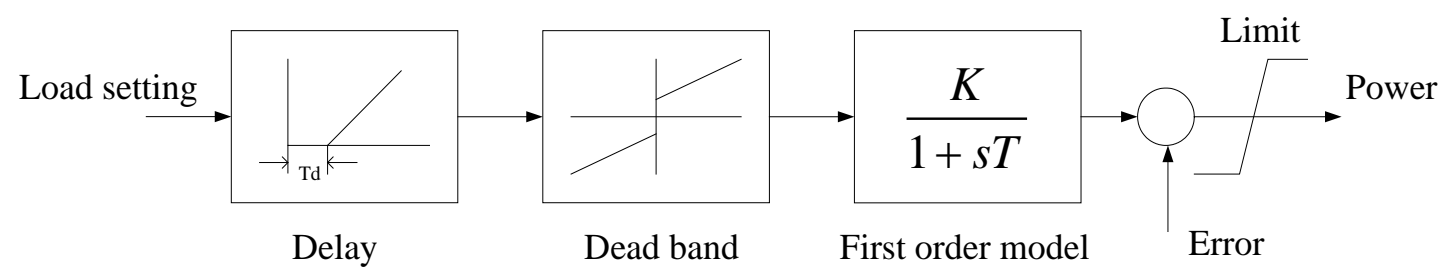

Figure 6: Block diagram of the hydro power plant model.

The hydro power plant model includes:

- a delay block simulating the delay in the plant's response (Td) to the changing regulation signal (load setting)

- a dead band element

- a first-order plant response model

- an error range simulating deviations of the actual plant response from the load setting

- a limiting element restricting the maximum and minimum regulation output provided by the plant.

Figure 7 represents the hydro power plant model's response to step changes in the plant's operating set point.

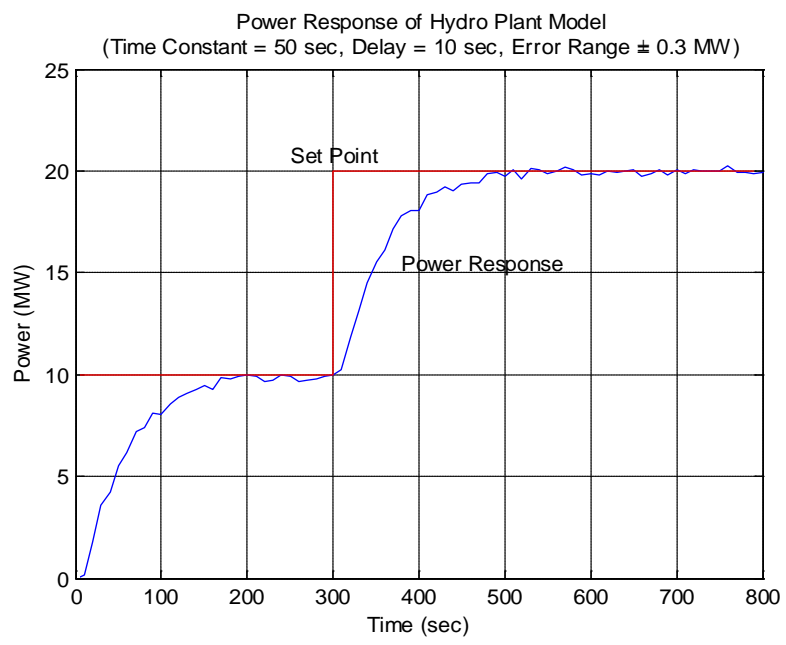

Figure 7: Hydro power plant model response to step signals. 


\subsubsection{Constraints}

The control algorithm seeks an optimal trade-off between the flywheel's state of charge (SOC) and the hydro power plant's output related to the efficiency of the hydro power plant. The relative weight of these two objectives has a significant influence on system behavior and must be chosen carefully. By changing the relative weight, the system can be designed to let either the flywheel or the hydro plant take a relatively larger share of the regulation task.

The optimization variables, $X_{f w}$ and $X_{h y d}$, denote the regulation power output from the flywheel and the hydro plant, respectively.

\subsubsection{Non-interdependent Constraints}

Power output or input from a flywheel is limited by the power converter limits:

$$
P_{f w \text { min }} \leq X_{f w} \leq P_{f w \text { max }}
$$

Furthermore, the energy stored in the flywheel cannot go below a certain minimum value or exceed a certain maximum value during the following period of operation:

$$
E_{f w, \text { min }} \leq E_{f w, \text { next }} \leq E_{f w, \text { max }}
$$

The relationship between energy and power is given by

$$
E_{f w, \text { next }}=E_{f w}-X_{f w} \cdot \Delta t
$$

which when inserted into Eq. 2 gives:

$$
\frac{E_{f w}-E_{f w, \max }}{\Delta t} \leq X_{f w} \leq \frac{E_{f w}-E_{f w, \text { min }}}{\Delta t}
$$

The hydro plant is similarly constrained by its physical upper and lower limits of power output:

$$
P_{h y d, \text { min }} \leq P_{h y d} \leq P_{h y d, \text { max }}
$$

The total power output from the hydro plant, $P_{h y d}$, is a sum of the scheduled output and the regulation output:

$$
P_{h y d}=P_{h y d, s c h}+X_{h y d}
$$

which when inserted into Eq. 6 gives the limit for the regulation output: 


$$
P_{\text {hyd,min }}-P_{\text {hyd,sch }} \leq X_{\text {hyd }} \leq P_{\text {hyd, max }}-P_{\text {hyd,sch }}
$$

In addition, the capacity reserved for regulation may have an upper and lower limit:

$$
P_{\text {hyd,cap, min }} \leq X_{\text {hyd }} \leq P_{\text {hyd,cap, } \text { max }}
$$

To summarize, the optimization variables, $X_{f w}$ and $X_{h y d}$ are bound by the noninterdependent limits given by:

$$
\begin{aligned}
& X_{f w, \text { min }} \leq X_{f w} \leq X_{f w, \text { max }} \\
& X_{h y d, \text { min }} \leq X_{h y d} \leq X_{h y d, \text { max }} \\
& X_{f w, \text { min }}=\max \left(P_{f w \text { min }}, \frac{E_{f w}-E_{f w, \text { max }}}{\Delta t}\right) \\
& X_{f w, \text { max }}=\min \left(P_{f w \text { max }}, \frac{E_{f w}-E_{f w, \text { min }}}{\Delta t}\right) \\
& X_{h y d, \text { min }}=\max \left(P_{h y d, c a p, \text { min }}, P_{h y d, \text { min }}-P_{h y d, \text { sch }}\right) \\
& X_{h y d, \text { max }}=\min \left(P_{h y d, c a p, \max }, P_{h y d, \text { max }}-P_{h y d, \text { sch }}\right)
\end{aligned}
$$

\subsubsection{Interdependent Constraints}

The total regulation performed by both units must match the regulation signal $R S$, which is the input to the control algorithm:

$$
X_{f w}+X_{\text {hyd }}=R S
$$

\subsubsection{Objective Function}

The objective function is the sum of two quadratic functions: one for the flywheel and the other for the hydro plant:

$$
\text { Loss }=\text { Loss }_{f w}+\text { Loss }_{\text {hyd }}
$$

The design of the flywheel loss function aims at maintaining the energy stored in the flywheel at a certain level, i.e., Efw,offset. The deviation from this level in the next period of operation adds quadratically to the cost:

$$
\operatorname{Loss}_{f w}=a_{f w}\left(E_{f w, \text { next }}-E_{f w, o f f s e t}\right)^{2}
$$

Figure 8 shows a plot of the flywheel objective function depending on energy deviation. 


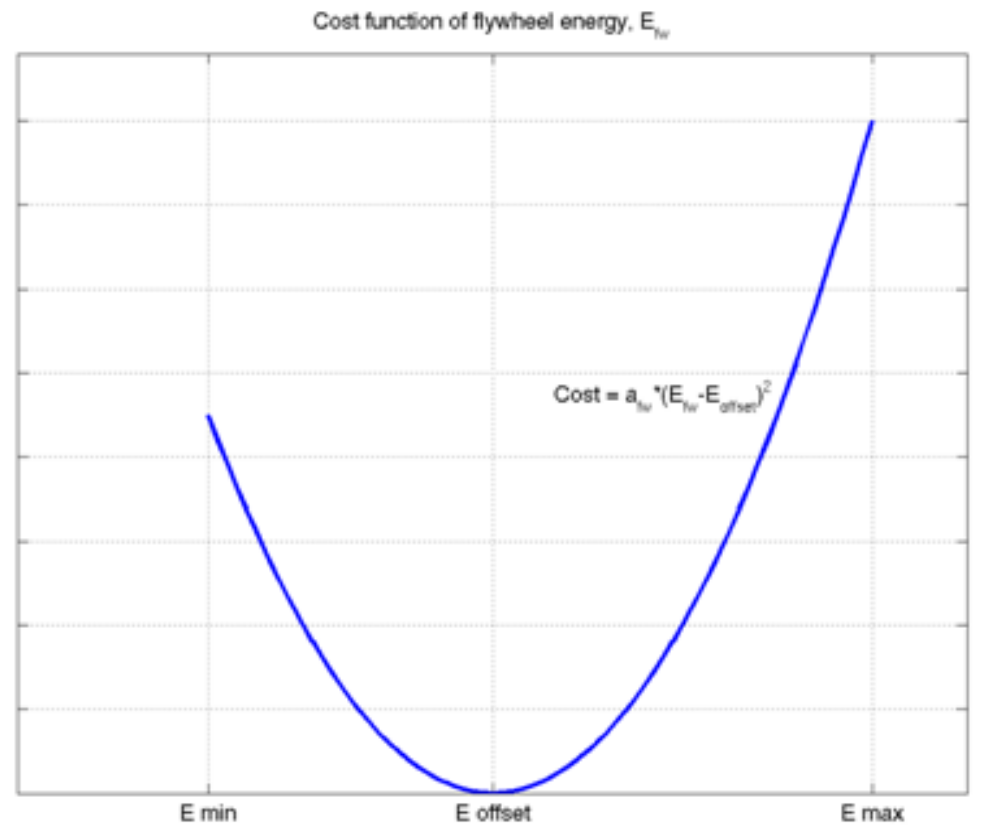

Figure 8: The plot of the flywheel energy deviation loss function.

Because the optimization variable is power, not the energy, the objective function is written as a function of $X_{f w}$ by inserting Eq. 4 into Eq. 13:

$$
\begin{aligned}
& \operatorname{Loss}_{f w}=a_{f w} \cdot\left(E_{f w}-X_{f w} \cdot \Delta t-E_{f w, o f f s e t}\right)^{2} \\
& =a_{f w} \cdot\left(\left(E_{f w}-E_{f w, o f f s e t}\right)^{2}+\left(X_{f w} \cdot \Delta t\right)^{2}-2 \cdot\left(E_{f w}-E_{f w, o f f s e t}\right) \cdot X_{f w} \cdot \Delta t\right)
\end{aligned}
$$

The function of the other optimization variable $X_{h y d}$ is designed to reflect the preferred operation at the most efficient power output setpoint. Deviation from the optimum adds quadratically to the loss:

$$
\text { Cost }_{\text {hyd }}=a_{\text {hyd }} \cdot\left(P_{\text {hyd }}-P_{\text {hyd }, e f f}\right)^{2}
$$

Figure 9 shows a plot of the hydro power plant loss function, which helps to minimize deviations of the hydro power plant output from the maximum efficiency point.

The cost function of a hydro power plant is written as a function of the optimization variable $X_{\text {hyd }}$ by inserting Eq. 7 into Eq. 15:

$$
\begin{aligned}
& \text { Cost }_{\text {hyd }}=a_{\text {hyd }} \cdot\left(P_{\text {hyd ,sch }}+X_{\text {hyd }}-P_{\text {hyd ,eff }}\right)^{2} \\
& =a_{\text {hyd }} \cdot\left(\left(P_{\text {hyd }, \text { sch }}-P_{\text {hyd ,eff }}\right)^{2}+X_{\text {hyd }}^{2}+2 \cdot X_{\text {hyd }} \cdot\left(P_{\text {hyd sch }}-P_{\text {hyd,eff }}\right)\right)
\end{aligned}
$$




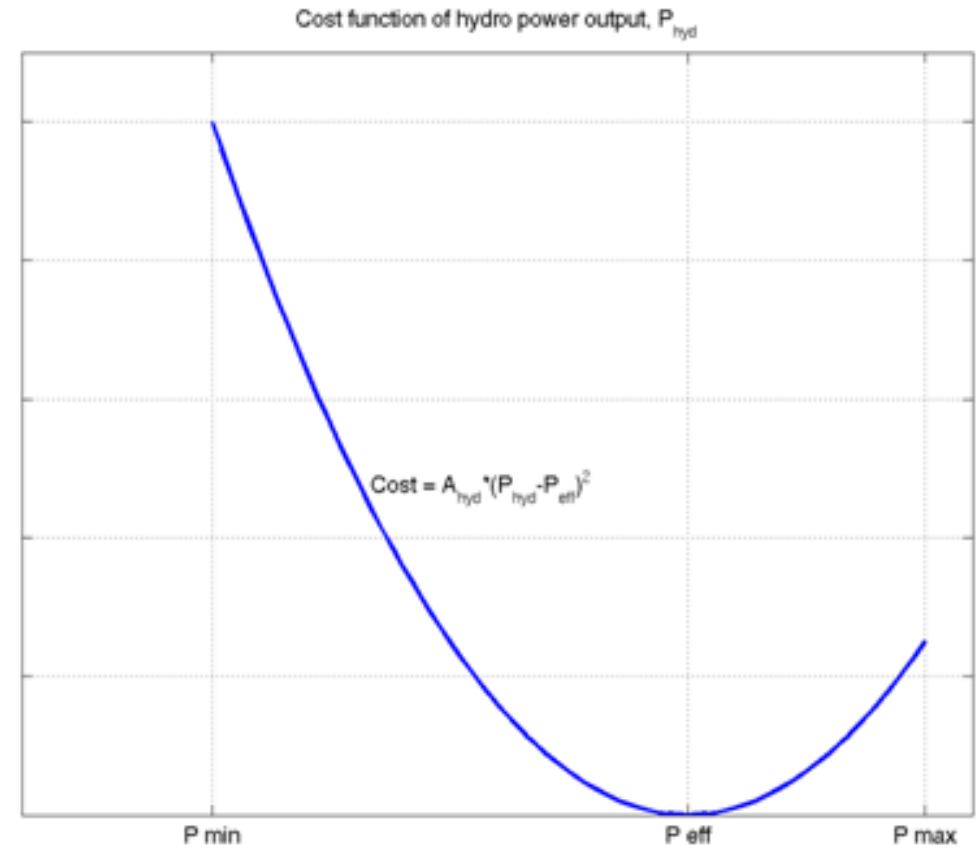

Figure 9: Loss function of the hydro power plant.

\subsubsection{Resulting Minimization Problem}

Then, the problem is formulated as a global minimization problem. The global minimization problem is solved by minimizing the function given by the sum of the loss functions in Eq. 13 and Eq. 14. The total objective function may thus be written as:

$$
\text { Loss }=\frac{1}{2} \cdot X \cdot H \cdot X^{T}+f^{T} \cdot X
$$

where:

$$
X=\left[\begin{array}{c}
X_{f w} \\
X_{h y d}
\end{array}\right], H=\left[\begin{array}{cc}
2 \cdot a_{f w} \cdot \Delta t^{2} & 0 \\
0 & 2 \cdot a_{h y d}
\end{array}\right] \text {, and } f=\left[\begin{array}{c}
-2 \cdot a_{f w} \cdot\left(E_{f w}-E_{f w, o f f e s t}\right) \cdot \Delta t \\
2 \cdot a_{h y d} \cdot\left(P_{h y d, \text { sch }}-P_{h y d, \text { eff }}\right)
\end{array}\right] \text {. }
$$

As shown in Figure 10, the algorithm successfully allocated the fast regulation component of the signal to the flywheel and the slow one to the hydro power plant. Note that based on the objective function, a lower flywheel index, $\alpha_{f w}$, means less loss for the flywheel regulation service, so the control algorithm will allocate more signal to the flywheel when $a_{f w}=0.1$ than $a_{f w}=1.0$, as shown in Figure 11. 


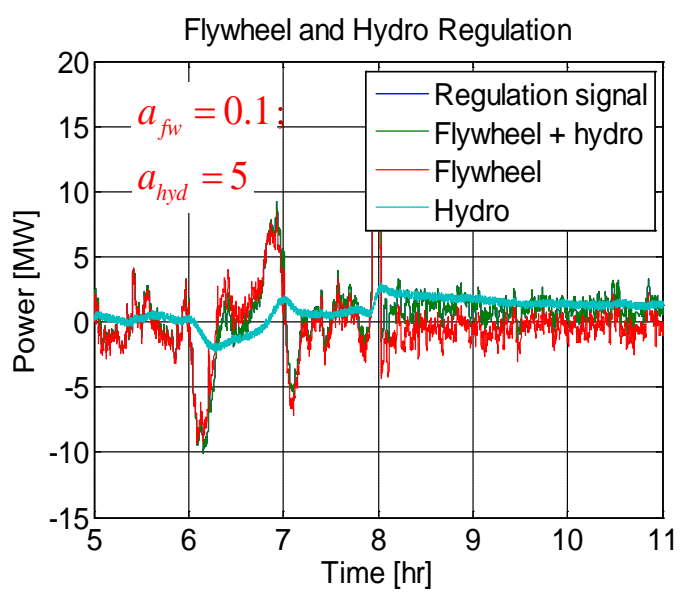

Figure 10: The combined regulation service provided by the flywheel and a hydro power plant ( $\left.a_{f w}=0.1 ; a_{h y d}=5\right)$.

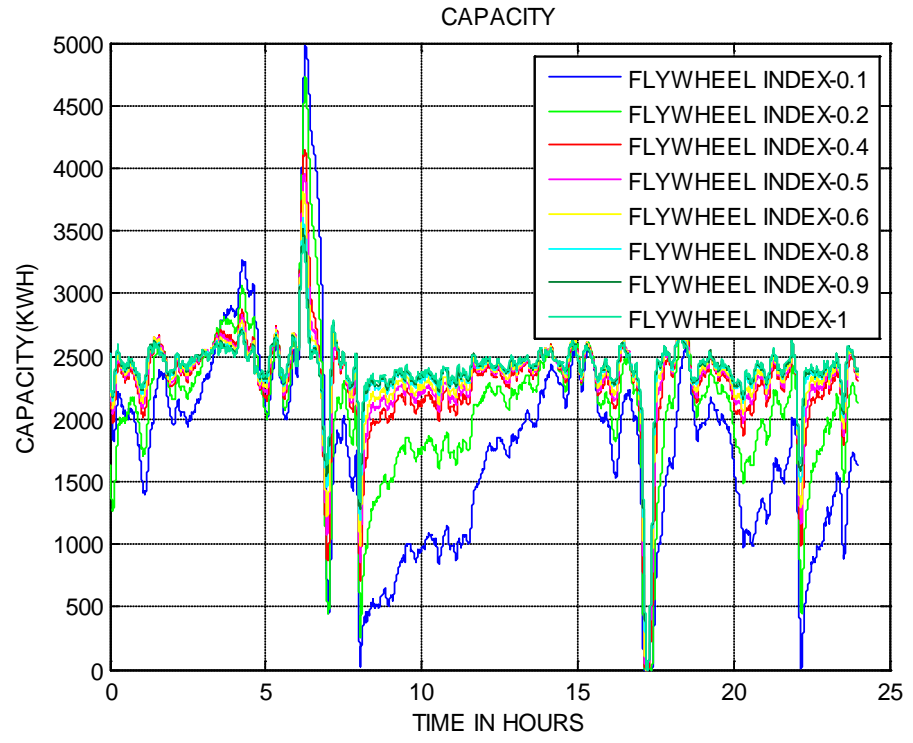

Figure 11: The flywheel energy profile (flywheel index $a_{f w}$ from 0.1 to $1 ; a_{\text {hyd }}=1$ ).

In flywheel field tests, we set the flywheel index at $\alpha_{\text {fw }}=0.5$ and the hydro index at $\alpha_{\text {hyd }}=5.0$, with which the flywheel responds to an optimal share of regulation signals while maintaining a reasonable SOC. 


\subsection{Flywheel Field Experiments}

The experimental framework is shown in Figure 12. The input signals are regulation and ACE signals. The 4-second actual ACE and regulation signals from BPA and CAISO were used as test signals in scenarios representing the existing level of wind generation penetration. The 1minute simulated ACE signals representing 2013 wind penetration scenarios were used for $20 \%$ renewable penetration scenarios. (For the detailed methodology to generate simulated ACE signals, please refer to Makarov et al. [1][2][15].)

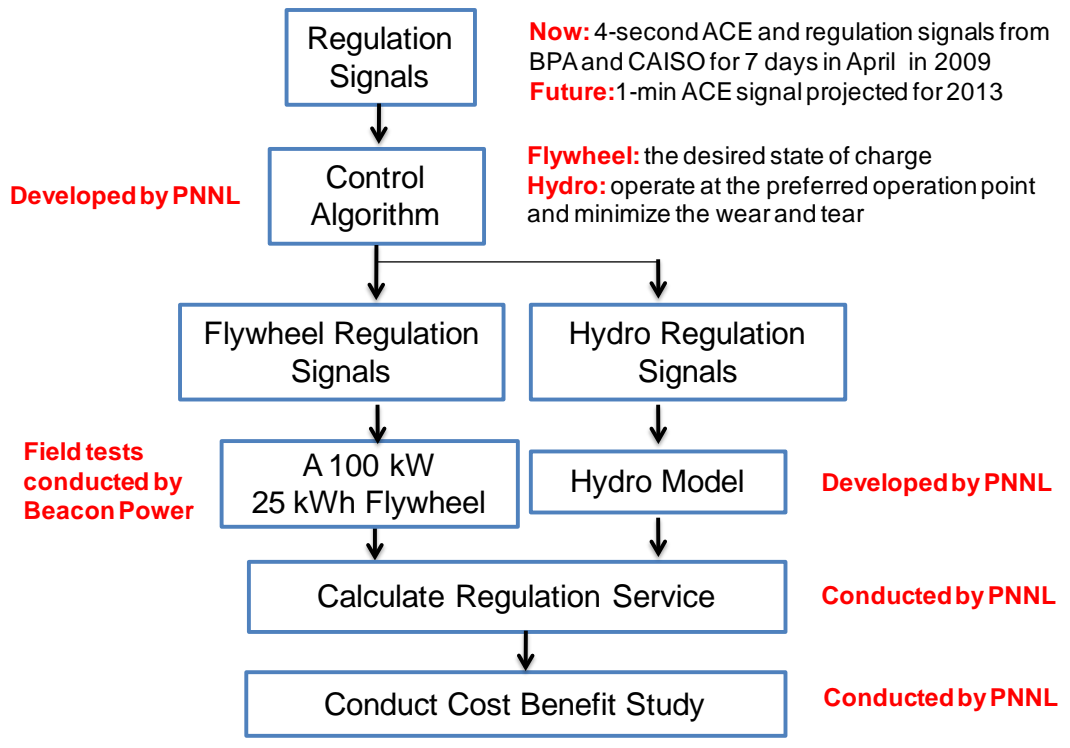

Figure 12: The experimental framework.

The test signal was normalized to fit $\pm 40 \mathrm{MW}$ range and then fed into the WAEMS controller $^{6}$, which allocated the signal to the flywheel energy storage (within $\pm 20 \mathrm{MW}$ ) and the hydro plant model (within $\pm 20 \mathrm{MW}$ ), so that the flywheel energy storage provided the fast regulating component while the hydro plant provided the slow one. The hydro power plant was also used to help the flywheel energy storage to maintain a desired level of the stored energy. In this project, we have not conducted field tests on a real hydro plant. The hydro power outputs were simulated outputs. The $\pm 20 \mathrm{MW}$ flywheel signal was further scaled down to $\pm 100 \mathrm{~kW}$ to operate the $25-\mathrm{kWh}, 100-\mathrm{kW}$ flywheel provided for the test by Beacon Power Corporation.

\footnotetext{
${ }^{6}$ The control algorithm used in the WAEMS controller to allocated the signals between the hydro plant and the flywheel was originally developed by PNNL in Phase I (refer to [1][14] for details). In Phase II, this control algorithm was modified and implemented on a real flywheel controller by Beacon Power engineers supported by PNNL researchers.
} 
All field tests were conducted at the Beacon Power facility located in Tyngsboro, MA. The field tests lasted for 8 weeks (March through April, 2010); test results were recorded by Beacon Power and delivered to PNNL on May 26, 2010. The performance and economic evaluations were performed by PNNL and will be discussed in Section 3.

In the following subsections, we will discuss the flywheel field test setup, the input data, and the scenario settings.

\subsection{The Field Test Setup}

In this project, the control algorithm was implemented through a remote function call over $\mathrm{TCP} / \mathrm{IP}$ to the Beacon master controller ${ }^{7}$ using the MATLAB TCP/IP toolbox. The master controller is an industrial PC with a Lynx operating system. Note that only one flywheel was used for the field test; a picture of this flywheel is shown in Figure 13.

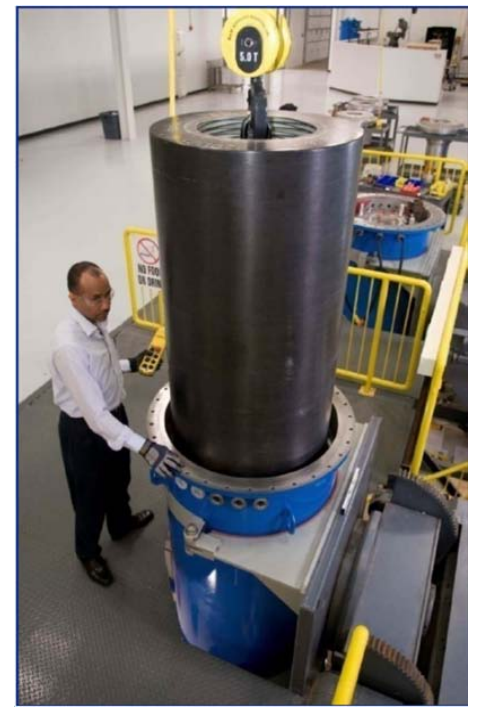

Figure 13: Assembling the 25-kWh, 100-kW flywheel used for the field test.

The regulation signal was passed to the master controller and the response is reported back to the PNNL WAEMS controller written in MATLAB that decides on the next value of the regulation output based on the response. The field test involved a single flywheel with a maximum capacity of $25-\mathrm{KWh}$ and could provide a maximum of $\pm 100-\mathrm{KW}$ regulation services. Thus, the $\pm 20 \mathrm{MW}$ regulation signal was divided by 200 before passing to the master controller and the response was scaled up by the same factor. The result for five different sets of data was recorded for further analysis. The recorded values include Hydro Regulation Signal (RS-hyd),

\footnotetext{
${ }^{7}$ The Beacon master controller distributes the control signals to all the flywheels based on the relative state of charge (SOC) of each flywheel. It controls all the flywheel wheels in an asset. An asset is a plant. A 20 MW plant with 20 control trailers (and 200 flywheels) is an asset, but a single control trailer with only 10 flywheels might also be an asset, if that is all the plant consists of as in this project's flywheel experiments.
} 
Hydro Response (P-hyd-reg), Flywheel Regulation Signal (RS-FW), Flywheel Response (P-FW), Total Regulation request (RS), Total Response (P-total) and Flywheel Capacity, as shown in Figure 14 and Figure 15.

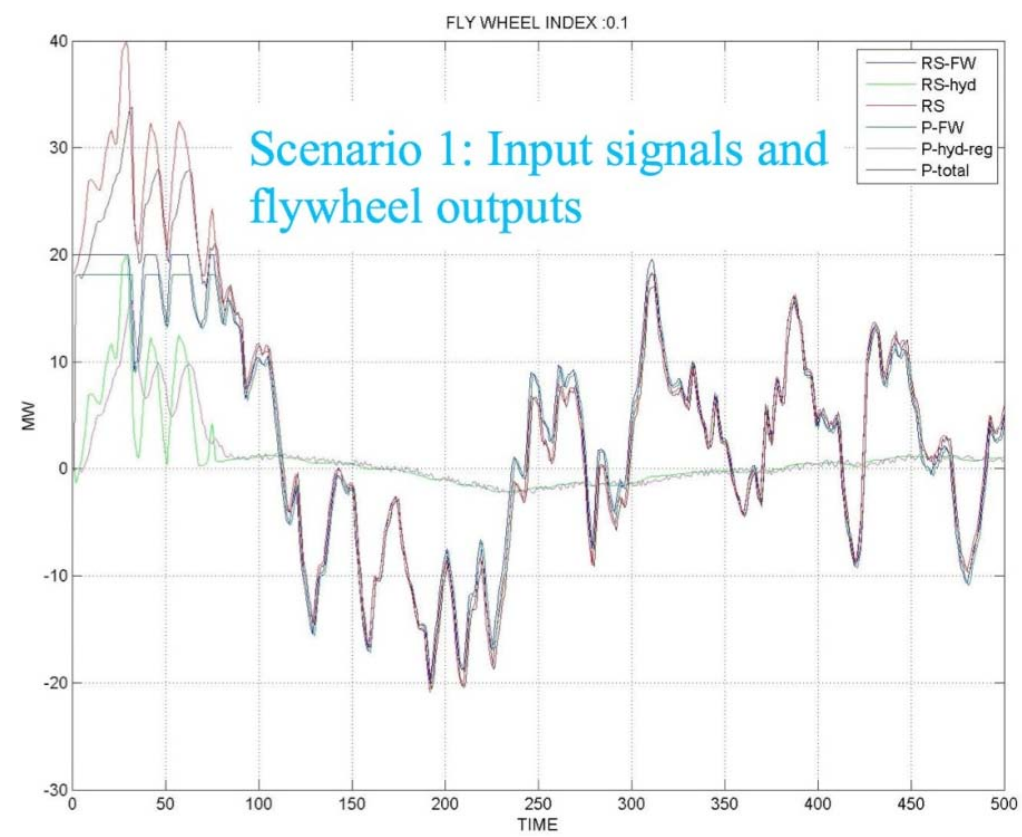

Figure 14: An example of input regulation signals and flywheel responses recorded in the field test.

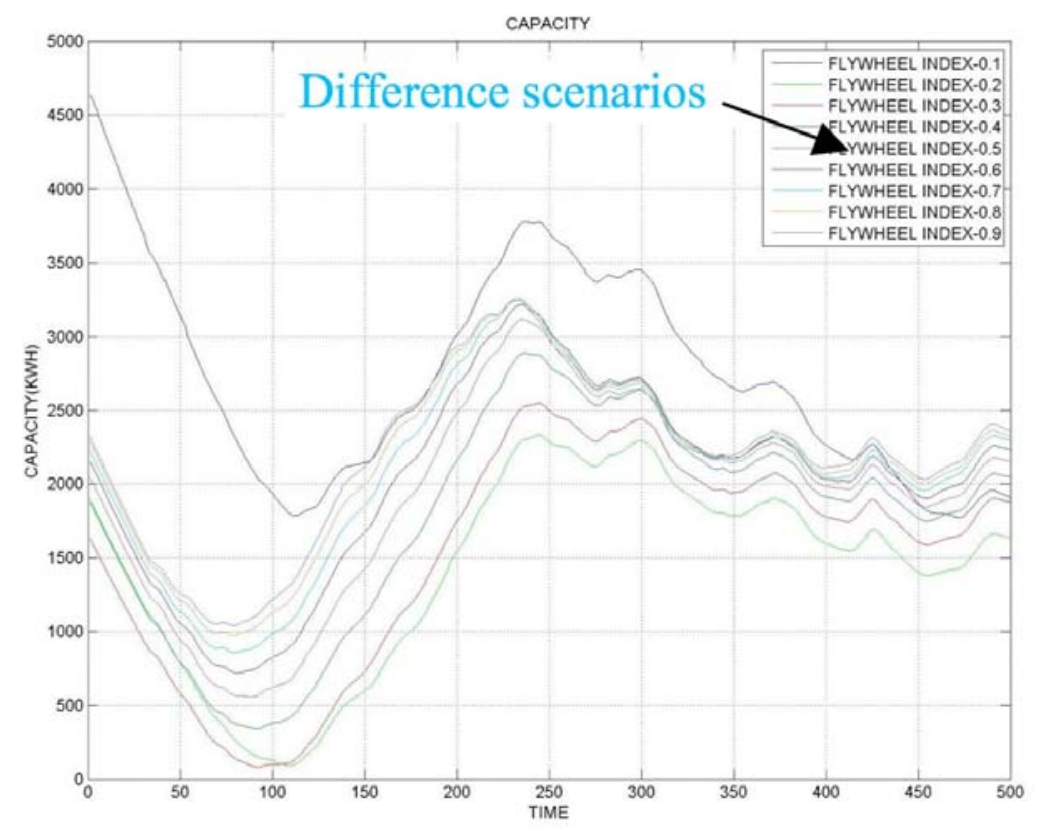

Figure 15: An example flywheel capacity levels recorded in the field test 


\subsection{Field Test Signals Preparation}

The PNNL team sent out data requests to the CAISO and BPA points of contact requesting the ACE and regulation signals, as shown in Table 2. As shown in Table 3, the April (April 13 to 19) ACE signals and regulation data were selected as the test signals for scenarios representing the current wind penetration; simulated ACE signals representing 2013 wind penetration scenarios were used for $20 \%$ renewable penetration scenarios. In the following subsections, we will present the characteristics of these test signals.

Both ACE and regulation signals were used as test signals. As shown in Figure 16, regulation signals were generated by CAISOs automatic generation control (AGC) mechanism designed for conventional generators. As a fast regulating resource, the flywheel can respond to raw ACE signals instead of processed regulation signals that are sent to generators, which may simplify the regulation process and reduce the regulation capacity [3].

Table 2: BPA and CAISO data requests.

\begin{tabular}{|c|c|c|c|c|c|c|}
\hline & Data Type & $\begin{array}{l}\text { Time } \\
\text { Step }\end{array}$ & Start & End & Representing Condition & File Format \\
\hline \multirow{3}{*}{ CAISO } & \multirow{3}{*}{$\begin{array}{l}\text { A) Regulation and ACE signals } \\
\text { for a typical hydro power plant } \\
\text { or a typical regulating unit } \\
\text { singals } \\
\text { B) Total Regulation and ACE } \\
\text { Signals }\end{array}$} & \multirow{3}{*}{$4 \mathrm{Sec}$} & 25-Aug-08 & 31-Aug-08 & CAISO summer peak & \multirow{6}{*}{ CSV } \\
\hline & & & 8-Dec-08 & 14-Dec-08 & BPA winter peak & \\
\hline & & & 13-Anr-09l & 19-Anr-09l & wind volatilitve & \\
\hline \multirow{3}{*}{ BPA } & \multirow{3}{*}{$\begin{array}{l}\text { A) Hydro plant X: } \\
\text { 1) Basepoint Adjustment } \\
\text { 2) regulation } \\
\text { B) Total Regulation Signals include: } \\
\text { 1) Total Basepoint Adjustment } \\
\text { 2) Total regulation }\end{array}$} & \multirow{3}{*}{$4 \mathrm{Sec}$} & 25-Aug-08 & 31-Aug-08 & CAISO summer peak & \\
\hline & & & 8-Dec-08 & 14-Dec-08 & BPA winter peak & \\
\hline & & & 13-Apr-09 & 19-Apr-09 & wind volatility & \\
\hline
\end{tabular}

Table 3: Test signal sent to Beacon Power.

\begin{tabular}{|c|c|c|c|c|c|}
\hline & $\begin{array}{l}\text { Test Start } \\
\text { Date }\end{array}$ & $\begin{array}{l}\text { Test End } \\
\text { Date }\end{array}$ & Description & $\begin{array}{c}\text { Range } \\
\text { [Low High] } \\
\text { (MW) }\end{array}$ & File Name \\
\hline \multirow{3}{*}{$\begin{array}{l}\text { Real Operation } \\
\text { Data: } \\
\text { April 13-19, } 2009\end{array}$} & 15-Mar-10 & 22-Mar-10 & $\begin{array}{c}\text { BPA+CAISO } \\
\text { Area Control Error }\end{array}$ & {$[-800800]$} & Apr_CAandBPA_SigACE.mat \\
\hline & 22-Mar-10 & 29-Mar-10 & $\begin{array}{c}\text { BPA (Unit X) } \\
\text { base-point adjustment }\end{array}$ & {$[-344$ 386] } & Apr_gcl_sigReg.mat \\
\hline & 29-Mar-10 & 5-Apr-10 & $\begin{array}{c}\text { CA (Unit X) } \\
\text { Regulation } \\
\end{array}$ & {$\left[\begin{array}{ll}-52 & 57\end{array}\right]$} & April_CA_UnitXSigReg.mat \\
\hline \multirow{2}{*}{$\begin{array}{l}\text { Simulated Data: } \\
\text { BPA: } 2013 \\
\text { CAISO: } 30 \% \\
\text { renewables }\end{array}$} & 12-Apr-10 & 19-Apr-10 & $\begin{array}{c}\text { CA } 2013 \\
\text { Area Control Error }\end{array}$ & {$[-600650]$} & Fut_Apr33wind_CAACE.mat \\
\hline & 26-Apr-10 & 3-May-10 & $\begin{array}{c}\text { BPA } 2013 \\
\text { Area Control Error }\end{array}$ & {$[-400400]$} & Fut_Apr33wind_BPAACE.mat \\
\hline
\end{tabular}




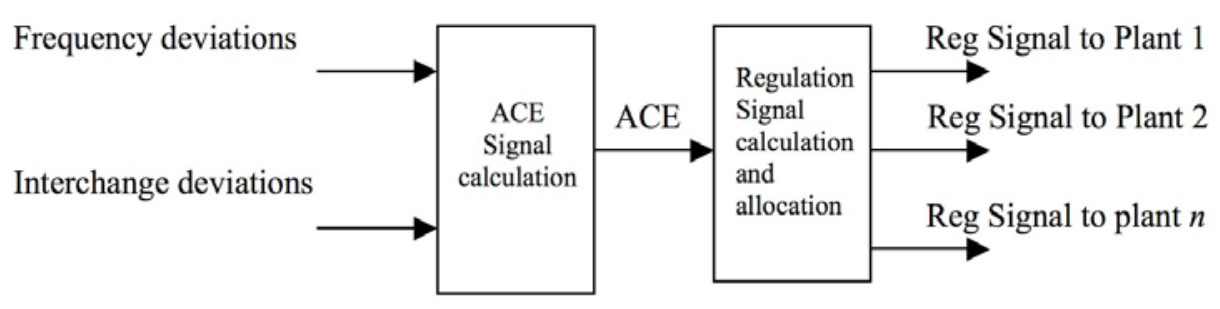

Figure 16: The block diagram of ACE and regulation signal calculation.

\subsubsection{The Characteristics of the CAISO ACE Signal}

The probability density functions (PDFs) of the actual CAISO ACE signals in April 2009, August 2008, and December 2008 are shown in Figure 17. The ACE signal in April 2009 had the biggest variation.

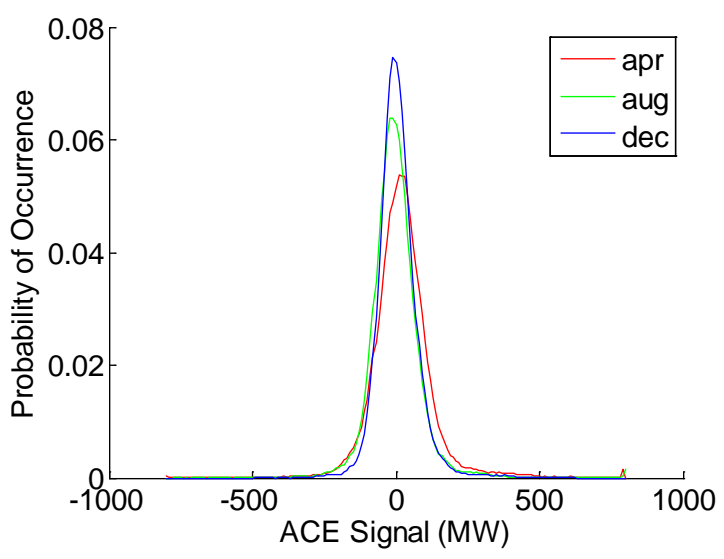

Figure 17: The PDFs of CAISO ACE signals.

The CAISO ACE signal, wind generation, total generation, regulation requirement, and average regulation prices between April 13 and April 18, 2009, are shown in Figure 18 through Figure 21. Below are a few observations on the CAISO April data set:

- As shown in Figure 18, the ACE signal had a high spike at Hour 156. The majority (99.13\%) of ACE signals are inside [-500 500] MW; 97.6\% of ACE signals are inside [330 330] MW.

- As shown in Figure 19 and Figure 20, the wind generation was less than $8 \%$ of total generation capacity. The wind generation could ramp from 0 to $1500 \mathrm{MW}$ in 10 hours or so, representing an averaged ramp of $150 \mathrm{MW} / \mathrm{hr}$.

- As shown in Figure 21, the regulation up (RegUp) and down (RegDn) requirements normally had the same magnitudes and were around 340 MW except for some morning and evening peak hours, for which the requirement can be as high as 500 MW during the selected week in April. 
- As shown in Figure 21, the RegUP and RegDn prices are normally different from each other and can spike from a few dollars to over a thousand dollars per MW. With higher wind penetration, these price spikes are expected to happen more often, especially in areas where fast responsive regulating resources, such as pumpedhydro or hydro power plants, are scarce. Energy storage devices, such as flywheels, will be of great value in those areas where wind penetration increases.

- As shown in Figure 22, the CAISO monthly report shows that in April 2009, the daily average regulation up prices varies from $\$ 2 / \mathrm{MW}$ to $\$ 21 / \mathrm{MW}$. Regulation-up prices are usually a few dollars more expensive than the regulation-down prices.
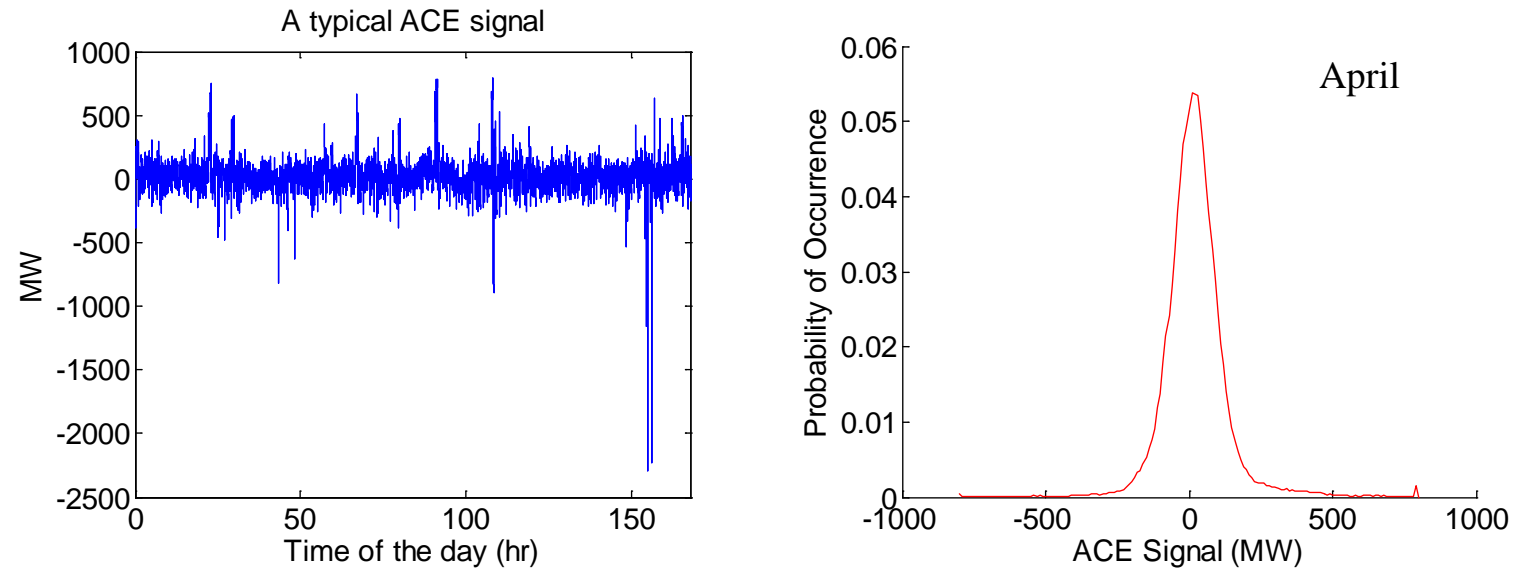

Figure 18: The CAISO ACE signal and its PDF (April 13-18, 2010).
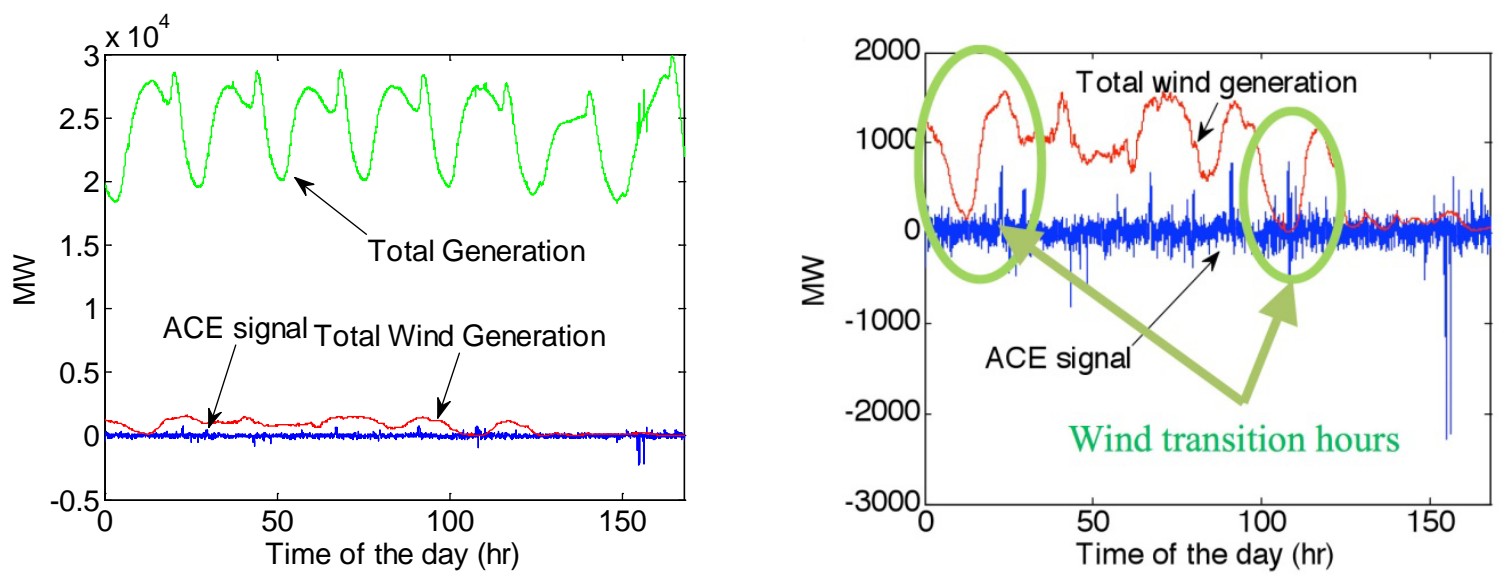

Figure 19: The CAISO total generation, total wind generation, and ACE signal (April 13-18, 2010). 

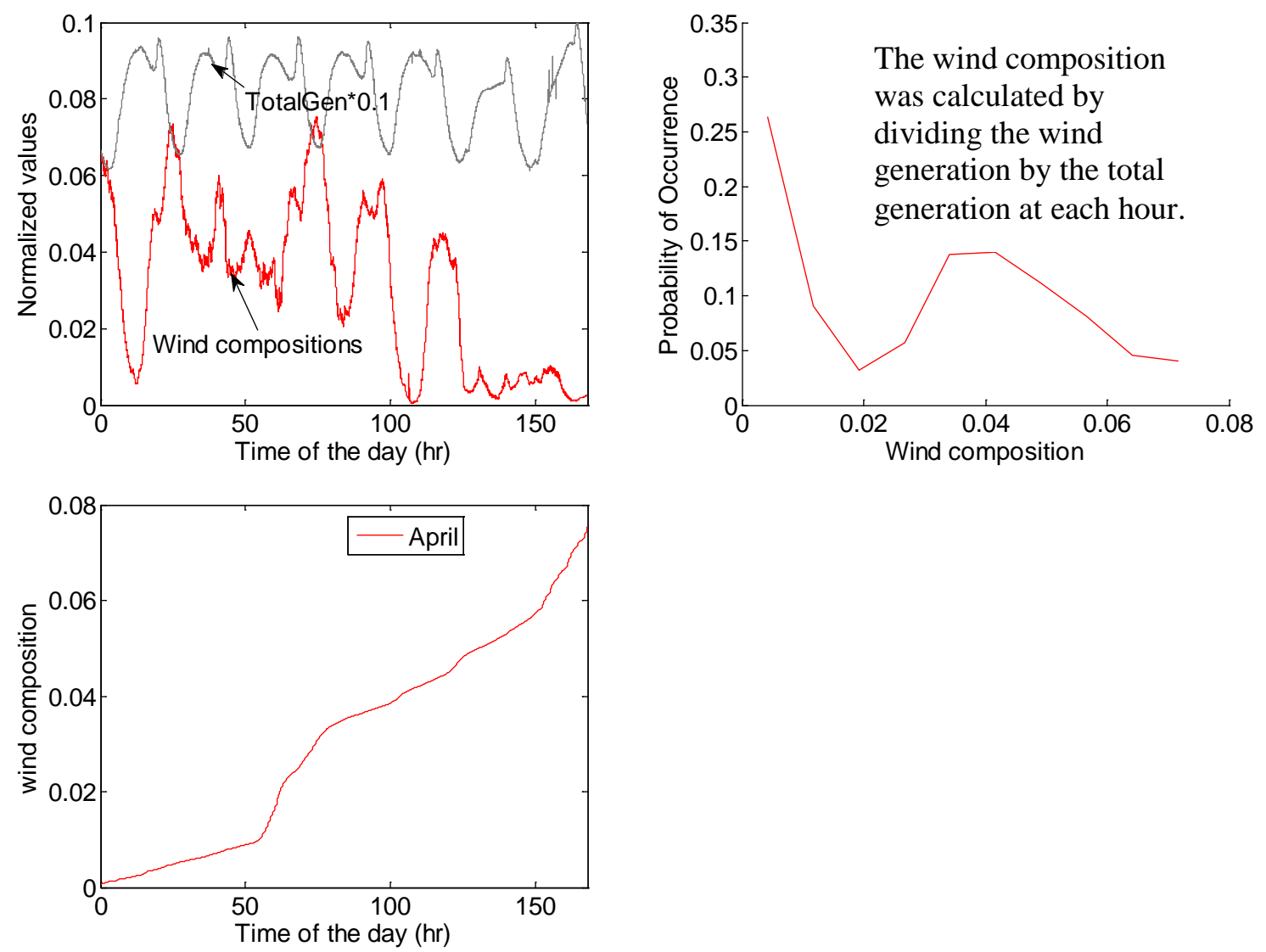

Figure 20: The wind generation composition (Total wind generation divided by total generation; April 13-18, 2010).
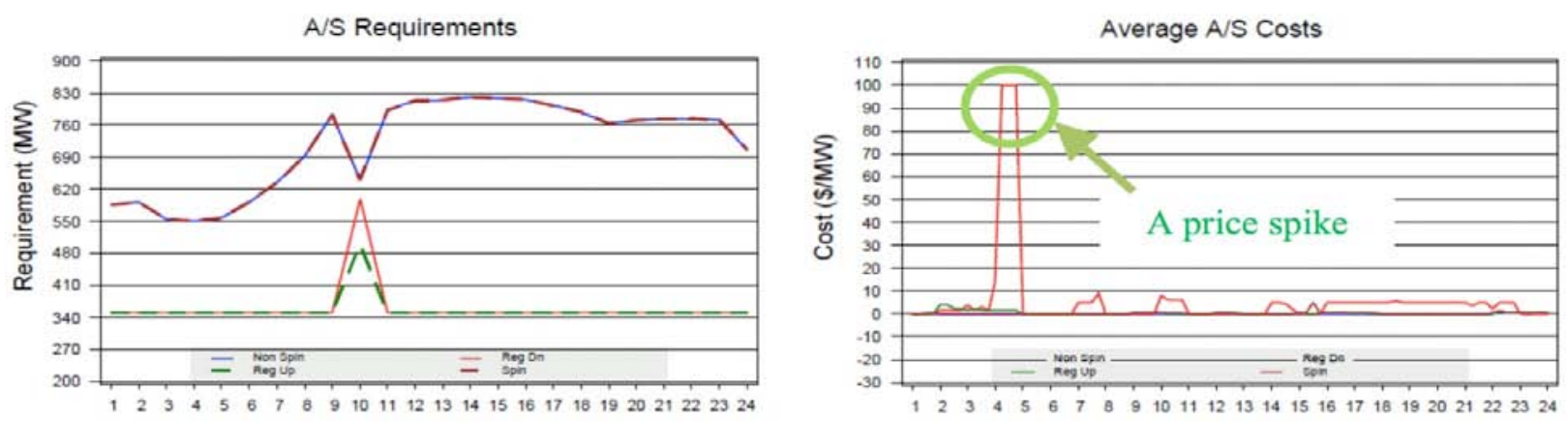

(a) April 13

Figure 21: The real-time ancillary service requirements and average prices (April 13-18, 2010) [16]. 

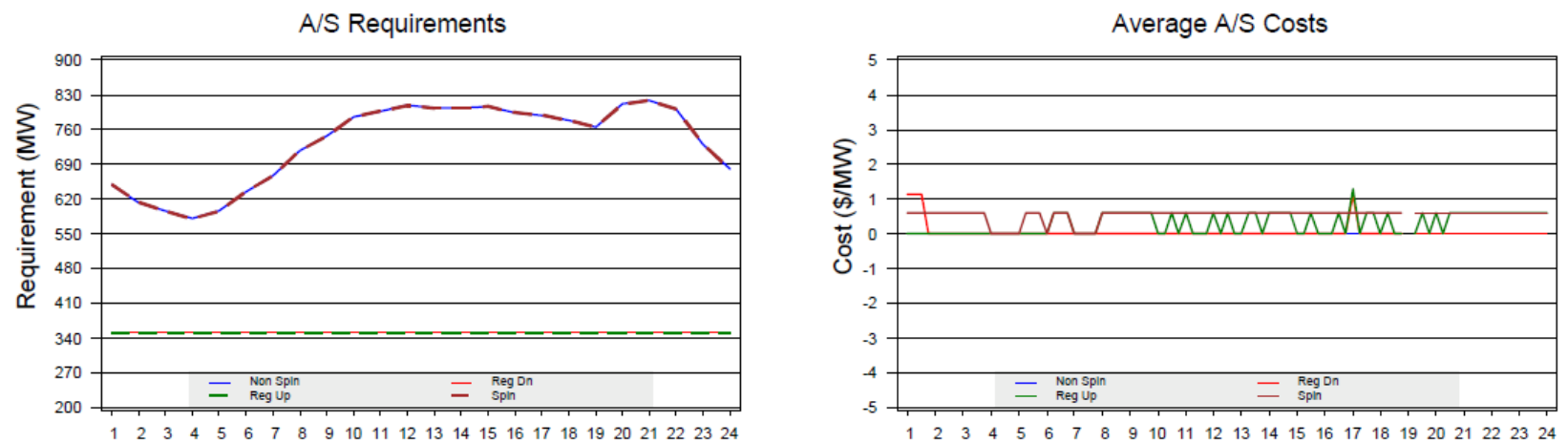

(b) April 14
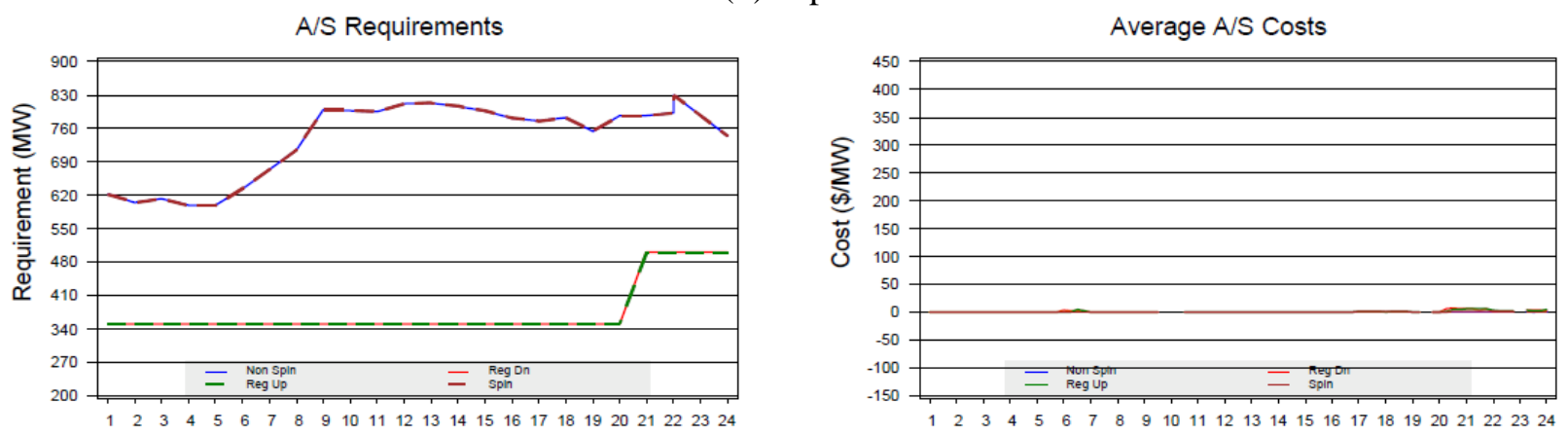

(c) April 14
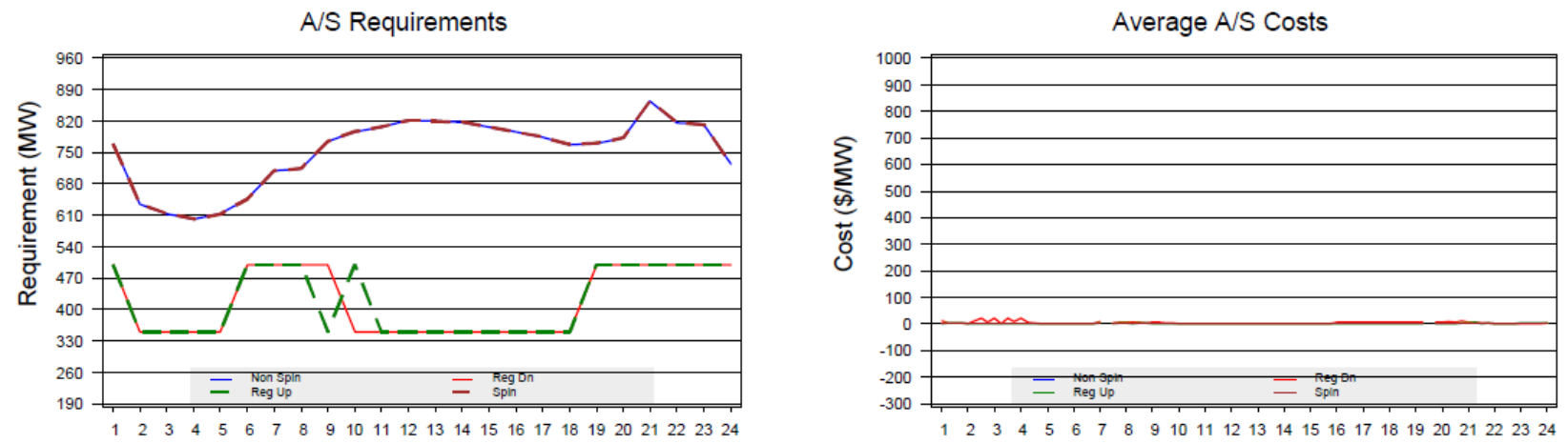

(d) April 15
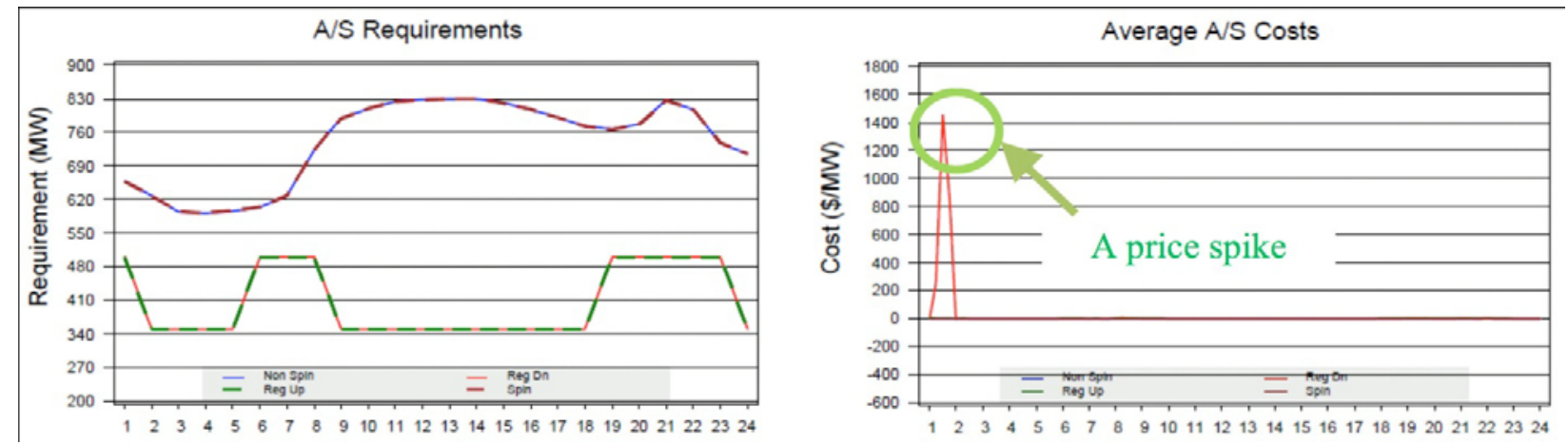

(e) April 16

Figure 21 (cont'd) 

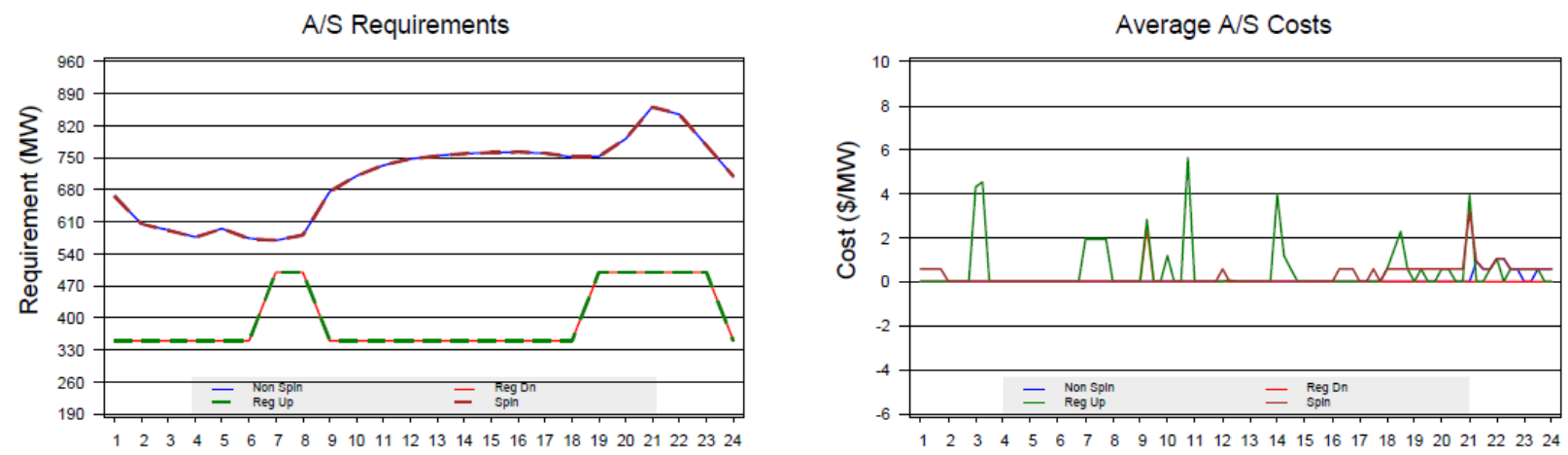

(f) April 17
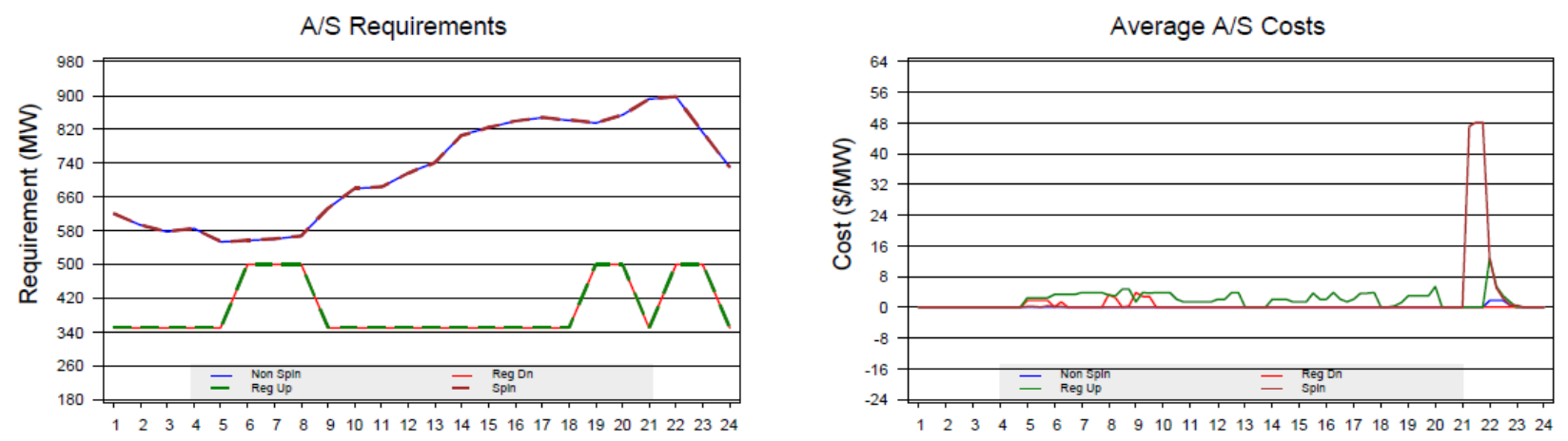

(g) April 18

Figure $21\left(\right.$ cont'd) $^{\prime}$

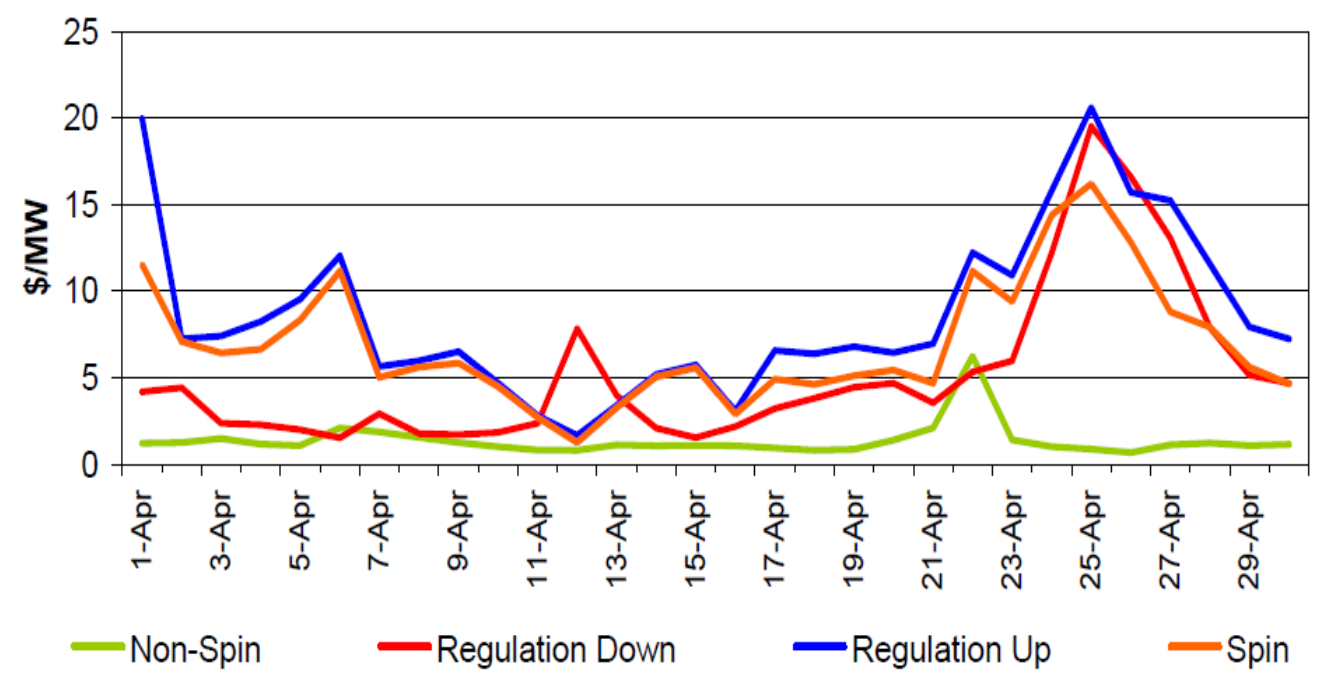

Figure 22: CAISO ancillary service average prices for April 2009 [17] 


\subsubsection{The Characteristics of the BPA ACE Signal}

The BPA ACE signal, wind generation, total generation, regulation requirement, and average regulation prices between April 13 and April 18, 2010, are shown in Figure 23 through Figure 25. Below are a few observations of the BPA April data set:

- As shown in Figure 23, the ACE signal is smaller than the CAISO signal and does not have high spikes (99.93\% of ACE signals are inside [-200 200] MW; 98.02\% of ACE signals are inside [-100 100] MW). This may be explained by a smaller size of the BPA system comparing with the CAISO system and the higher quality regulation service provided by BPA's hydro power plants. However, when wind generation penetration increases, BPA may run out of hydro regulating resources, especially when irrigation and fish considerations are placing more and more stringent constraints on the amount and rate of the water flow that a hydro plant can release. Therefore, finding alternative fast regulating resources may be necessary in the future.

- As shown in Figure 24 and Figure 25, wind generation consists of less than $40 \%$ of BPA's total load. Note that BPA generation is far greater than the BPA load. Because we did not have the BPA generation for this time period, we could not obtain the wind share with respect to the total BPA generation, which is critical to evaluating the wind penetration test case.

- The wind generation can ramp up or down a few hundred MW/hr.
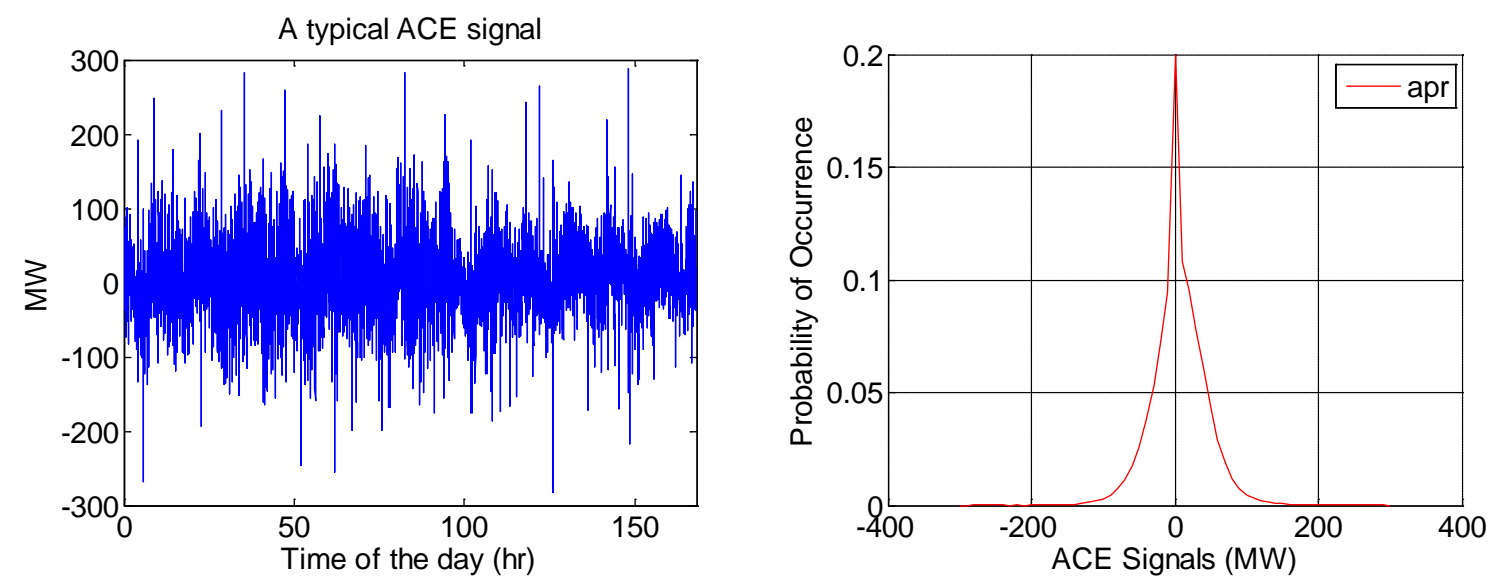

Figure 23: The BPA ACE signal and its PDF (April 13-18, 2010). 

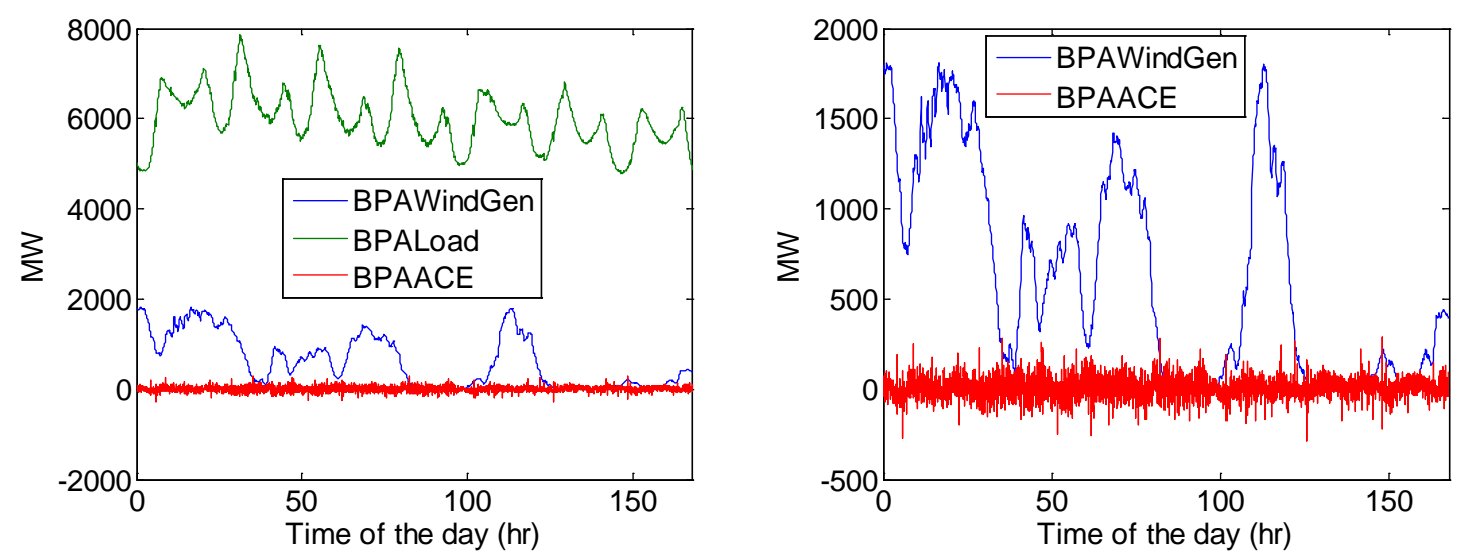

Figure 24: The BPA total load, total wind generation, and ACE signal (April 13-18, 2010) [18]
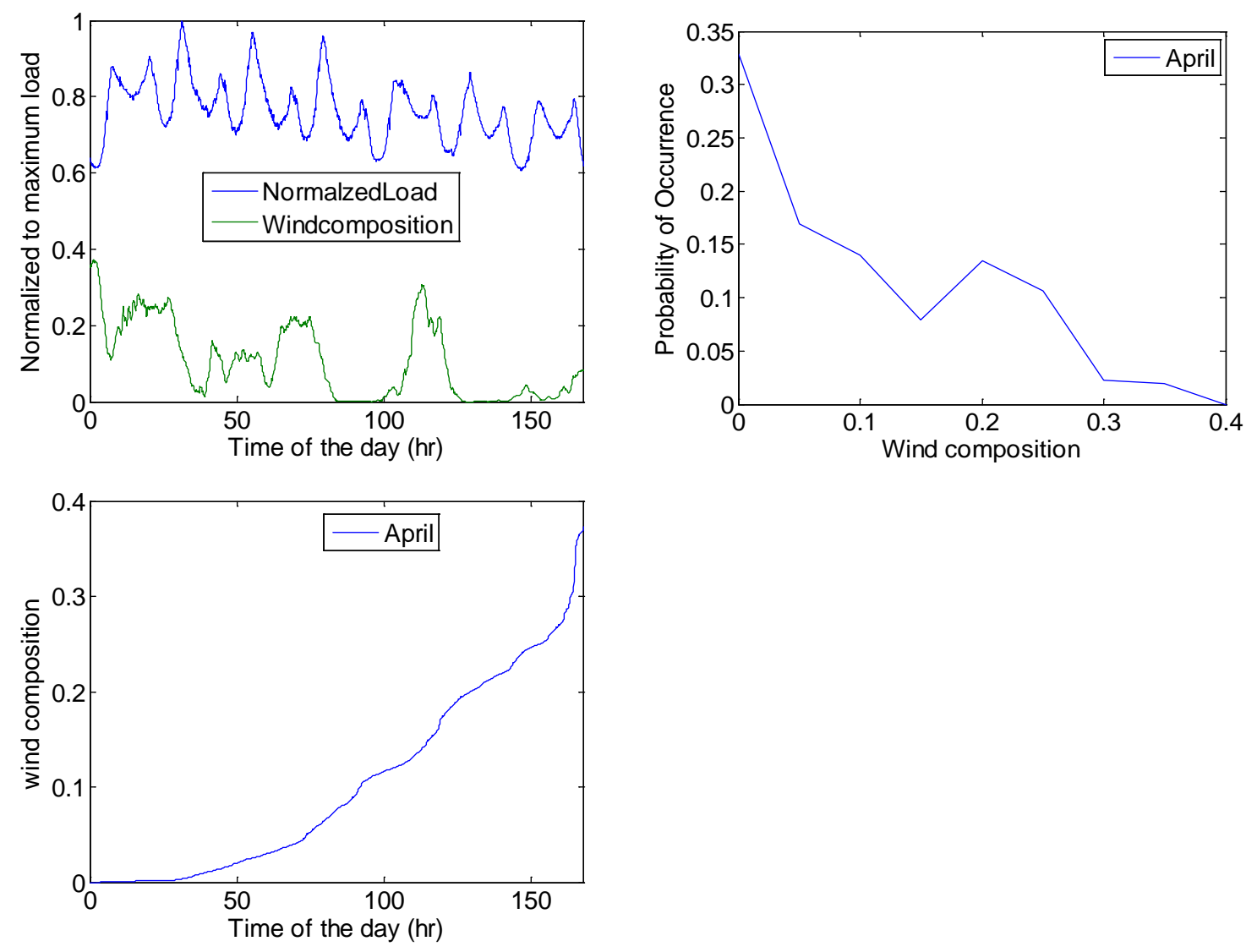

Figure 25: The BPA total load and wind generation composition (April 13-18, 2010).

\subsubsection{The Characteristics of the Aggregated CAISO and BPA ACE Signal}

The BPA, CAISO, and combined ACE (BPA+CAISO) and their probability density functions (PDFs) are shown in Figure 26. A total of 99.52\% of the combined ACE signal is inside [-500 500] MW, and $98.73 \%$ is inside [-330 330] MW. Note that for the CAISO ACE, the percentages are 
99.13\% and 97.6\%, respectively. Therefore, combining the ACE signal will smooth the CAISO ACE signal slightly.

The total energy of the regulation signal, $E_{A C E}$, can be calculated by

$$
E_{A C E}=\sum_{i=1}^{n=151200} P_{A C E}(i) \times \Delta t=\sum_{i=1}^{n=151200} P_{A C E}(i) \times \frac{4}{3600}
$$

Let $i$ represent the $i^{\text {th }}$ data point. If the signal is 4-second apart for a week in length, there are 151200 data points in total. Then, the regulation energies for the BPA, CAISO, and BPA+CAISO ACE signals were calculated and are shown in Table 4 . Note that by simply combining the two signals, the required regulation energy was reduced by $23 \%$.
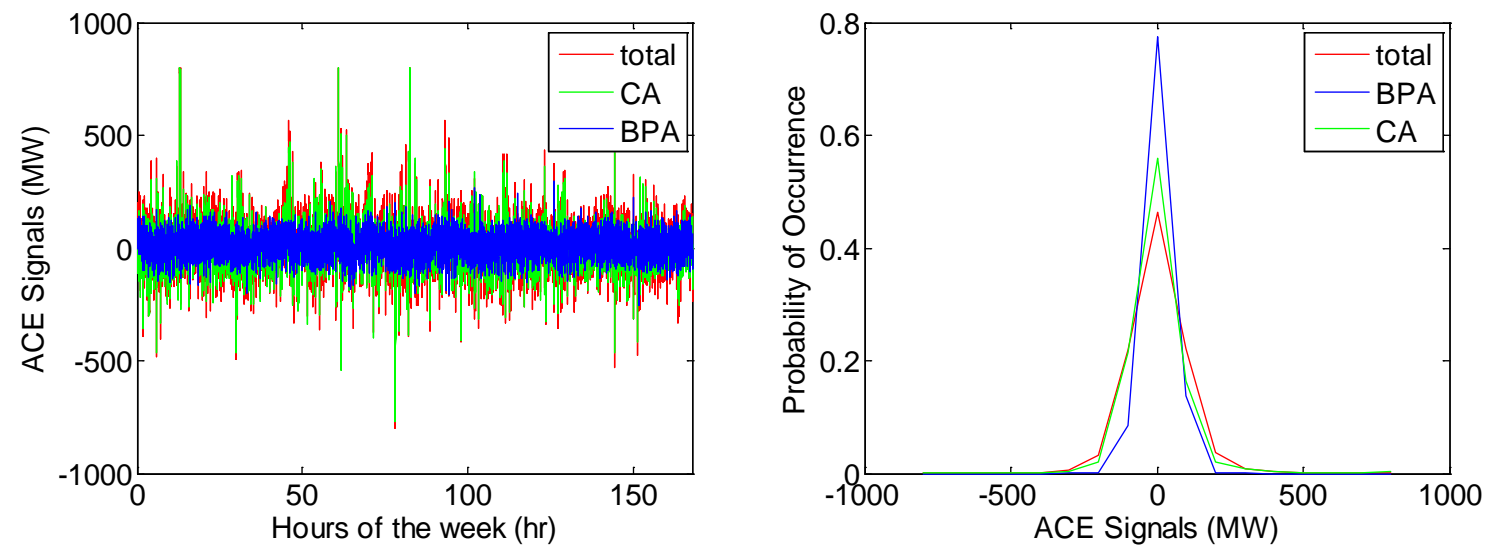

Figure 26: The BPA+CAISO ACE signal and its PDF (April 13-18, 2010).

Table 4: The regulation energy savings by ACE sharing.

\begin{tabular}{|c|c|c|c|c|c|}
\hline & $\begin{array}{c}\text { BPA } \\
(\mathrm{GWh}) \\
E_{A C E}^{B P A}\end{array}$ & $\begin{array}{c}\text { CAISO } \\
\text { (GWh) } \\
E_{A C E}^{C A}\end{array}$ & $\begin{array}{c}\text { Shared ACE } \\
\qquad \begin{array}{c}(\mathrm{GWh}) \\
E_{A C E}^{B P A+C A}\end{array}\end{array}$ & $\begin{array}{c}\text { Not Shared } \\
(\mathrm{GWh}) \\
E_{A C E}^{B P A}+E_{A C E}^{C A}\end{array}$ & $\frac{E_{A C E}^{B P A+C A}}{E_{A C E}^{B P A}+E_{A C E}^{C A}}$ \\
\hline April 13-19, 2009 & 5.6 & 10.225 & 15.825 & 12.208 & $0.77 \%$ \\
\hline
\end{tabular}

\subsubsection{The Characteristics of the Base-point Adjustment Signal of a Hydro Plant in BPA Balancing Authorities}

The BPA base-point adjustment signal ${ }^{8}$ and its PDF are shown in Figure 27. We selected the BPA base-point adjustment signal because the BPA regulation signal is merged into the base-point adjustment signal, which is, in turn, sent to the hydro turbine controller every 4

\footnotetext{
${ }^{8}$ The basepoint adjustment equals the generation requirement minus the sum of the generator basepoints. The basepoint adjustment signal is allocated to plants according to their percent response. The generation requirement is the amount of generation needed to meet the area load.
} 
seconds to control the widget gate movements. In addition, the regulation signal is discontinuous, as shown in Figure 28. The discontinuity occurs because the dynamic dead-band method, used by BPA to generate the regulation signal, ignores some small power variations. Responding to the discontinuous regulation signal will significantly underuse the flywheel capability and result in unnecessary energy losses in the flywheel's operation during idling periods. Therefore, to reduce the wear and tear of the hydro turbine and effectively use the fast regulating capacity of the flywheel, we chose to let the flywheel respond to the fast changing component in the base-point adjustment signal during our tests.
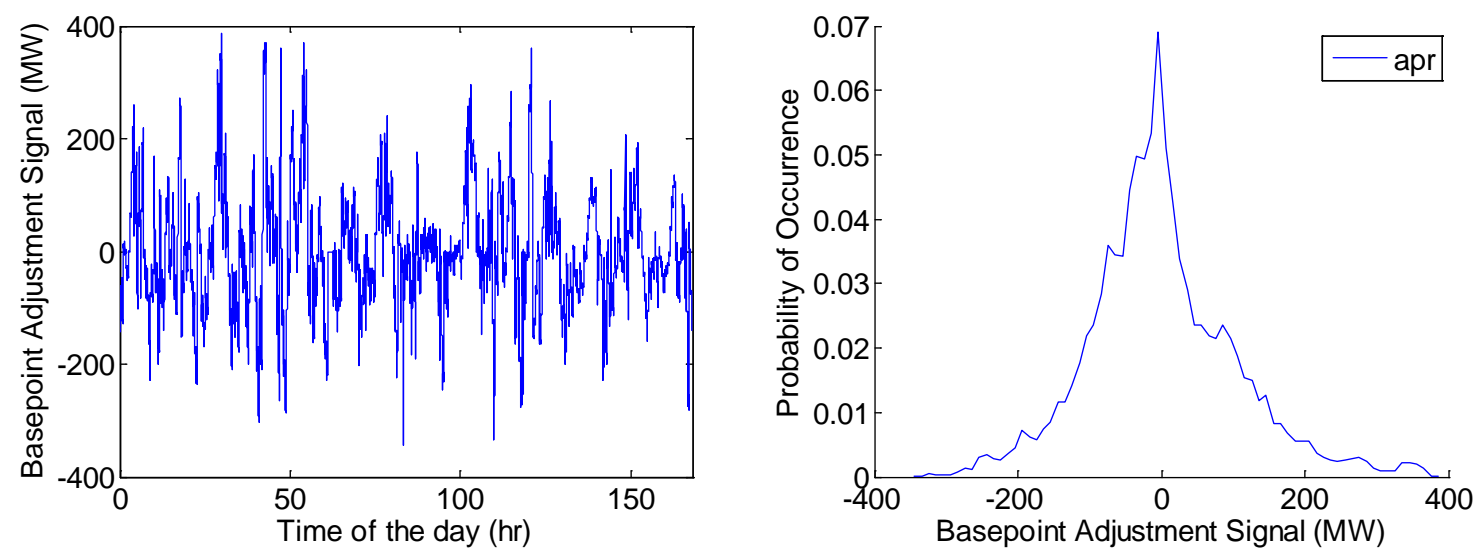

Figure 27: The base-point adjustment signal and its PDF for a BPA hydro unit (April 13-18, 2010).

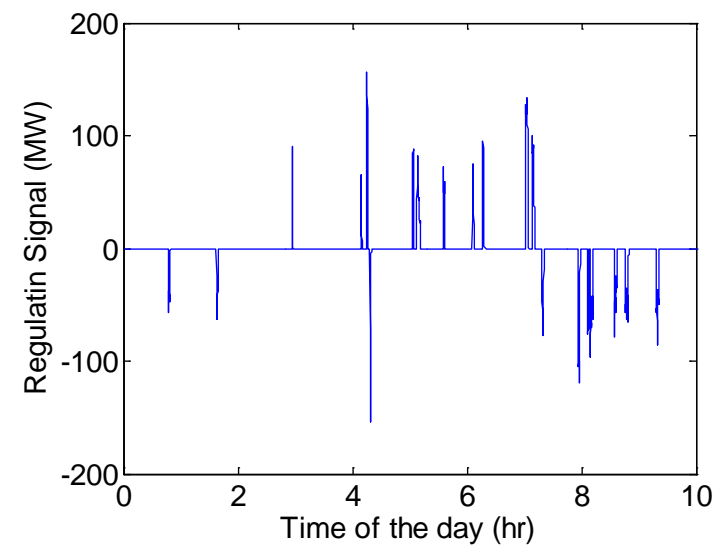

Figure 28: The regulation signal of a BPA hydro unit (April 13, 0:00 - 10:00 am).

\subsubsection{The Characteristics of the Regulation Signal of a Hydro Plant in the CAISO Balancing Authorities}

The regulation signals sent to a hydro plant by CAISO include regulation high and low limits, and the dispatch operating target $\left(\mathrm{DOT}^{9}\right)$, as shown in Figure 29. Note that the regulation

${ }^{9}$ The DOT is calculated every 5 minutes based on optimization from the Market system. 
signal was always positive for a hydro unit because of the DOT component. However, for a flywheel, the energy regulation is through charging (RegDn: $\left.P_{f w}<0\right)$ and discharging (RegUp: $\left.P_{f w}>0\right)$. Therefore, the test signal, $P_{\text {test }}$, is obtained by $P_{\text {reg }}-D O T$.

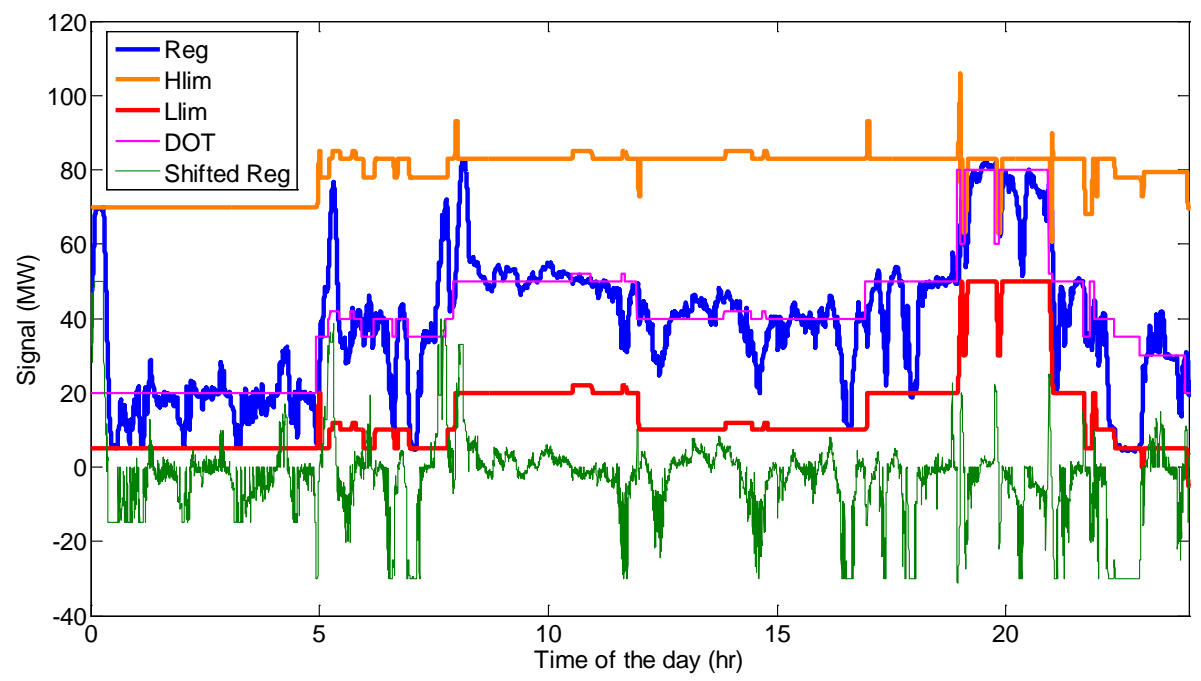

Figure 29: The regulation signals sent to a hydro unit in a CAISO control area.

\subsubsection{The Characteristics of the Future BPA, CAISO, and Aggregated (BPA+CAISO) ACE Signals}

Historical data (2006 load and wind data) were used to simulate the load-balancing processes in the BPA and CAISO control areas in 2013. Then, capacity, ramp rate, and ramp duration characteristics were extracted from the simulation results to calculate regulation requirements. The methodologies were described in [1][2] for CAISO ACE signal generation (representing 20\% renewable penetration) and in [19][20] for the BPA ACE signal generation. The ACE signals increased in both the magnitude and ramps in 2013 because the renewable penetration was $20 \%$ or more in BPA and CAISO controlled areas (see Figure 30 to Figure 32).
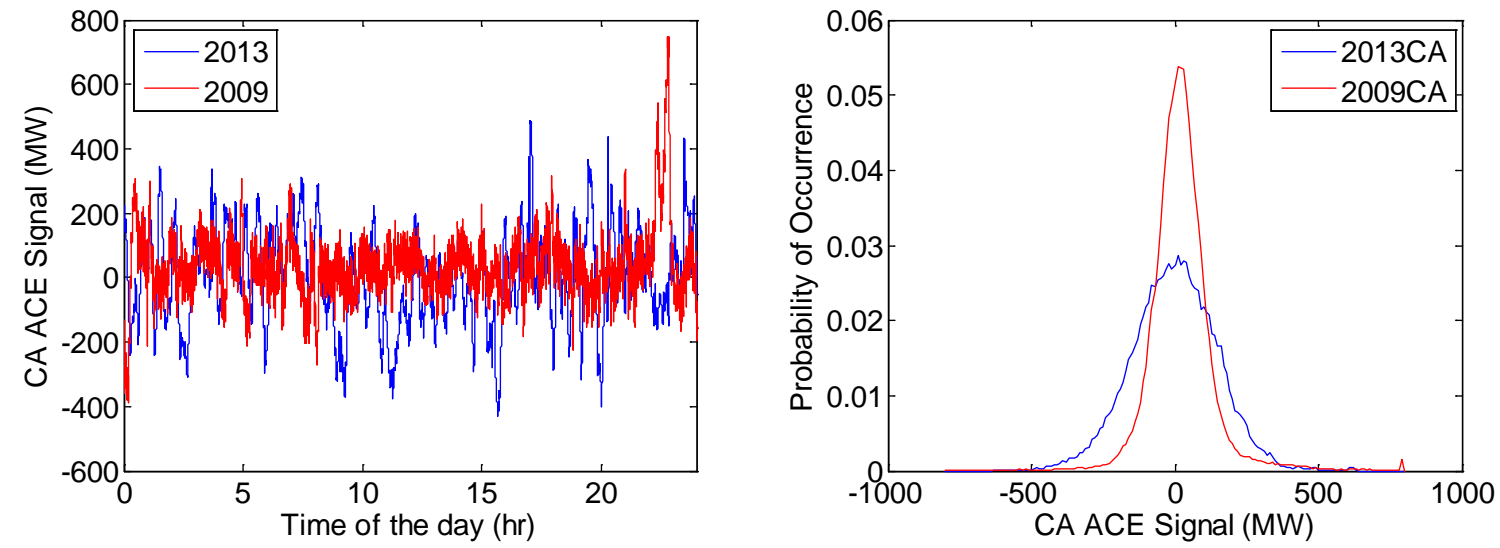

Figure 30: The CAISO ACE signal and its PDF (Scenario 2013). 

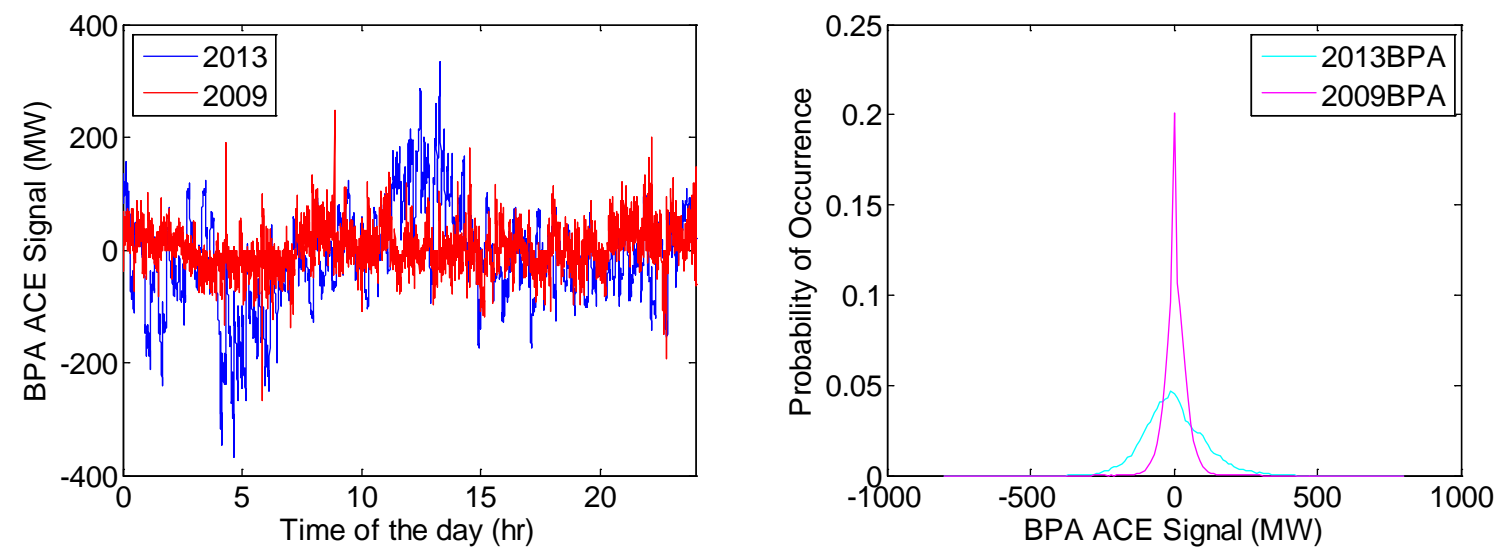

Figure 31: The BPA ACE signal and its PDF (Scenario 2013).
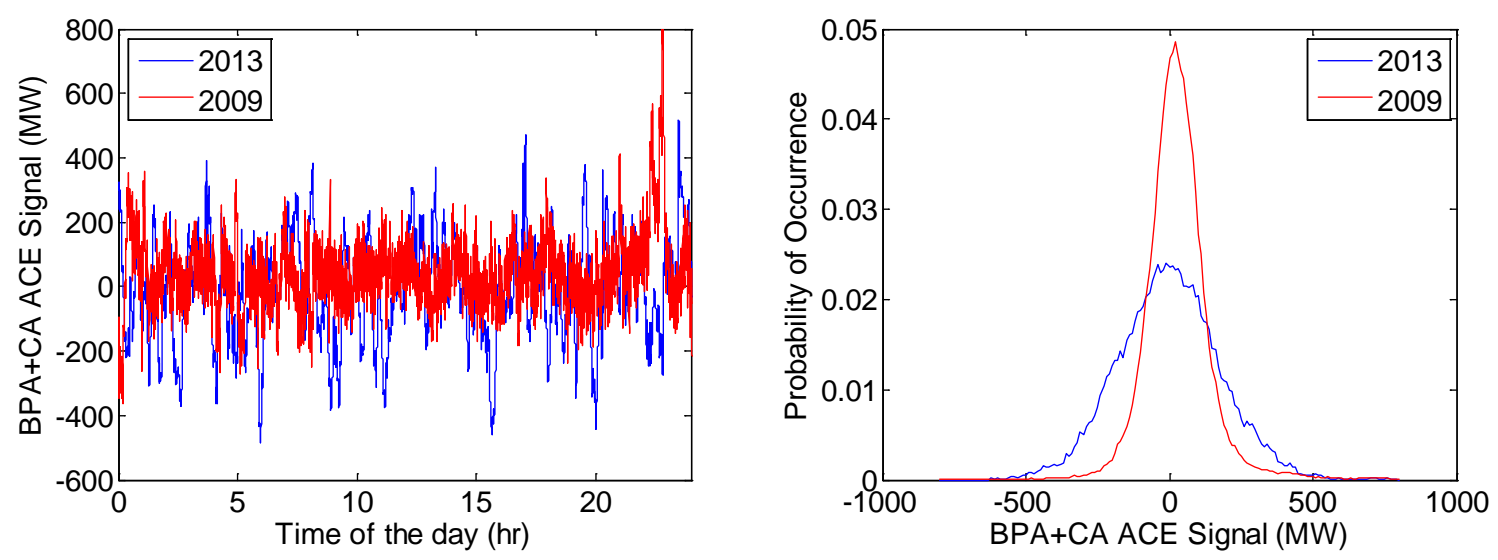

Figure 32: The BPA+CAISO ACE signal and its PDF (Scenario 2013).

\subsubsection{The Test Signals Normalization}

The test signal was first scaled down to $\pm 40 \mathrm{MW}$ and then sent to the WAEMS controller. Using the algorithm described in Section 1.4, the controller allocated the signal between the flywheel (within $\pm 20 \mathrm{MW}$ ) and hydro plant (within $\pm 20 \mathrm{MW}$ ) so that the flywheel provided the fast regulating signal and the hydro plant provided the slow one while helping the flywheel maintain a desired SOC. The hydro signal was then sent to the hydro model coded in MATLAB as described in Section 1.4.1. Note that the hydro outputs were simulation outputs. The \pm 20 flywheel signal was further downsized to $\pm 100 \mathrm{~kW}$ to operate the $25-\mathrm{kWh}, 100-\mathrm{kW}$ flywheel selected for test. 


\subsection{Flywheel Performance Evaluation}

This chapter presents the proposed flywheel performance evaluation criteria and field test results based on them. Five field tests have been performed as described in Section 2.2. The test signal was sent out at a 4-second interval and the test ran for a week. In all five flywheel field tests, we set the flywheel index to $\alpha_{f w}=0.5$ and the hydro index to $\alpha_{\text {hyd }}=5.0$ in Eqn. (16).

The following legends are used in all figures presented in Section 3:

- TOT: the input regulation signal

- TOTOutput: the total output (flywheel + hydro)

- Sigfw: the fast varying component of the input regulation signal sent to the flywheel

- fwOutput: the flywheel power output

- Sighyd: the slow varying component of the input regulation signal sent to the hydro power plant

- hydOutput: the hydro model output

- hyd: the hydro power plant

- fw: the flywheel energy storage

- fwonly: the regulation service provided by a stand-alone flywheel energy storage

- hydonly: the regulation services provided by a stand-alone hydro power plant

- hyd+fw: the flywheel energy storage operated in conjunction with a hydro power plant and controlled by a WAEMS controller

\subsection{Performance Criteria}

The following evaluation criteria were used:

- $T_{\text {fade }}$ is the fade time. Fade time refers to a time period during which a flywheel can no longer fully respond to the regulation signal. For example, when the flywheel is fully charged or discharged, it can no longer respond to the regulation signal. If $T$ is the length of the test signal, the percent of time, $K_{\text {meet }}$, during which the flywheel meets the regulation requirement, is then defined as

$$
K_{\text {meet }}=\frac{T_{\text {fade }}}{T}
$$

- $E_{\text {hyd }}$ is the net absolute regulating energy provided by the hydro power plant. $E_{f w}$ is the net absolute regulation energy provided by the flywheel. 


$$
\begin{aligned}
& E_{f w}=\sum_{i=1}^{N} P_{f w}(i) \times \Delta t \\
& E_{\text {hyd }}=\sum_{i=1}^{N} P_{h y d}(i) \times \Delta t
\end{aligned}
$$

where $P_{f w}$ and $P_{\text {hyd }}$ are the regulation signals sent to the flywheel and hydro unit, respectively; $N$ is the number of time intervals; and $i$ is the $i^{\text {th }}$ time interval. For the test signals, $\Delta t$ is 4 seconds; $N$ is $151,200(15 \times 60 \times 24 \times 7$ data points $)$.

- Define mileage $M$ as the sum of the ramp, $\Delta P$, per data point. Let

$$
\Delta P=P(i)-P(i-1)
$$

then we have:

$$
\begin{aligned}
& M_{\text {up }}=\sum \Delta P=\sum_{i=2}^{N}[P(i)-P(i-1)] \quad \text { if } \quad \Delta P_{i}^{1}=P(i)-P(i-1) \geq 0 \\
& M_{\text {down }}=\sum \Delta P=\sum_{i=2}^{N}[P(i-1)-P(i)] \quad \text { if } \quad \Delta P_{i}^{1}=P(i)-P(i-1) \leq 0
\end{aligned}
$$

where $N$ is the number of data points.

- Define the flywheel utilization rate $K_{u}$ as:

$$
K_{u}=\frac{P_{a v e}}{P_{\text {rated }}}
$$

or

$$
K_{u}=\frac{E_{T}}{E_{T}^{\max }}=\frac{E_{T}}{P_{\text {rated }} T}
$$

where $P_{a v e}$ is the mean absolute output of the flywheel (MW) in response to the regulation signal, $P_{\text {rated }}$ is the rated power $(\mathrm{MW}), E_{T}^{\max }=P_{\text {rated }} \times 24 \times 7$ is the maximum weekly energy that can be provided by the flywheel (MWh), and $E_{T}=P_{a v e} \times 24 \times 7$ is the mean absolute value of the actual weekly energy provided by the flywheel (MWh). Thus, the flywheel has a 100\% utilization rate if charging or discharging always at its rated power. 


\subsection{Field Test 1: CAISO and BPA ACE Signal Sharing}

In Test 1, the ACE signal was the aggregated ACE signal of the CAISO and BPA balancing authorities, as described in Section 2.2.3. The modeling results of the hydro-only ${ }^{10}$ and flywheelonly ${ }^{11}$ cases are provided to compare the field test results with a hydro-flywheel co-optimizing system. The performance metrics are summarized in Table 5, and the results are plotted out in Figure 33 through Figure 37.

The modeling results indicated the following:

- The flywheel followed the regulation signal within 6 seconds. Because the signal was sent out at 4-second intervals, the flywheel output lagged the input signal by 4 to 5.5 seconds, as illustrated in Figure 33.

- The WAEMS controller successfully allocated the signal between the flywheel and the hydro power plant. The flywheel SOC was maintained within a desired range $99.5 \%$ of the time, which was greatly improved from the $69.78 \%$ of the flywheel-only case, as illustrated in Figure 34.

- The hydro plant mileage was reduced from 20,632 MW to 8,613 MW (a 58.3\% reduction) compared with the hydro-only option (see Table 5) indicating that the fast ramping component has been shifted to the flywheel. This ramp reduction is also clearly illustrated in Figure 37.

- The field tests and modeling results indicate that both the magnitude and ramp required from a hydro plant are reduced when the hydro plant provides regulation together with a flywheel. Table 5 shows a 25\% reduction (from 0.6337 GWh to 0.4748 GWh) in the total regulating energy and average power output (from 3.772 MW to $2.83 \mathrm{MW})$.

- The flywheel fade time was significantly reduced when operating together with the hydro plant. The fast regulation components were taken care of by the flywheel energy storage. When the flywheel deviated from its preferred SOC, the hydro plant offered support to bring the flywheel back. However, from the results, we noticed that the algorithm can be further optimized to reduce these small or continuous movements of the hydro plants. This will be addressed in future design considerations.

\footnotetext{
${ }^{10}$ In the "hydro-only" case, the hydro power plant provides the regulation signal alone.

${ }^{11}$ In the "flywheel-only" case, the flywheel energy storage provides the regulation signal alone.
} 
Table 5: The performance of the three cases.

\begin{tabular}{|c|c|c|c|}
\hline $\begin{array}{c}\text { Signal length: } 168 \text { hours } \\
\text { April 13-19, } 2010\end{array}$ & Hydro Only & Flywheel Only & $\begin{array}{l}\text { Hydro+Flywheel } \\
\text { (Field-test Results) }\end{array}$ \\
\hline$E_{A C E}$ Total signal energy (GWh) & 0.6794 & 0.6794 & 0.6794 \\
\hline$E_{\text {hyd }}$ Hydro signal energy (GWh) & 0.6337 & $\mathrm{n} / \mathrm{a}$ & 0.4748 \\
\hline$E_{f w}$ Flywheel signal energy (GWh) & $\mathrm{n} / \mathrm{a}$ & 0.3871 & 0.4776 \\
\hline Fade time $T_{\text {fade }}(\mathbf{h r})$ & $\mathrm{n} / \mathrm{a}$ & 50.77 & 0.83 \\
\hline$\%$ time meet requirement $K_{\text {meet }}$ & $\mathrm{n} / \mathrm{a}$ & $69.78 \%$ & $99.5 \%$ \\
\hline Flywheel utilization $\left(K_{u}\right)$ & $\mathrm{n} / \mathrm{a}$ & $11.5 \%$ & $14.2 \%$ \\
\hline$\left|P_{\text {ave }}^{\text {hyd }}\right|$ Average hydro signal (MW) & 3.772 & $\mathrm{n} / \mathrm{a}$ & 2.83 \\
\hline$\left|P_{a v e}^{f w}\right|$ Average flywheel signal (MW) & $\mathrm{n} / \mathrm{a}$ & 2.304 & 2.84 \\
\hline Hydro Mileage Up (MW) & 20632 & $\mathrm{n} / \mathrm{a}$ & 8613 \\
\hline Hydro Mileage Down (MW) & 20631 & $\mathrm{n} / \mathrm{a}$ & 8613 \\
\hline Flywheel Mileage Up (MW) & $\mathrm{n} / \mathrm{a}$ & 44493 & 64169 \\
\hline Flywheel Mileage Down (MW) & $\mathrm{n} / \mathrm{a}$ & 44485 & 64161 \\
\hline
\end{tabular}



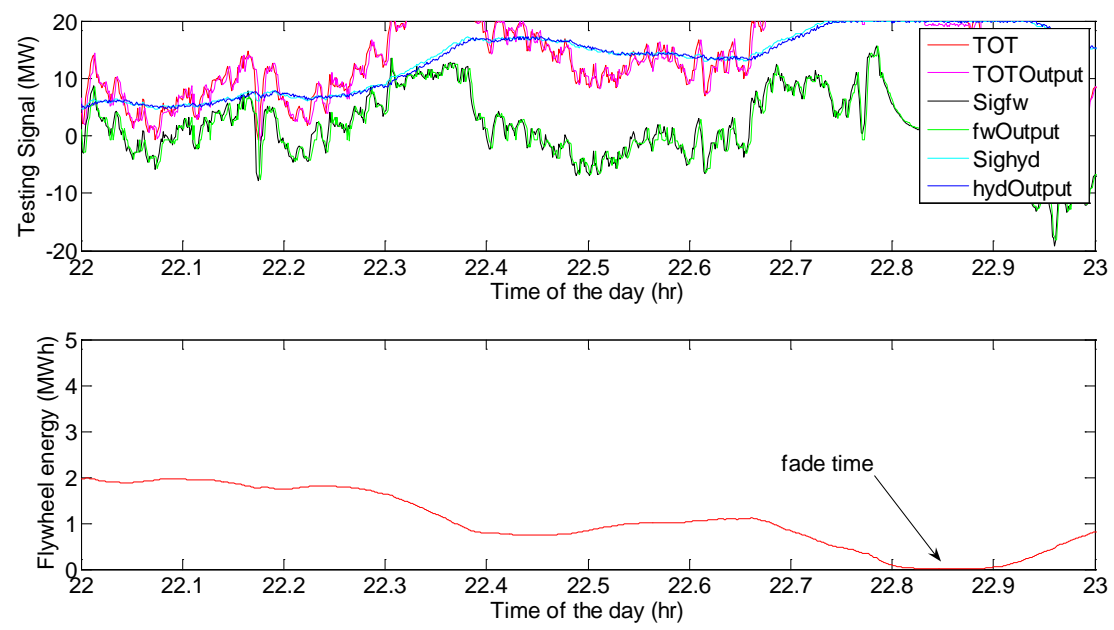

(a)
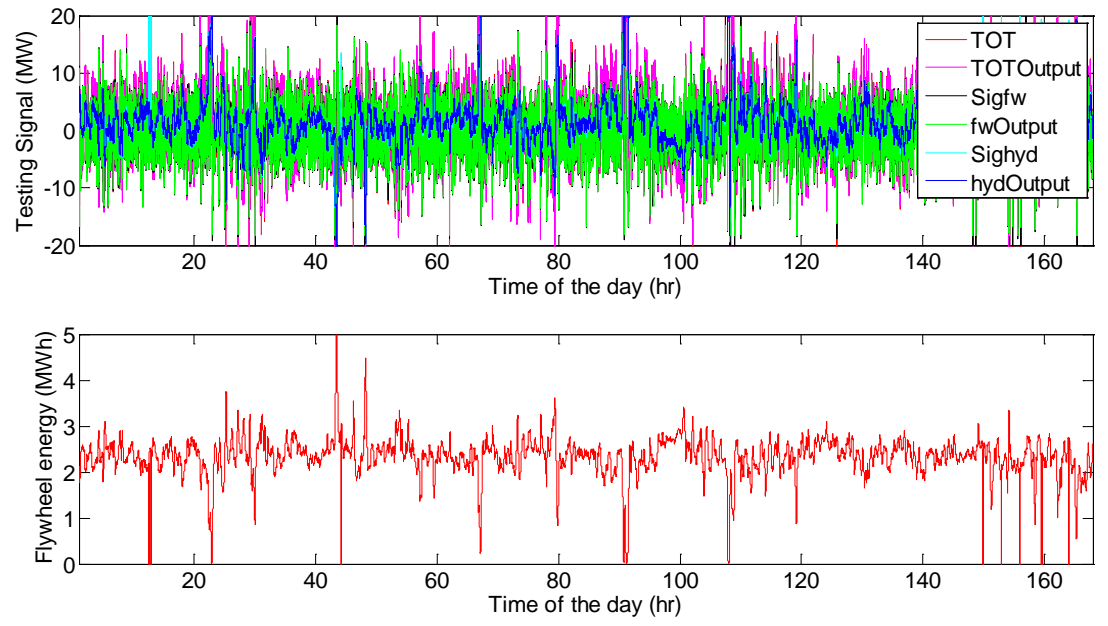

(b)

Figure 33: The test signals and the output signals. (a) A zoom-in view, (b) hours 0 to 168. 

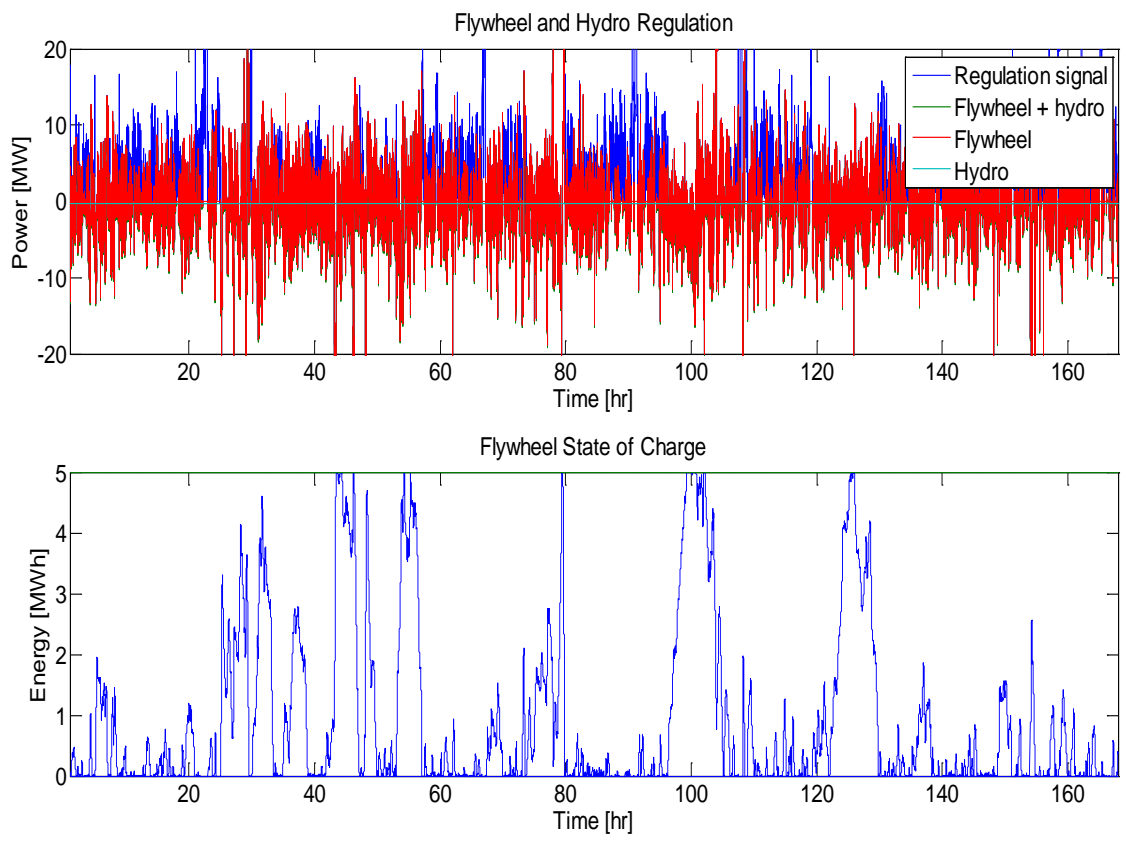

Figure 34: The test signals and the output signals (flywheel without energy management).
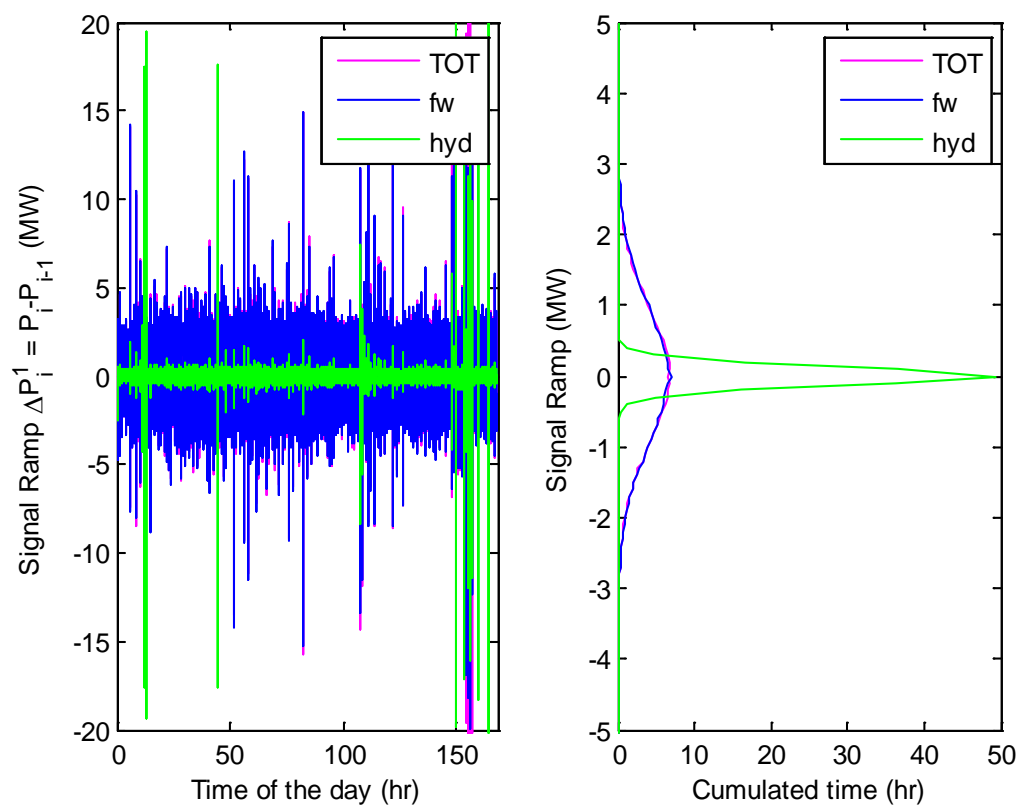

Figure 35: The ramps of the field test signals $\mathrm{N}-(\mathrm{N}-1)$. 


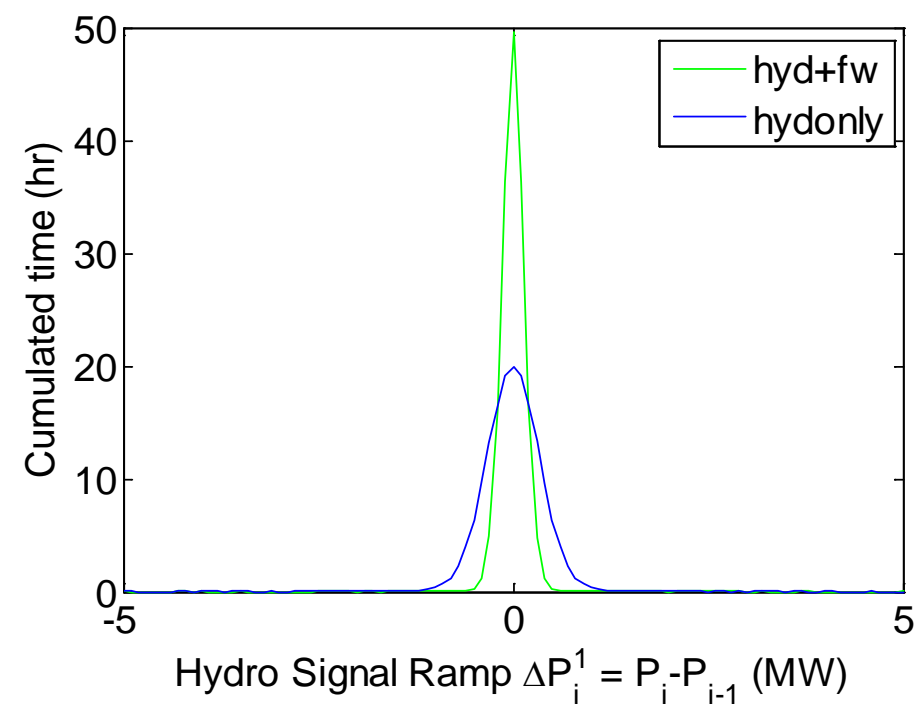

hyd +fw: The flywheel energy storage is operated in conjunction with a hydro power plant to provide the regulation service together.

hydonly: The hydro power plant provides the regulation signal alone.

Figure 36: The ramps of the regulation signals sent to the hydro power plant

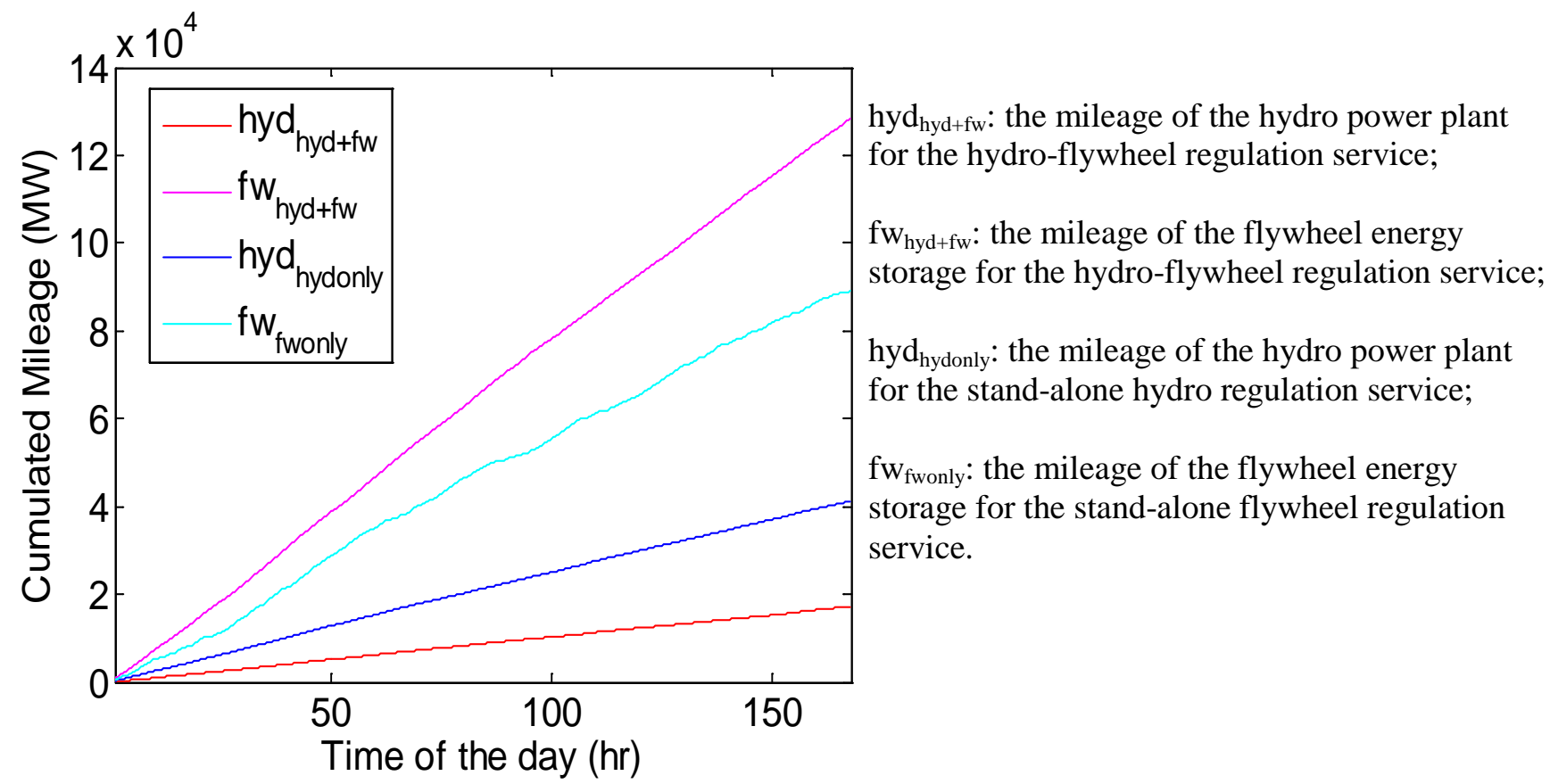

Figure 37: The cumulated mileages of different cases. 


\subsection{Field Test 2: The BPA Base-point Adjustment Signal}

In Test 2, the BPA base-point adjustment signal sent to a hydro power plant was used to evaluate the flywheel's performance. Again, the modeling results of the hydro-only and flywheel-only cases were provided for comparison. The performance metrics are summarized in Table 6, and the results are plotted out in Figure 38 and Figure 41.

The modeling results indicate the following:

- As shown in Table 6, the overall performance decreased compared with Test 1 . The flywheel SOC was maintained $95 \%$ of the time within the desired range (Figure 38) instead of the $99.5 \%$ obtained in Test 1 (Figure 33). In the flywheel-only case, the regulation requirement can be met only $40 \%$, as illustrated in Figure 39. This is because the base-point adjustment signal is a mixed signal of regulation and load following, which is sent to the hydro controller by BPA to perform the loadfollowing and regulation services. The field test results indicate that for slower (varying in minutes) load-following signals, the algorithm designed for regulation signals (varying in seconds) needs to be revised. This is valuable information for the direction of future research.

- The hydro signal mileage was reduced from 3,829 MW (hydro-only) to 1,949 MW (hydro-flywheel), a $50.9 \%$ reduction as shown in Table 6 . This ramp reduction is also shown in Figure 42.

- The field tests and modeling results indicate that, with the current control algorithm, the magnitude and ramp required of a hydro plant are reduced, but not significantly, when the hydro plant provides regulation and load following together with a flywheel. Table 5 shows an 11\% reduction (from $1.1993 \mathrm{GWh}$ to $1.0625 \mathrm{GWh}$ ) in the total regulating energy and a 13\% reduction in average power output (from $8.75 \mathrm{MW}$ to $7.61 \mathrm{MW})$.

- The flywheel has a dead-band when the signal is too small, as shown in Figure 38(a). Future algorithm designs should account for the flywheel dead-band when allocating signals. 
Table 6: The performance of the three cases.

\begin{tabular}{|c|c|c|c|}
\hline $\begin{array}{c}\text { Signal length: } 140 \text { hours } \\
\text { April 13-19, } 2010\end{array}$ & Hydro Only & Flywheel Only & $\begin{array}{l}\text { Hydro-flywheel } \\
\text { (Field-test Results) }\end{array}$ \\
\hline$E_{A C E}$ Total signal energy (GWh) & 1.1387 & 1.1387 & 1.1387 \\
\hline$E_{\text {hyd }}$ Hydro signal energy (GWh) & 1.1993 & $\mathrm{n} / \mathrm{a}$ & 1.0652 \\
\hline$E_{f w}$ Flywheel signal energy (GWh) & $\mathrm{n} / \mathrm{a}$ & 0.6691 & 0.3791 \\
\hline Fade time $T_{\text {fade }}(\mathrm{hr})$ (out of $168 \mathrm{hr}$ ) & $\mathrm{n} / \mathrm{a}$ & 84.38 & 7.43 \\
\hline$\%$ time meet requirement $K_{\text {meet }}$ & $\mathrm{n} / \mathrm{a}$ & $40 \%$ & $95 \%$ \\
\hline Flywheel utilization $\left(K_{u}\right)$ & $\mathrm{n} / \mathrm{a}$ & $24 \%$ & $13 \%$ \\
\hline$\left|P_{\text {ave }}^{\text {hyd }}\right|$ Average hydro signal (MW) & 8.75 & $\mathrm{n} / \mathrm{a}$ & 7.61 \\
\hline$\left|P_{a v e}^{f w}\right|$ Average fw signal (MW) & $\mathrm{n} / \mathrm{a}$ & 4.779 & 2.7 \\
\hline Hydro Mileage Up (MW) & 3829 & $\mathrm{n} / \mathrm{a}$ & 1949 \\
\hline Hydro Mileage Down (MW) & 3382 & $\mathrm{n} / \mathrm{a}$ & 1943 \\
\hline Flywheel Mileage Up (MW) & $\mathrm{n} / \mathrm{a}$ & 6480 & 15358 \\
\hline Flywheel Mileage Down (MW) & $\mathrm{n} / \mathrm{a}$ & 6465 & 15342 \\
\hline
\end{tabular}



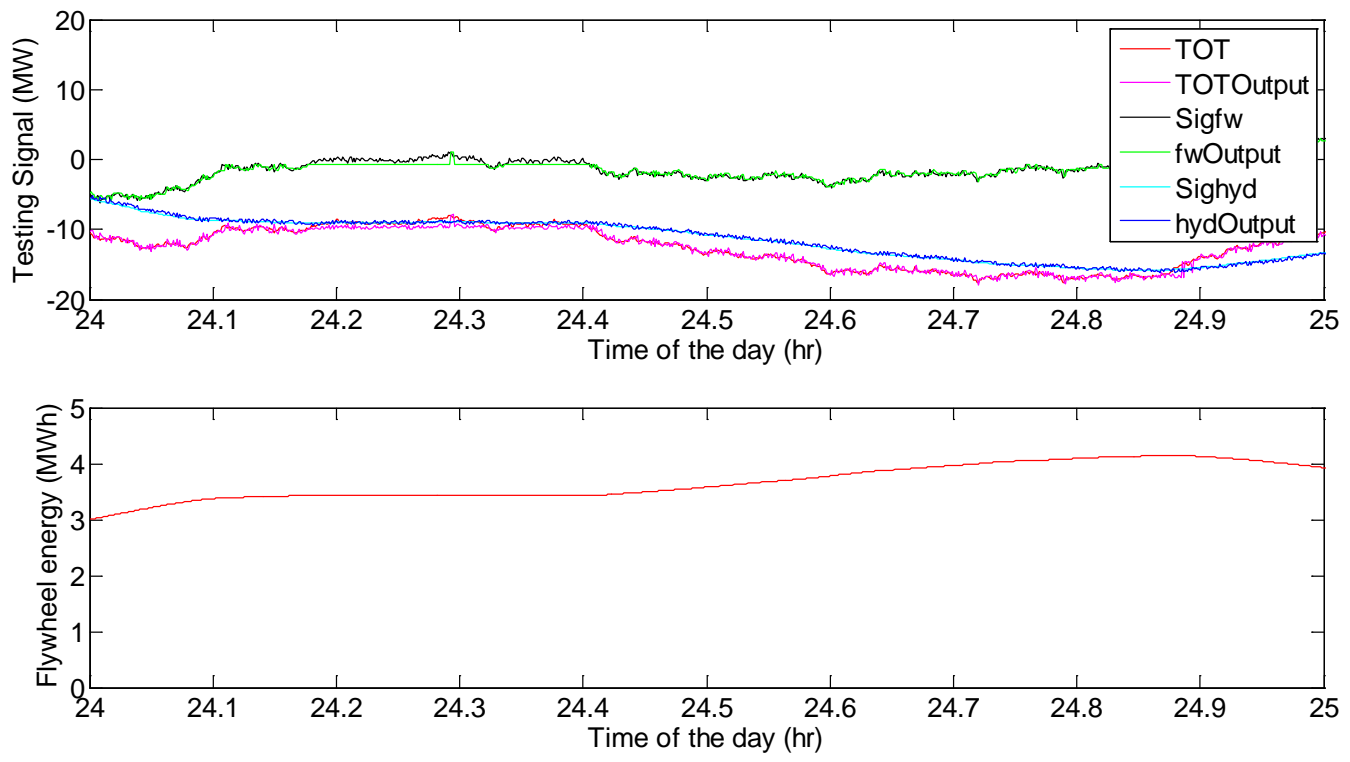

(a)
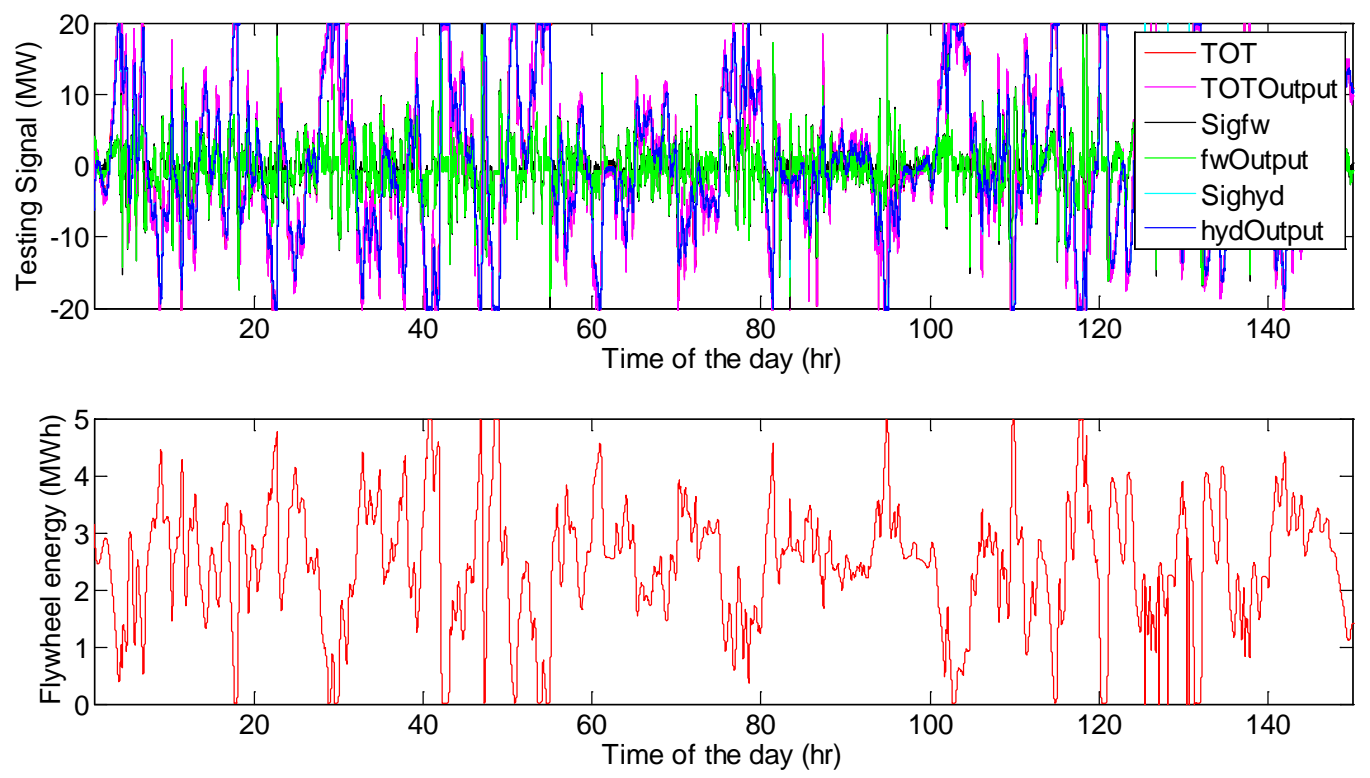

(b)

Figure 38: The test signals and the output signals. (a) A zoom-in view, (b) hours 0 to 168. 


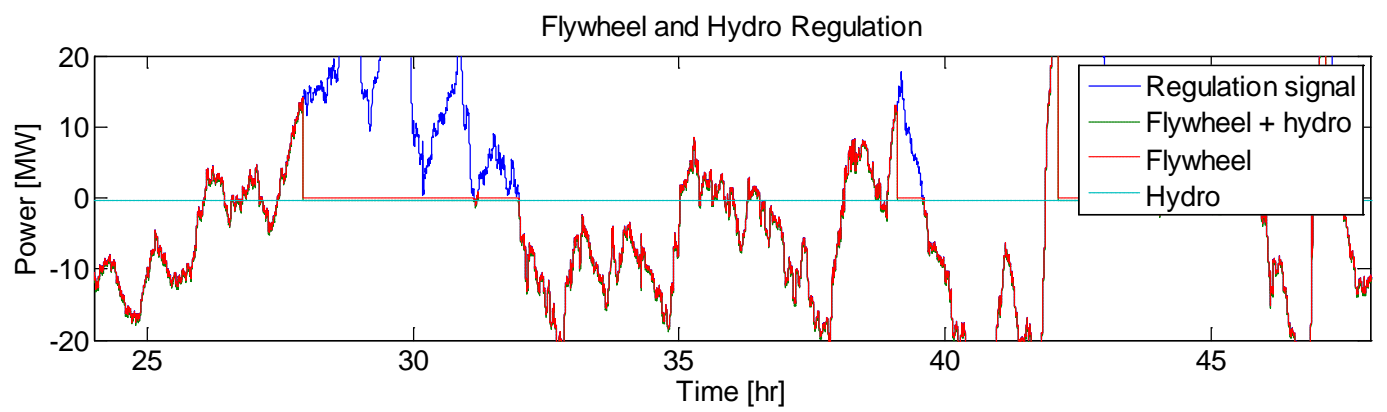

Flywheel State of Charge

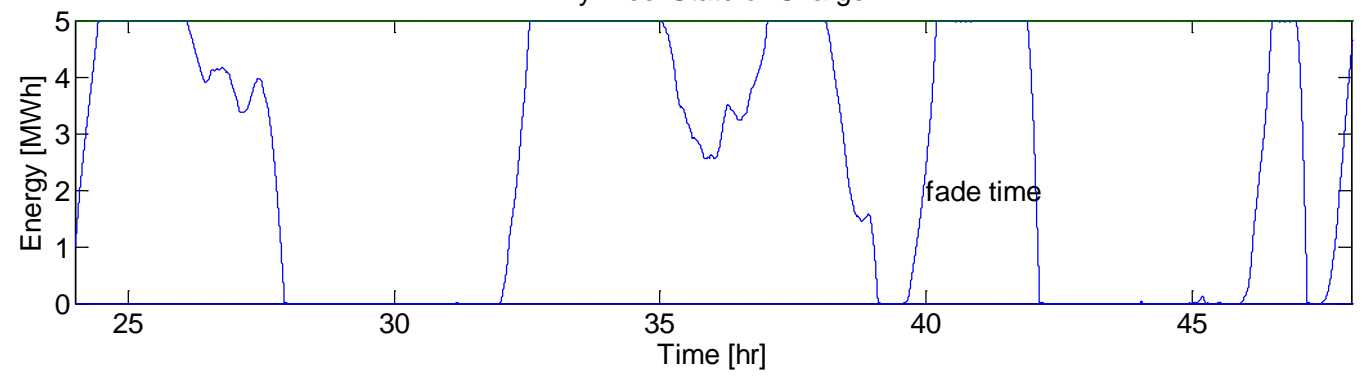

(a)

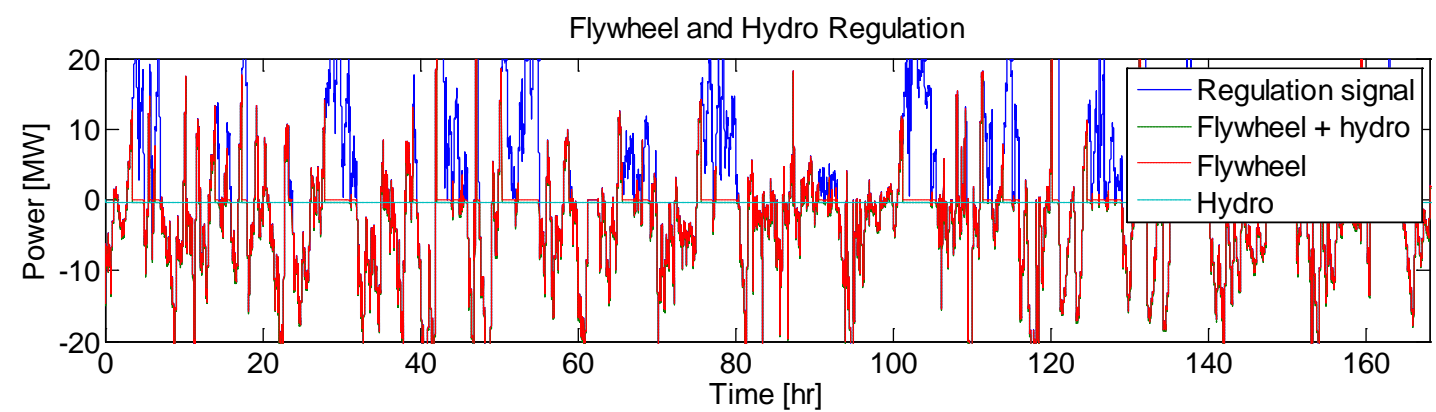

Flywheel State of Charge

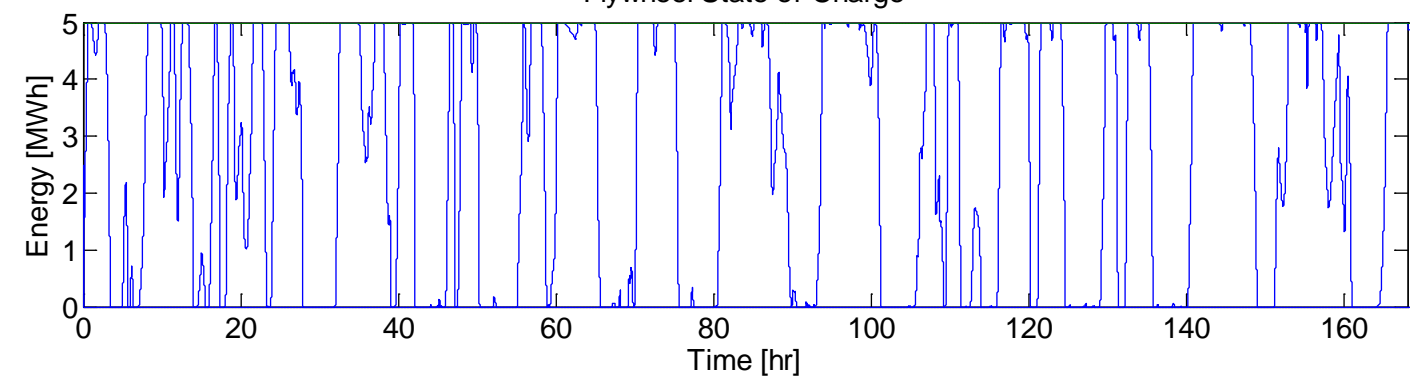

(b)

Figure 39: The test signals and the output signals (flywheel without energy management). 

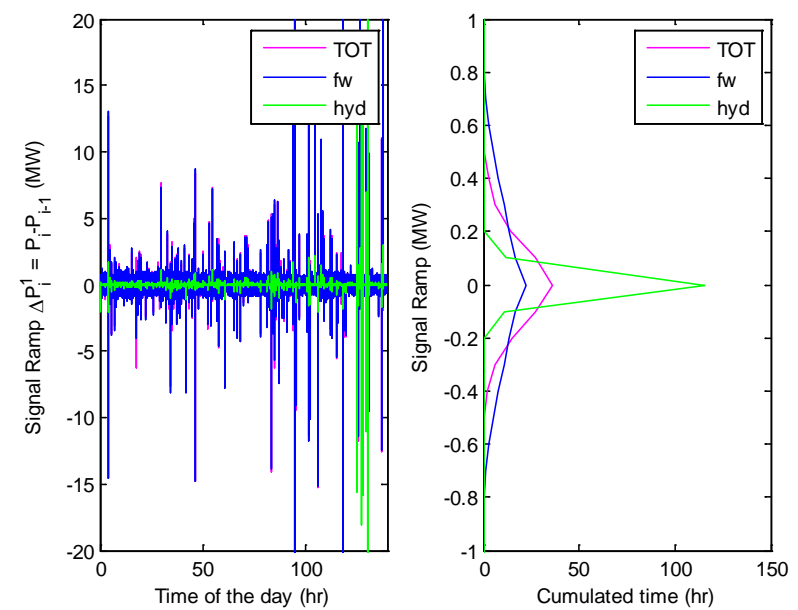

Figure 40: The ramps of the field test signals N-(N-1) (hours 1 to 140).

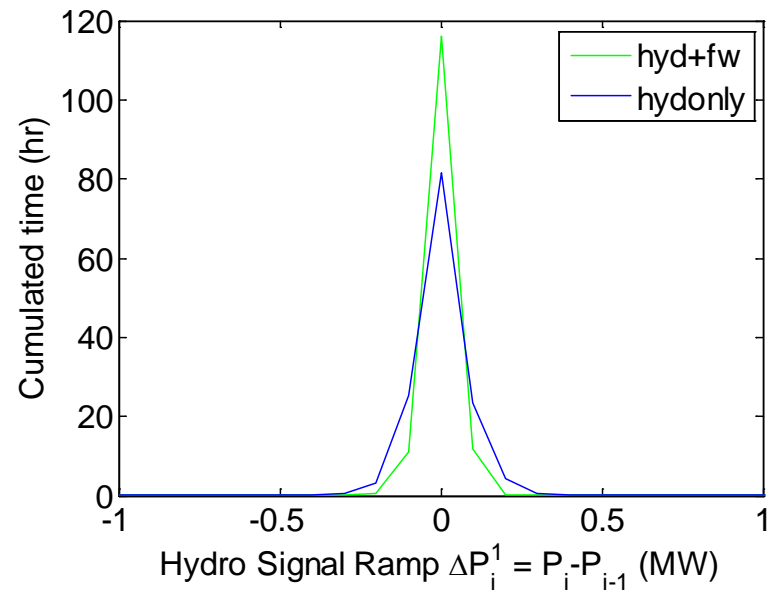

hyd+fw: The flywheel energy storage is operated in conjunction with a hydro power plant to provide the regulation service together.

hydonly: The hydro power plant provides the regulation signal alone.

Figure 41: The ramps of the regulation signals sent to the hydro power plant

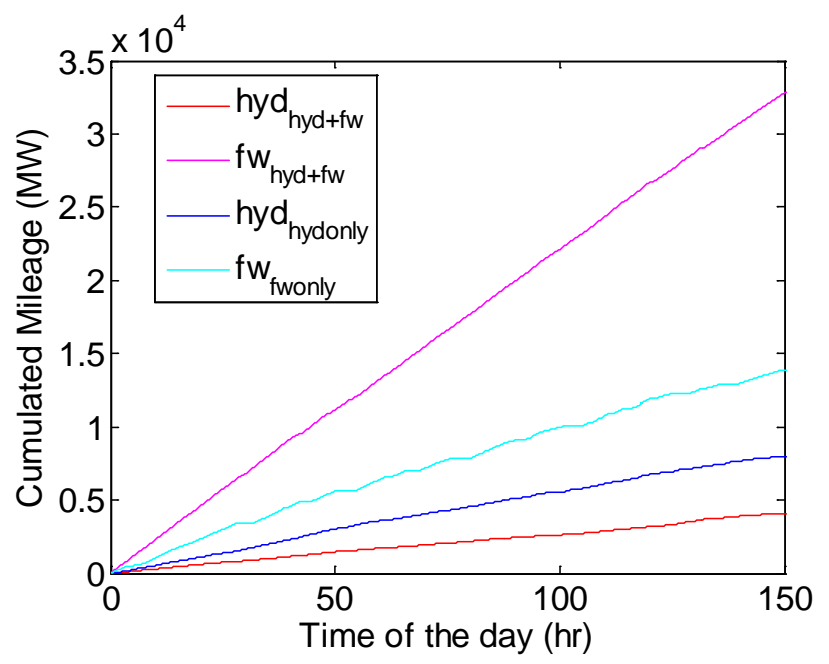

hydd $\mathrm{hyd}_{\mathrm{fw}}$ : the mileage of the hydro power plant for the hydro-flywheel regulation service;

$f w_{h y d+f w}$ : the mileage of the flywheel energy storage for the hydro-flywheel regulation service;

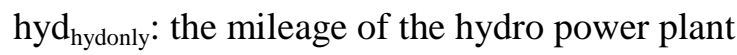
for the stand-alone hydro regulation service;

$\mathrm{fw}_{\mathrm{fwonly}}$ : the mileage of the flywheel energy storage for the stand-alone flywheel regulation service.

Figure 42: The cumulated mileages of different cases. 


\subsection{Field Test 3: Flywheel Responses to the CAISO Regulation Signal Sent to a Hydro Unit}

In Test 3, a scaled regulation signal of a CAISO hydro power plant was used to test the flywheel's performance. Again, the hydro-only and the flywheel-only cases were simulated for comparison. The performance metrics are summarized in Table 7, and results are plotted in Figure 43 and Figure 47.

The modeling results indicated the following:

- The WAEMS controller performance was similar to Test 1 as shown in Table 7. The flywheel SOC was maintained $99 \%$ of the time within the desired range (Figure 43), a little bit lower than the $99.5 \%$ obtained in Test 1 (Figure 33), which is greatly improved compared with the flywheel-only case $(60.8 \%)$, as illustrated in Figure 44.

- The mileage of the hydro power plant was reduced from 11,902 to 4,828 (a $59.4 \%$ reduction) in the hydro-flywheel case, showing that the fast-ramping component has been shifted to the flywheel. This ramp reduction is also shown in Figure 47.

Table 7: The performance of the three cases.

\begin{tabular}{|l|c|c|c|}
\hline \multicolumn{1}{|c|}{$\begin{array}{c}\text { Signal length: 153 hours } \\
\text { April 13-19, 2010 }\end{array}$} & Hydro Only & Flywheel Only & $\begin{array}{c}\text { Hydro-flywheel } \\
\text { (Field-test Results) }\end{array}$ \\
\hline$E_{\text {ACE }}$ Total signal energy (GWh) & 0.8758 & 0.8758 & 0.8758 \\
\hline$E_{\text {hyd }}$ Hydro signal energy (GWh) & 0.8832 & $\mathrm{n} / \mathrm{a}$ & 0.7266 \\
\hline$E_{\text {fw }}$ Flywheel signal energy (GWh) & n/a & 0.6577 & 0.5550 \\
\hline Fade time $T_{\text {fade }}($ hr) (out of 168 hr) & n/a & 60.25 & 1.54 \\
\hline \% time meet requirement $K_{\text {meet }}$ & n/a & $60.8 \%$ & $99 \%$ \\
\hline Flywheel utilization ( $\left.K_{u}\right)$ & n/a & $21 \%$ & $48 \%$ \\
\hline$\left|P_{\text {ave }}^{\text {hyd }}\right|$ Average hydro signal (MW) & 5.75 & n/a & 3.62 \\
\hline$\left|P_{\text {ave }}^{\text {fw }}\right|$ Average fw signal (MW) & n/a & 4.283 & 4828 \\
\hline Hydro Mileage Up (MW) & 11902 & n/a & 4832 \\
\hline Hydro Mileage Down (MW) & 11902 & n/a & 33704 \\
\hline Flywheel Mileage Up (MW) & n/a & 22053 & 33723 \\
\hline Flywheel Mileage Down (MW) & n/a & 22053 & \\
\hline
\end{tabular}



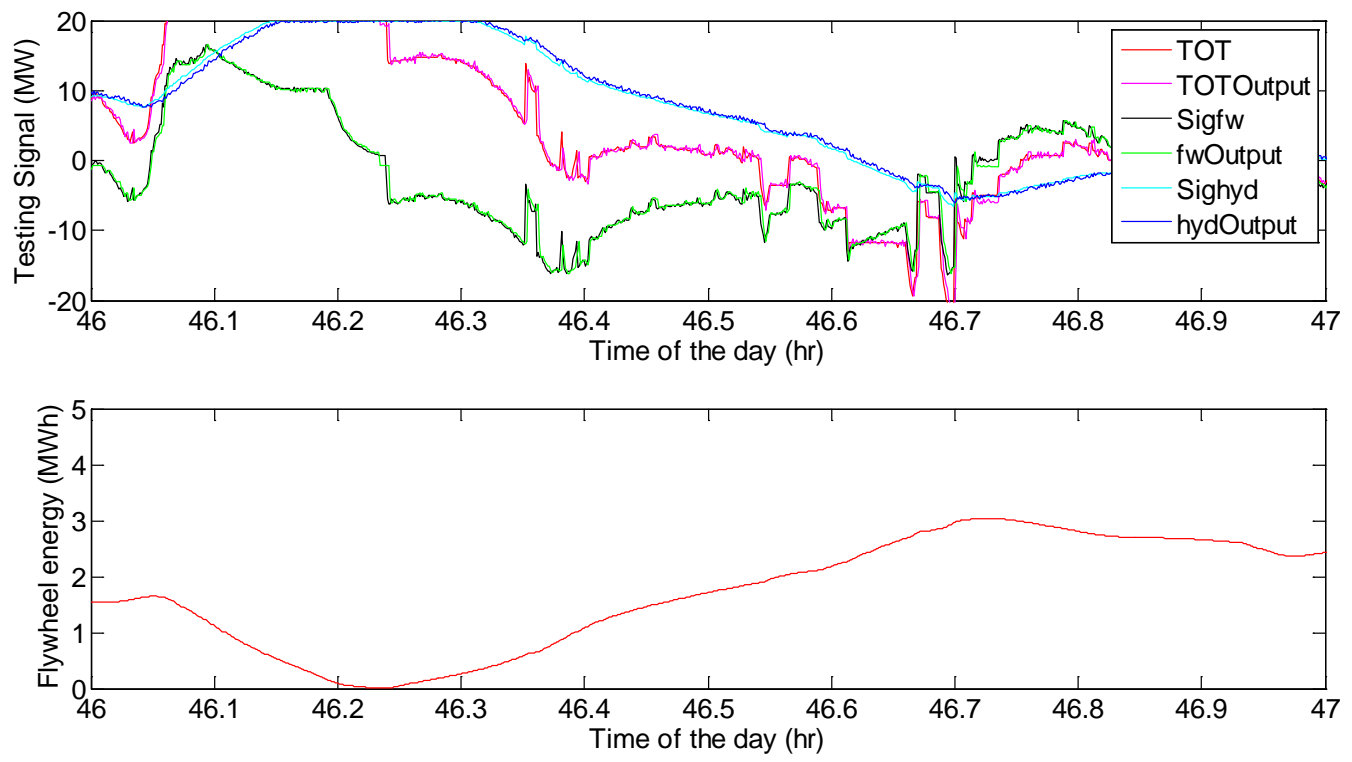

(a)
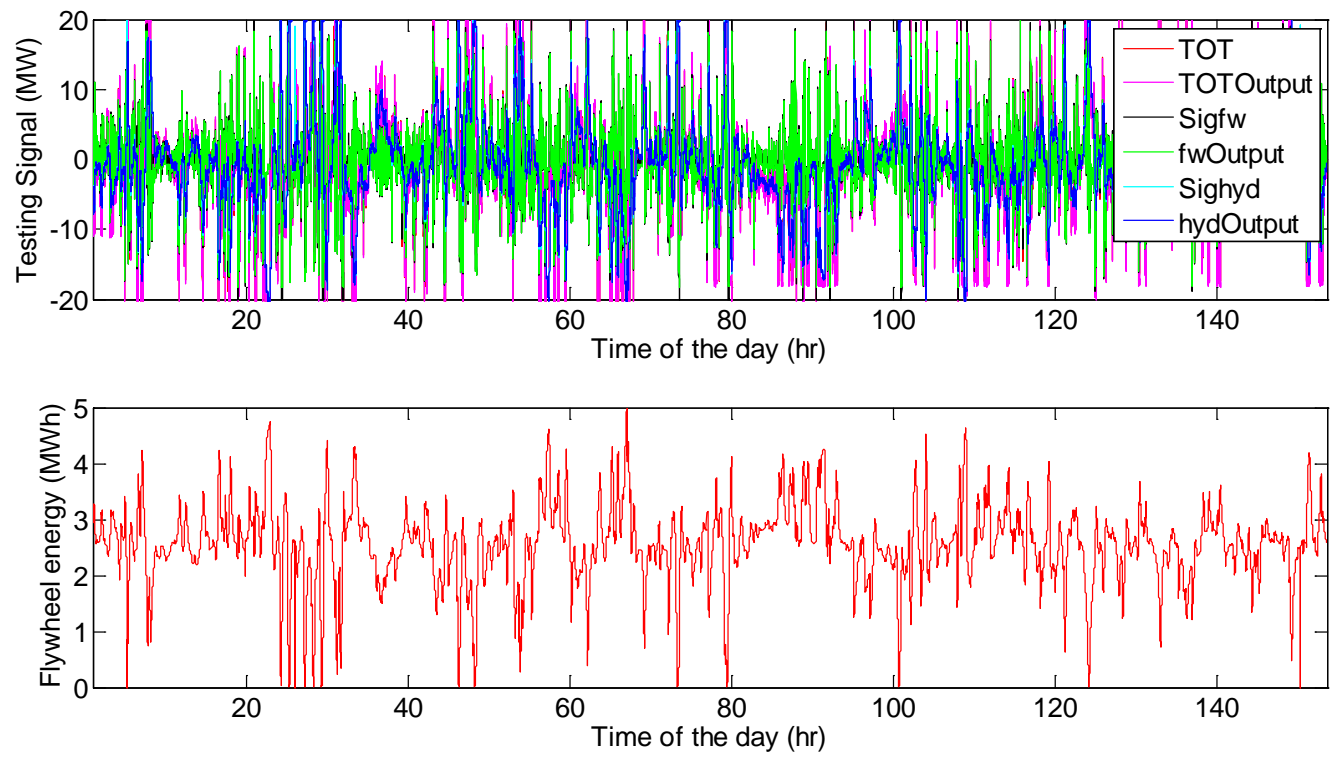

(b)

Figure 43: The test signals and the output signals. (a) A zoom-in view, (b) hours 0 to 153. 

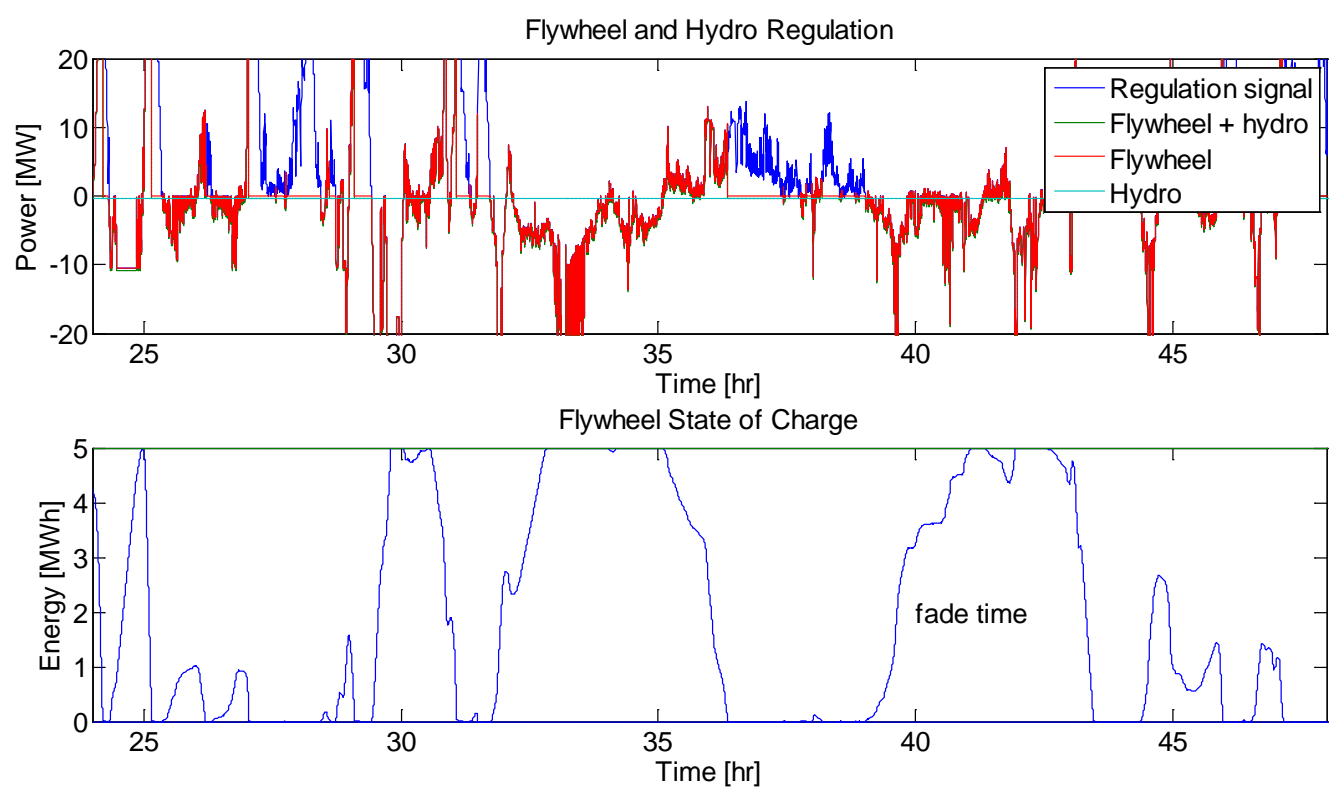

Figure 44: The test signals and the output signals (flywheel without energy management).
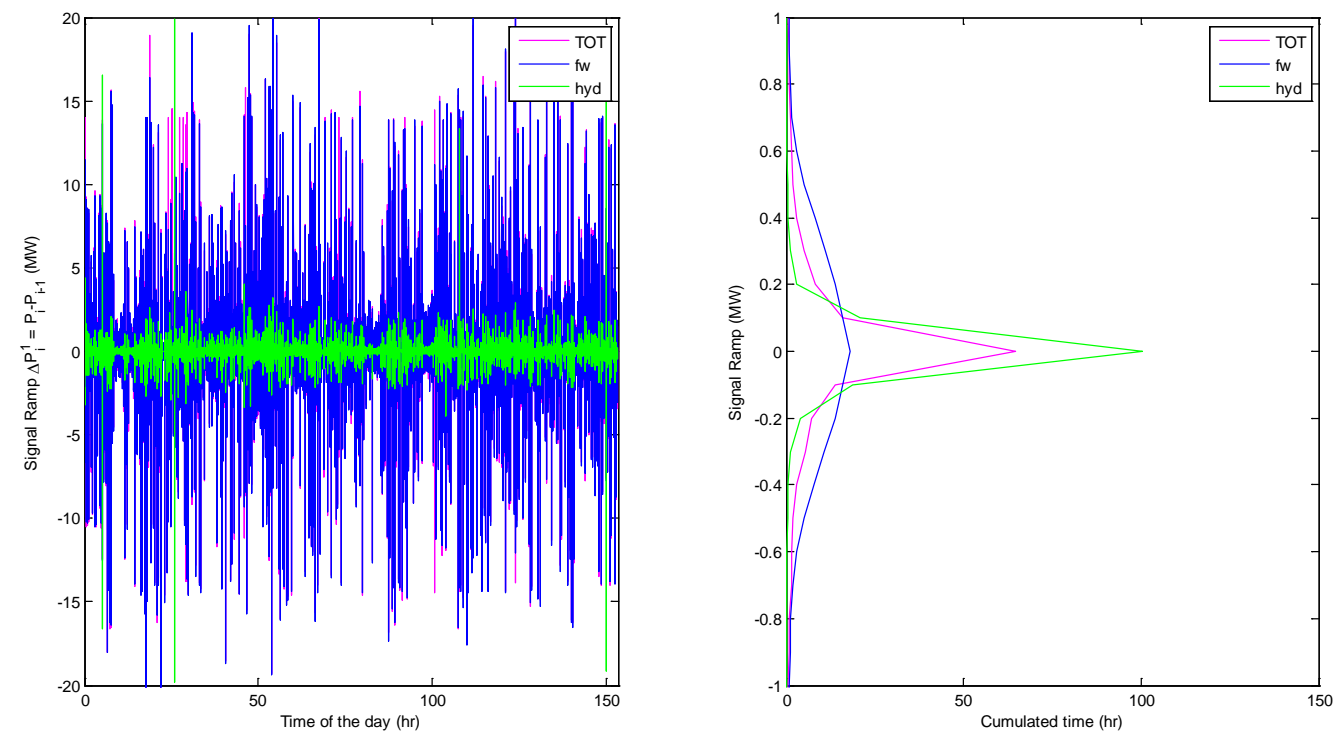

Figure 45: The ramps of the field test signals N-(N-1) (hours 1 to 153). 


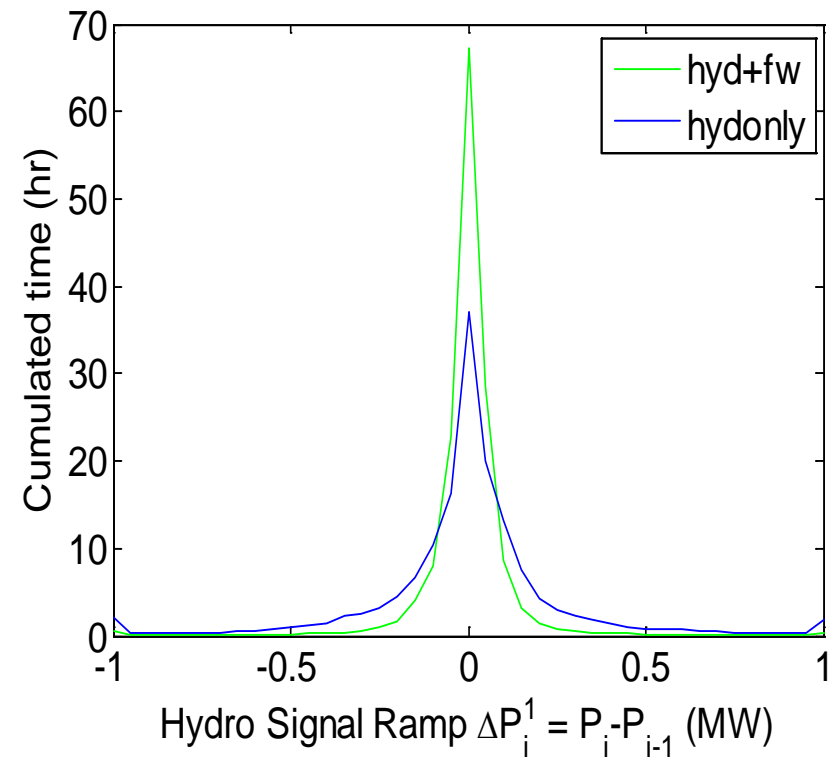

hyd +fw: The flywheel energy storage is operated in conjunction with a hydro power plant to provide the regulation service together.

hydonly: The hydro power plant provides the regulation signal alone.

Figure 46: The ramps of the regulation signals sent to the hydro power plant.

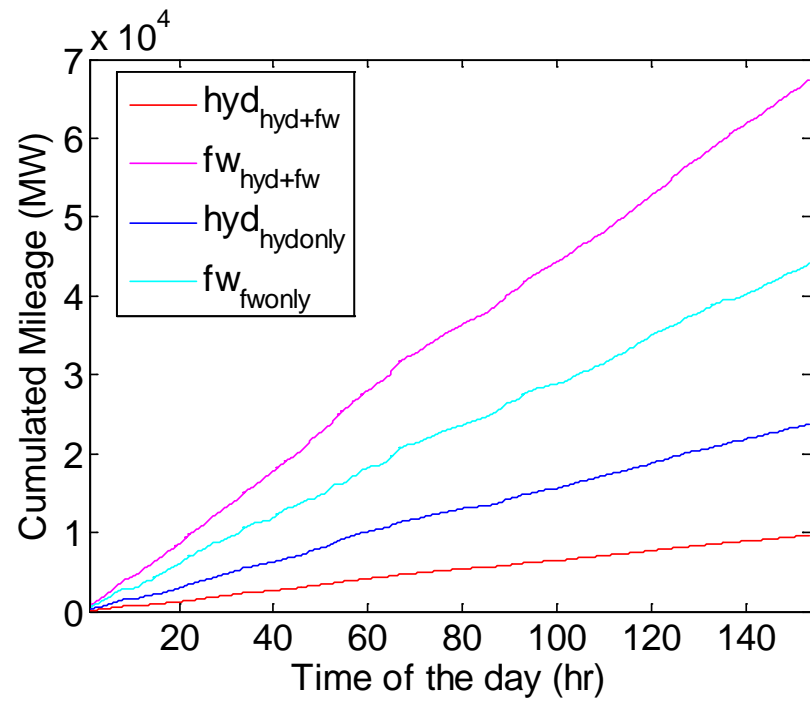

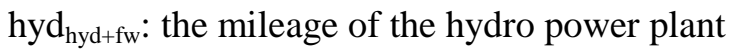
for the hydro-flywheel regulation service;

$f w_{h y d+f w}$ : the mileage of the flywheel energy storage for the hydro-flywheel regulation service;

hyd $_{\text {hydonly: }}$ the mileage of the hydro power plant for the stand-alone hydro regulation service;

$\mathrm{fw}_{\text {fwonly: }}$ the mileage of the flywheel energy storage for the stand-alone flywheel regulation service.

Figure 47: The cumulated mileages of different cases.

\subsection{Field Test 4: The Future Aggregated ACE Signal}

In Test 4, the future aggregated ACE signal (BPA+CAISO) was used to evaluate the flywheel's performance. Again, the hydro-only and flywheel-only cases were provided for comparison. The performance metrics are summarized in Table 8 , and results are plotted out in Figure 48 and Figure 52. 
The modeling results indicated the following:

- As shown in Table 8, the WAEMS controller was successfully tested as in Test 1 using the same set of control parameters as used in Test 1. The flywheel SOC was maintained $99.99 \%$ of the time within the desired range (Figure 48 ) instead of the 99.5\% obtained in Test 1 (Figure 33). In the flywheel-only case, the regulation requirement can be met $65 \%$ of the time, as illustrated in Figure 49 .

- As shown in Figure 48, the hydro signal varies more slowly and is smoother than the original signal. Compared with the hydro only option, the mileage of the hydro plant was reduced from 6,875 MW to 2,075 MW (a 70\% reduction) in the hydroflywheel case, showing that the fast ramping component has been shifted to the flywheel. This ramp reduction is also shown in Figure 50 through Figure 52.

Table 8: The performance of the three cases.

\begin{tabular}{|l|c|c|c|}
\hline \multicolumn{1}{|c|}{$\begin{array}{c}\text { Signal length: 103 hours } \\
\text { April 13-19, 2010 }\end{array}$} & Hydro Only & Flywheel Only & $\begin{array}{c}\text { Hydro-flywheel } \\
\text { (Field-test Results) }\end{array}$ \\
\hline$E_{\text {ACE }}$ Total signal energy (GWh) & 0.7135 & 0.7135 & 0.7135 \\
\hline$E_{\text {hyd }}$ Hydro signal energy (GWh) & 0.7104 & $\mathrm{n} / \mathrm{a}$ & 0.5428 \\
\hline$E_{\text {fw }}$ Flywheel signal energy (GWh) & $\mathrm{n} / \mathrm{a}$ & 0.5061 & 0.4259 \\
\hline Fade time $T_{\text {fade }}(\mathbf{h r})($ out of 168 hr) & $\mathrm{n} / \mathrm{a}$ & 36.28 & 0.01 \\
\hline \% time meet requirement $K_{\text {meet }}$ & $\mathrm{n} / \mathrm{a}$ & $65 \%$ & $100 \%$ \\
\hline Flywheel utilization ( $\left.K_{u}\right)$ & $\mathrm{n} / \mathrm{a}$ & $25 \%$ & 5.27 \\
\hline$\left|P_{\text {ave }}^{\text {hyd }}\right|$ Average hydro signal (MW) & 6.89 & $\mathrm{n} / \mathrm{a}$ & 4.17 \\
\hline$\left|P_{\text {ave }}^{f w}\right|$ Average fw signal (MW) & $\mathrm{n} / \mathrm{a}$ & 4.908 & 2075 \\
\hline Hydro Mileage Up (MW) & 6875 & $\mathrm{n} / \mathrm{a}$ & 2088 \\
\hline Hydro Mileage Down (MW) & 6888 & $\mathrm{n} / \mathrm{a}$ & 11939 \\
\hline Flywheel Mileage Up (MW) & n/a & 6505 & 11958 \\
\hline Flywheel Mileage Down (MW) & n/a & 6517 & \\
\hline
\end{tabular}



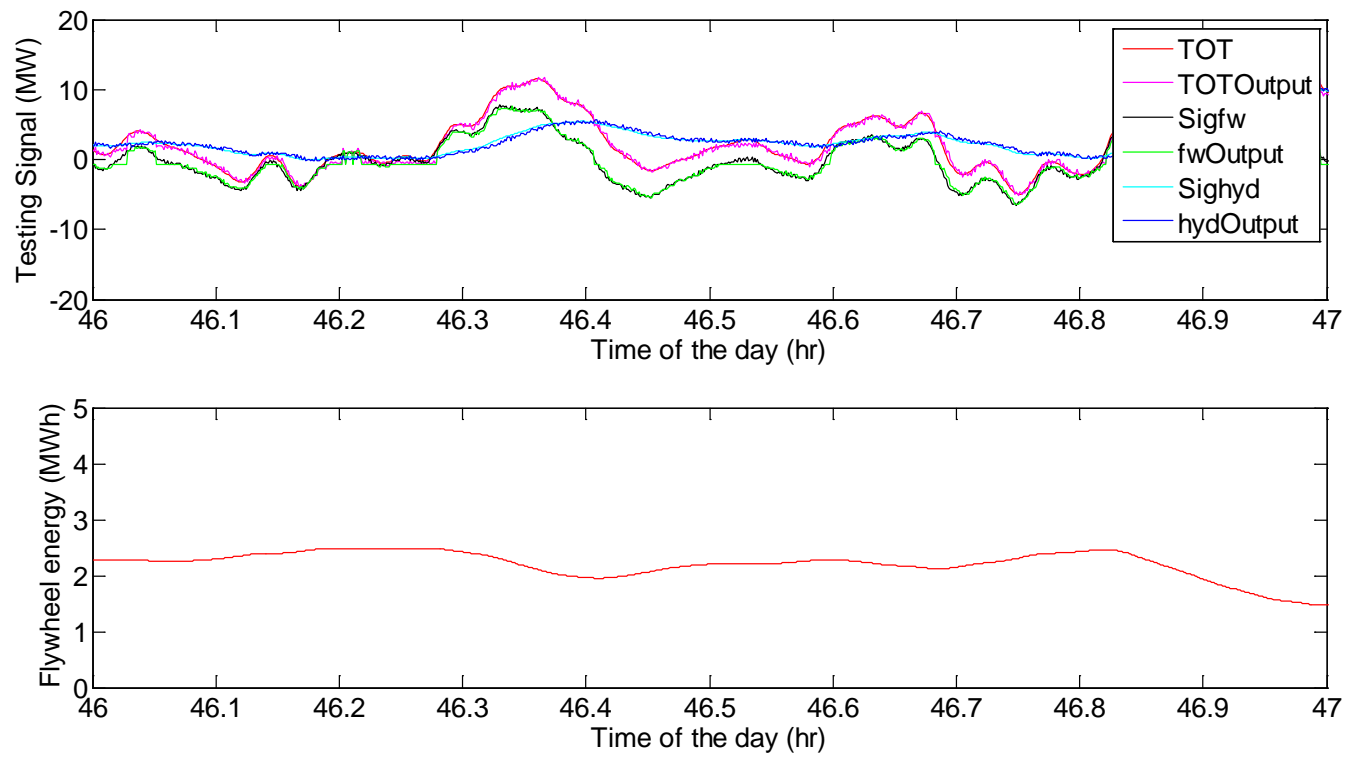

(a)
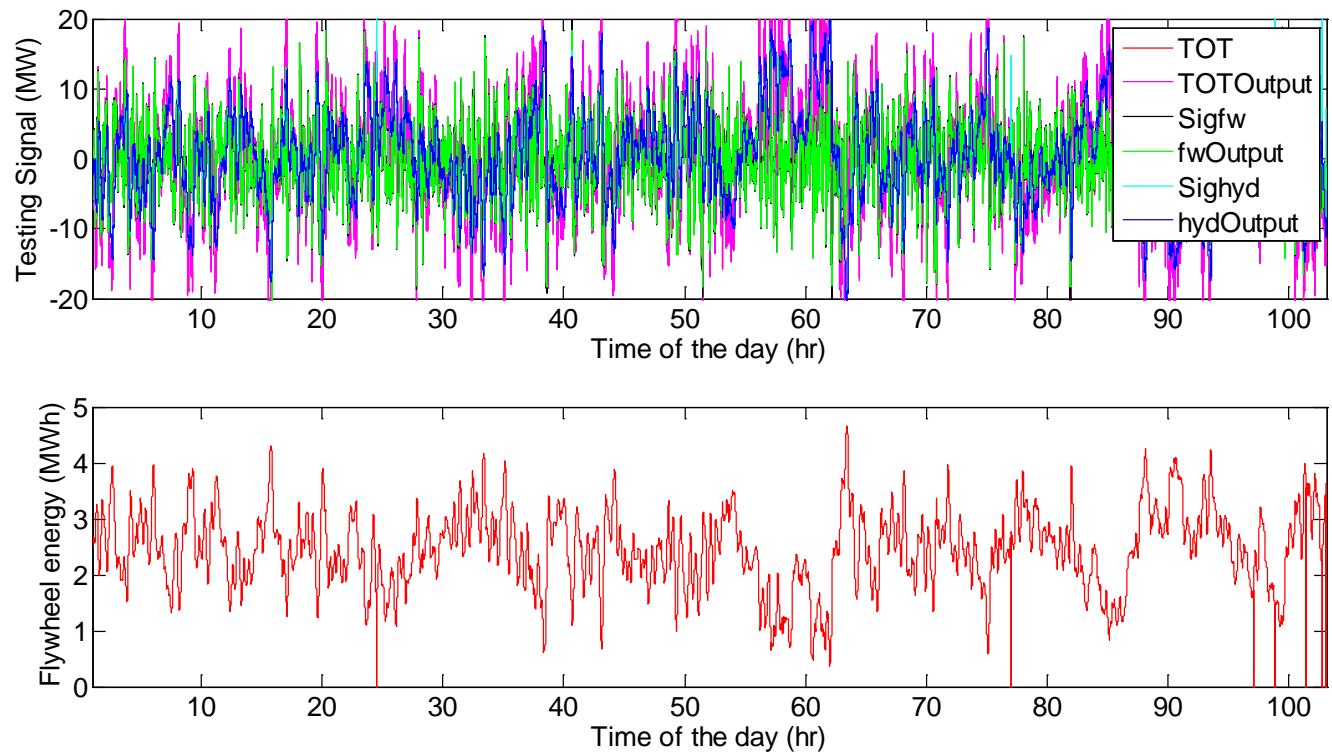

(b)

Figure 48: The test signals and the output signals. (a) A zoom-in view, (b) hours 0 to 103. 

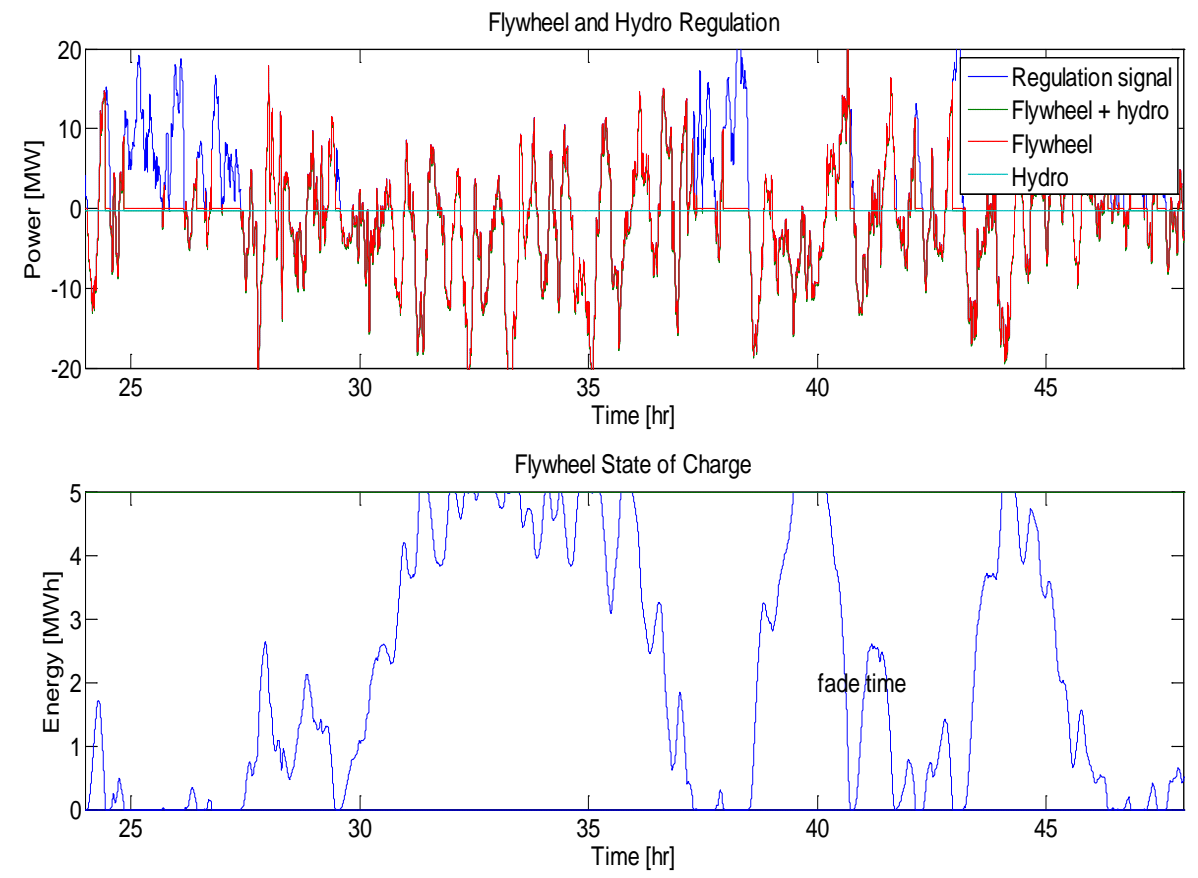

Figure 49: The test signals and the output signals (flywheel without energy management).
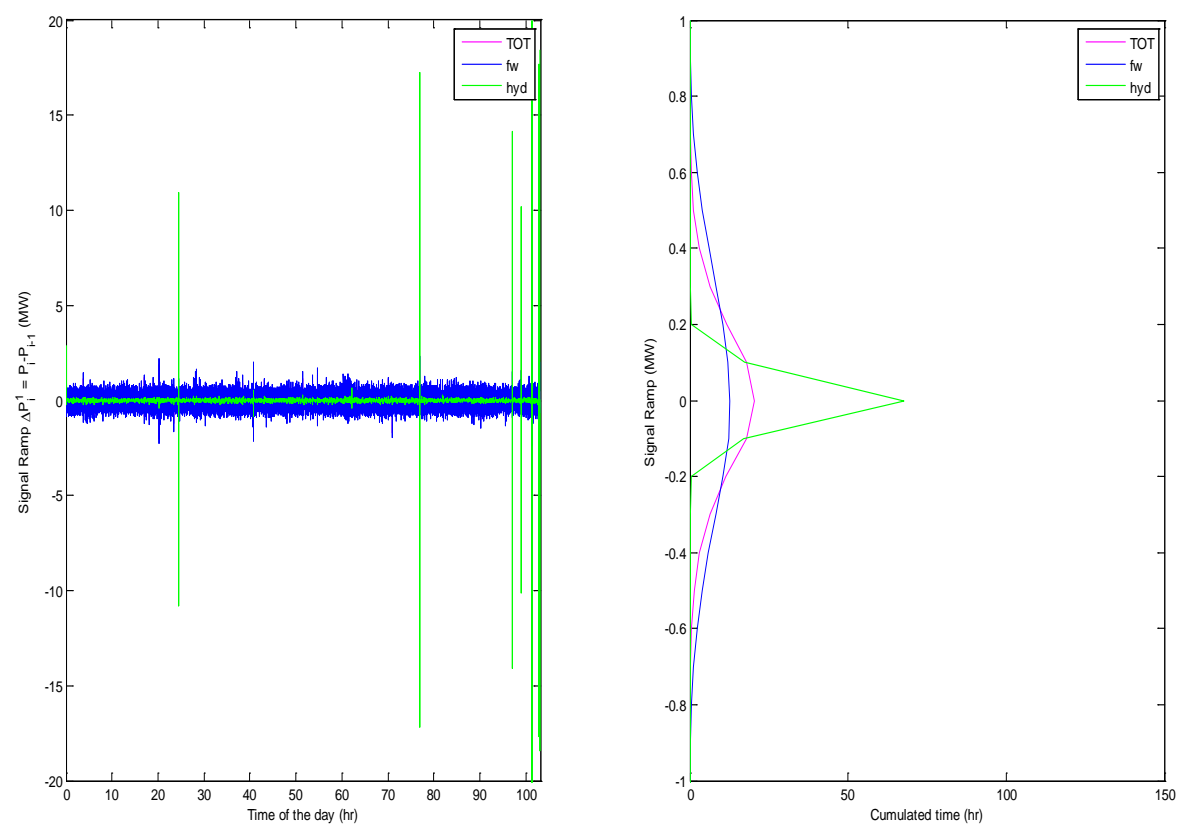

Figure 50: The ramps of the field test signals N-(N-1) (hours 1 to 103). 


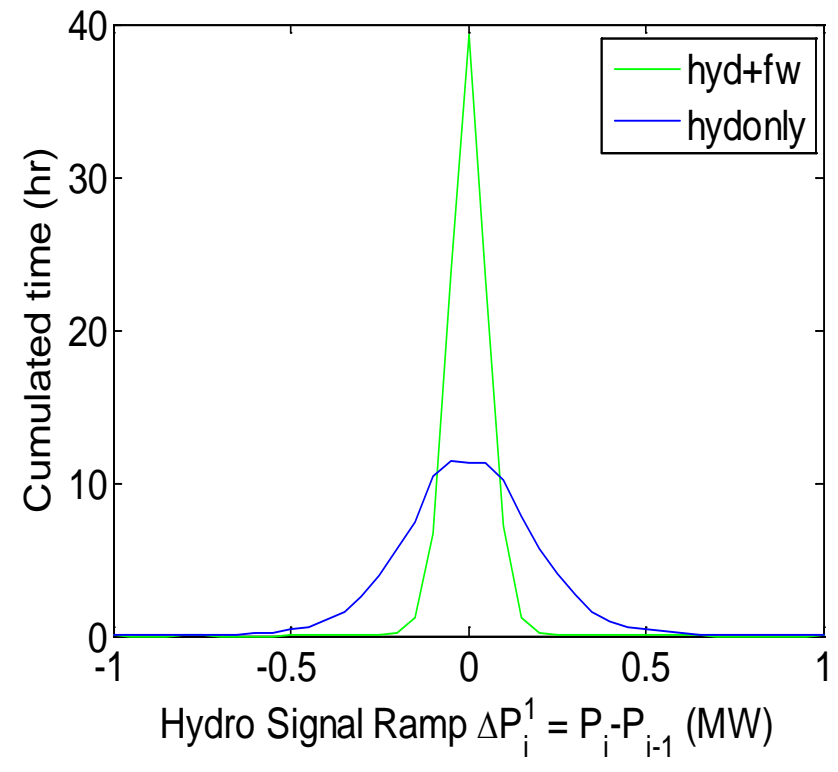

hyd + fw: The flywheel energy storage is operated in conjunction with a hydro power plant to provide the regulation service together.

hydonly: The hydro power plant provides the regulation signal alone.

Figure 51: The ramps of the regulation signals sent to the hydro power plant

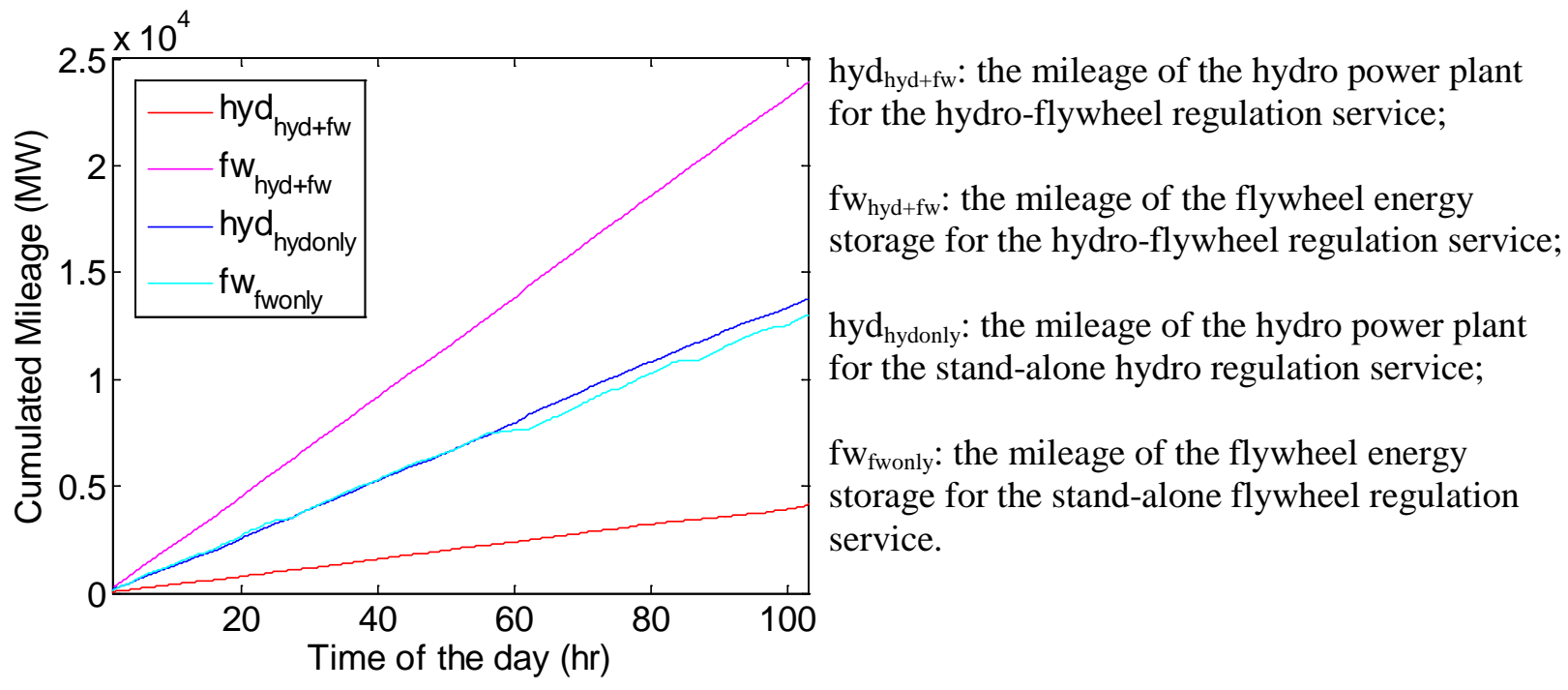

Figure 52: The cumulated mileages of different cases.

\subsection{Field Test 5: The Future BPA ACE Signal}

In Test 5, the future BPA ACE signal was used to evaluate the performance of flywheels. Again, the hydro-only and flywheel-only cases were provided for comparison. The performance metrics were summarized in Table 9, and results were plotted out in Figure 53 through Figure 57. 
The modeling results indicate the following:

- The flywheel SOC was maintained $98 \%$ of the time within the desired range (Figure 53 and Table 9) instead of 99.5\% obtained in Test 1 (Figure 33). Again, in the flywheel-only case, the regulation requirement can be met only $48 \%$ of the time, as illustrated in Figure 54.

- The mileage of the hydro power plant was reduced from 11,873 MW to 2,656 MW (a $77.6 \%$ reduction) as shown in Table 9, indicating that the fast-ramping component was shifted to the flywheel. This ramp reduction is also shown in Figure 57.

- Both the magnitude and ramp required of a hydro plant are reduced; Table 5 shows a $16 \%$ reduction (from $1.2731 \mathrm{GWh}$ to $1.0662 \mathrm{GWh}$ ) in the total regulating energy and a $16 \%$ reduction in average power output (from 7.58 MW to 6.35 MW).

Table 9: The performance of the three cases.

\begin{tabular}{|c|c|c|c|}
\hline $\begin{array}{c}\text { Signal length: } 168 \text { hours } \\
\text { April, } 2013\end{array}$ & Hydro Only & Flywheel Only & $\begin{array}{l}\text { Hydro-flywheel } \\
\text { (Field-test Results) }\end{array}$ \\
\hline$E_{A C E}$ Total signal energy (GWh) & 1.2677 & 1.2677 & 1.2677 \\
\hline$E_{\text {hyd }}$ Hydro signal energy (GWh) & 1.2731 & $\mathrm{n} / \mathrm{a}$ & 1.0662 \\
\hline$E_{f w}$ Flywheel signal energy (GWh) & $\mathrm{n} / \mathrm{a}$ & 0.8051 & 0.6422 \\
\hline Fade time $T_{\text {fade }}(\mathbf{h r})$ (out of $168 \mathbf{h r}$ ) & $\mathrm{n} / \mathrm{a}$ & 88.08 & 2.55 \\
\hline$\%$ time meet requirement $K_{\text {meet }}$ & $\mathrm{n} / \mathrm{a}$ & $48 \%$ & $98 \%$ \\
\hline Flywheel utilization $\left(K_{u}\right)$ & $\mathrm{n} / \mathrm{a}$ & $24 \%$ & $19 \%$ \\
\hline \begin{tabular}{|l|l|}
$P_{\text {ave }}^{\text {hyd }}$ & Average hydro signal (MW)
\end{tabular} & 7.58 & $\mathrm{n} / \mathrm{a}$ & 6.35 \\
\hline$\left|P_{a v e}^{f w}\right|$ Average fw signal (MW) & $\mathrm{n} / \mathrm{a}$ & 4.792 & 3.89 \\
\hline Hydro Mileage Up (MW) & 11873 & $\mathrm{n} / \mathrm{a}$ & 2656 \\
\hline Hydro Mileage Down (MW) & 11865 & $\mathrm{n} / \mathrm{a}$ & 2648 \\
\hline Flywheel Mileage Up (MW) & $\mathrm{n} / \mathrm{a}$ & 10478 & 21306 \\
\hline Flywheel Mileage Down (MW) & $\mathrm{n} / \mathrm{a}$ & 10478 & 21314 \\
\hline
\end{tabular}



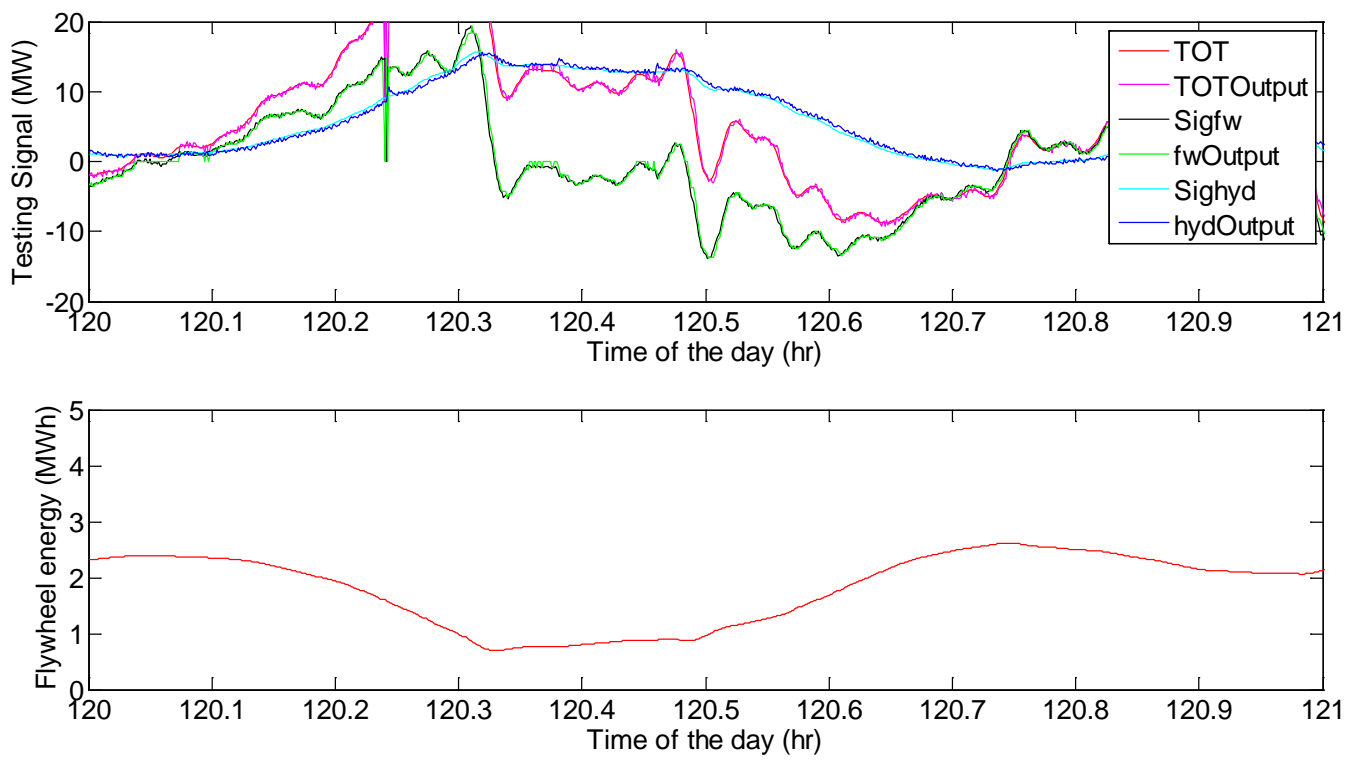

(a)
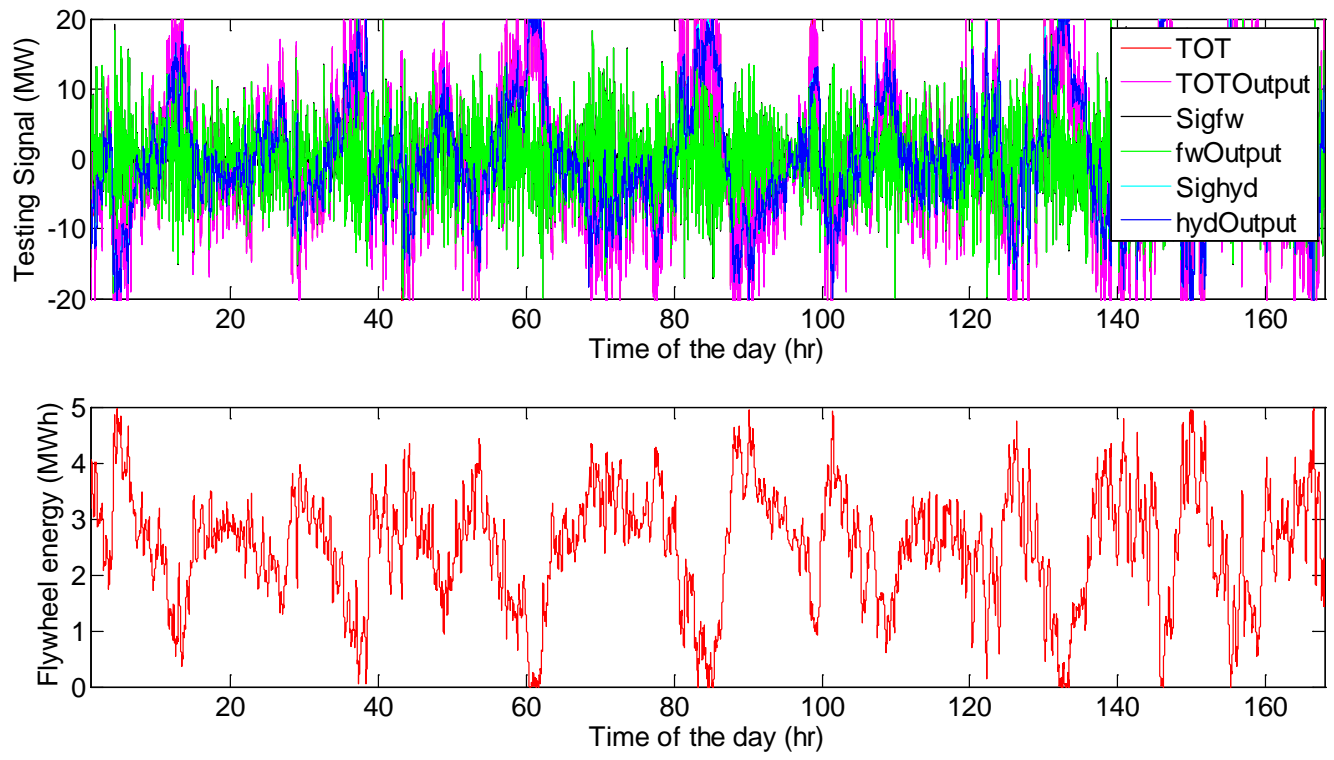

(b)

Figure 53: The test signals and the output signals. (a) A zoom-in view, (b) hours 0 to 103. 

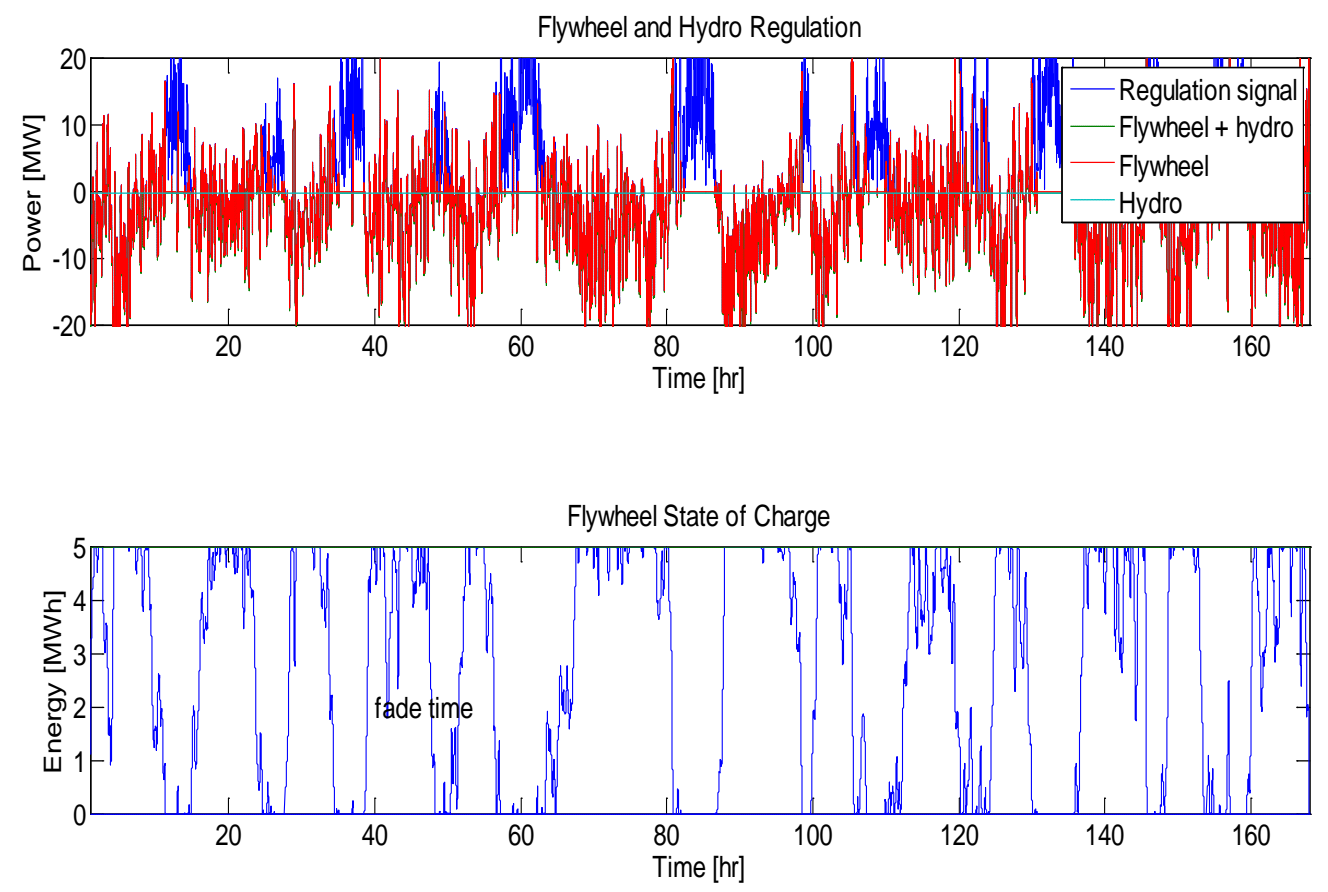

Figure 54: The test signals and the output signals (flywheel without energy management).
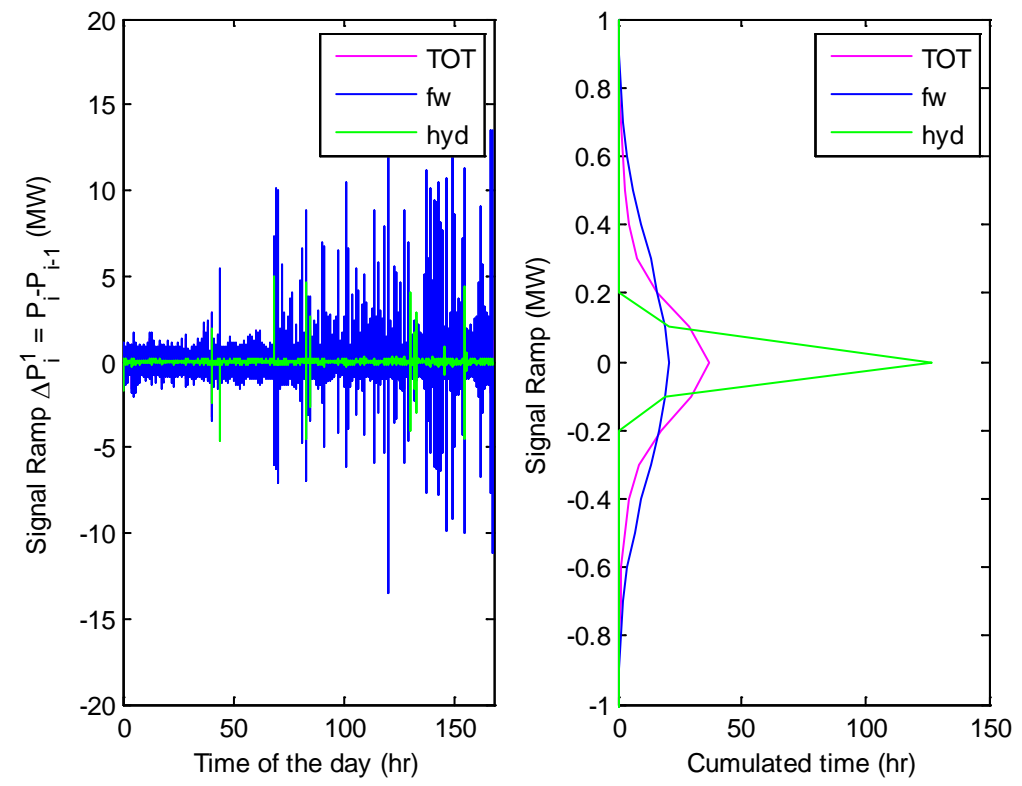

Figure 55: The ramps of the field test signals N-(N-1) (hours 1 to 168). 


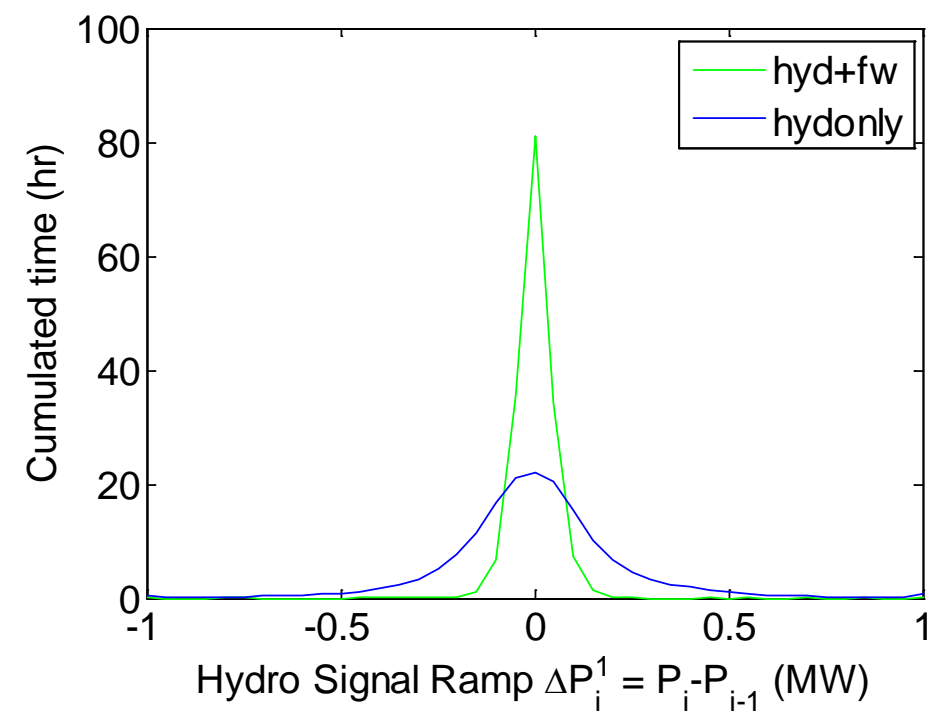

hyd +fw: The flywheel energy storage is operated in conjunction with a hydro power plant to provide the regulation service together.

hydonly: The hydro power plant provides the regulation signal alone.

Figure 56: The ramps of the regulation signals sent to the hydro power plant

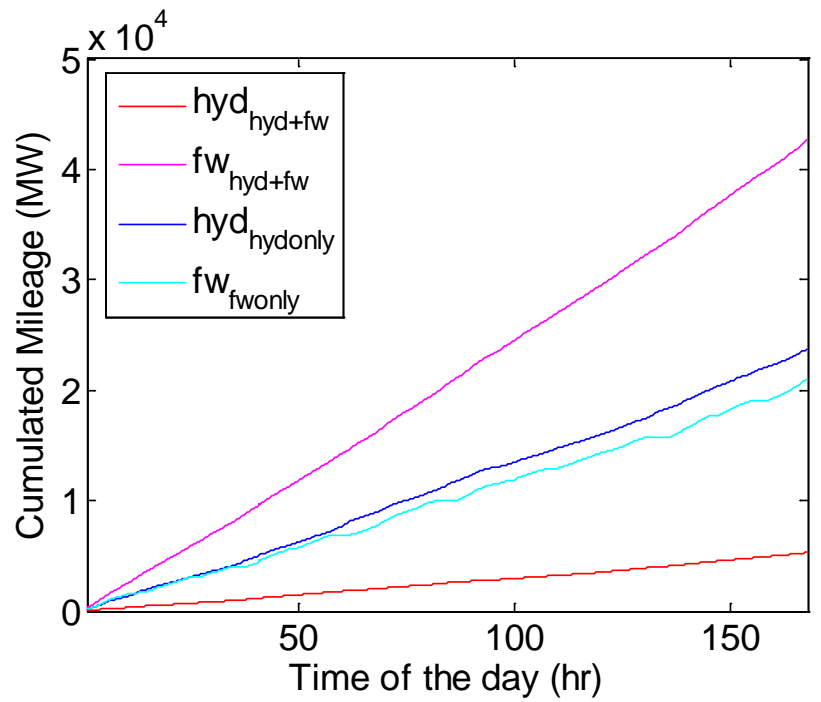

hyd $_{\text {hyd }+f w}$ : the mileage of the hydro power plant for the hydro-flywheel regulation service;

$\mathrm{fw}_{\mathrm{hyd}+\mathrm{fw}}$ : the mileage of the flywheel energy storage for the hydro-flywheel regulation service;

hyd $\mathrm{d}_{\text {hdonly }}$ : the mileage of the hydro power plant for the stand-alone hydro regulation service;

$\mathrm{fw}_{\text {fwonly: }}$ the mileage of the flywheel energy storage for the stand-alone flywheel regulation service.

Figure 57: The cumulated mileages of different cases. 


\subsection{Conclusions}

Table 10 summarizes the results of the five field tests in one table. From the test results we made the following observations and conclusions:

- The flywheel follows regulation signals closely with a 6-second response delay.

- The proposed WAEMS algorithm successfully allocated the fast component of the regulation signal to the flywheel and the slow one to the hydro power plant.

- The WAEMS combined service had the same fast-response characteristic as that provided by the flywheel storage alone. The combined regulation service is faster than that provided by the hydro-alone case when sharing regulation and ACE signals between the hydro and flywheel units.

- The WAEMS combined service was not strictly constrained by energy storage limits because the hydro plant supported the desired flywheels' energy level. The flywheel SOC is well maintained in all cases except the second one where the load-following signal components have greater DC offsets that cannot be fully accounted for by the control algorithm.

- The WAEMS control algorithm provided higher utilization rates and minimized fade time.

- The WAEMS control algorithm reduced wear and tear on the hydro unit and allows it to operate closer to its preferred operating point. The hydro plant responses are less frequent, and the ramps are lower. (A reduction in response or lesser mileage means less wear and tear for the hydro unit.)

- The flywheel-only operation mode requires, ideally, a well-balanced regulation signal that has zero-net-energy $\left(\sum_{i=t_{1}}^{t_{2}} P_{\text {reg }}^{u p}=\sum_{i=t_{1}}^{t_{2}} P_{\text {reg }}^{\text {down }}\right)$ over a 15-minute period. Otherwise, the flywheel may fail to maintain its SOC within $0 \%$ to $100 \%$, resulting in significant fade time. Therefore, for a stand-alone flywheel to meet the regulationduration requirement, one may issue a special regulation signal (the fast regulating component with no bias) to flywheels or operate flywheels with a non-intermittent generating resource to help regulate the flywheel SOC. The New York ISO (NYISO) [25] and the Midwest ISO [26] implemented this approach.

- The WAEMS algorithm developed in Phase I successfully separates the fast regulation signal from the slow one for a real flywheel. The performance was satisfactory considering the reduction in mileage for the hydro plant. However, there are a number of issues that need to be addressed in our future studies: 
o Dead-band. The flywheel has a small dead-band when the required regulating power is too small.

o Automatic control parameter selection. In the control algorithm, it was necessary to manually select a different $\alpha_{\text {hyd }}$ and $\alpha_{f w}$ to adjust the hydro and flywheel shares of the regulation signal. For each set of regulation signals, there is an optimal set of values. One can also adjust these values based on the SOC to avoid longer fade times. It will be worthwhile to set up an automatic parameter selection mechanism to adapt to these variables.

o Multiple objective functions. The current objective function place too much weight on maintaining the flywheel SOC at a specific operating point, for example, $50 \%$. As a result, the controller tries to bring the flywheel back to this set-point once there is a deviation, causing unnecessary responses in the flywheel that do not contribute to hydro mileage reduction. In fact, the flywheel does not have a specific preferred operation point that will make the least wear and tear, but rather it can be operated in a range with similar wear and tear, for example, from $0 \%$ to $80 \%$ charged. Therefore, future work should refine the objective function of the control algorithm to minimize the hydro response while maintaining the flywheel SOC within a preferred operation range. In addition, the economics need to be considered as an alternative objective function rather than this heavily performance-based objective function picked in the field test.

o For mixed signals that have the regulation- and load-following components, the algorithm needs to be adjusted to filter the fast regulation signal out of the mixed signal.

- The optimal capacity combination between the flywheel and hydro plant needs to be determined for a given regulation signal and a hydro power plant's performance characteristics. For example, if a $\pm 20 \mathrm{MW}$ flywheel can work with a hydro plant that can supply $\pm 5 \mathrm{MW}$ up to the $\pm 50 \mathrm{MW}$ regulation, then what is the optimal amount of regulation service that should be provided by the hydro power plant? The answer to this question needs further investigation. 
Table 10: The flywheel performance of the five test cases.

\begin{tabular}{|c|c|c|c|c|c|}
\hline $\begin{array}{c}\text { Assuming } 20 \text { years of } \\
\text { operation }\end{array}$ & $\begin{array}{c}2009 \text { April } \\
\text { BPA+CA } \\
\text { ACE } \\
(160 \mathrm{hr})\end{array}$ & $\begin{array}{l}2009 \text { April } \\
\text { BPA } \\
\text { Base-Point } \\
(160 \mathrm{hr})\end{array}$ & $\begin{array}{l}2009 \text { April } \\
\text { CA } \\
\text { Regulation } \\
(153.5 \mathrm{hr})\end{array}$ & $\begin{array}{c}2013 \\
\text { BPA+CA } \\
\text { ACE } \\
(103.1 \mathrm{hr})\end{array}$ & $\begin{array}{c}2013 \\
\text { BPA } \\
\text { ACE } \\
(160 \mathrm{hr})\end{array}$ \\
\hline $\begin{array}{l}E_{A C E}(\mathrm{GWh}) \\
\text { Input signal energy }\end{array}$ & 0.6794 & 1.1387 & 0.8758 & 0.7135 & 1.2677 \\
\hline $\begin{array}{l}E_{\text {hyd }}(\mathrm{GWh}) \\
\text { Hydro signal energy }\end{array}$ & 0.4748 & 1.0652 & 0.7266 & 0.5428 & 1.0662 \\
\hline $\begin{array}{l}E_{f w}(\mathrm{GWh}) \\
\text { Flywheel signal energy }\end{array}$ & 0.4776 & 0.3791 & 0.5550 & 0.4259 & 0.6422 \\
\hline$T_{\text {fade }}(\mathbf{h r})$ Fade time & 0.83 & 7.43 & 1.54 & 0.01 & 2.55 \\
\hline $\begin{array}{l}K_{\text {meet }} \text { Percent of time meeting } \\
\text { regulation requirement }\end{array}$ & $99.5 \%$ & $95 \%$ & $99 \%$ & $100 \%$ & $98 \%$ \\
\hline$K_{u}$ Utilization Rate & $14.2 \%$ & $13 \%$ & $18 \%$ & $21 \%$ & $19 \%$ \\
\hline $\begin{array}{l}\left|P_{\text {ave }}^{\text {hyd }}\right| \text { (MW) Average hydro } \\
\text { regulation signal }\end{array}$ & 2.83 & 7.61 & 4.73 & 5.27 & 6.35 \\
\hline $\begin{array}{l}\left|P_{a v e}^{f w}\right| \text { (MW) Average flywheel } \\
\text { signal }\end{array}$ & 2.84 & 2.7 & 3.62 & 4.17 & 3.89 \\
\hline Hydro Mileage Up (MW) & 8,613 & 1,949 & 4,828 & 2,075 & 2,656 \\
\hline Hydro Mileage Down (MW) & 8,613 & 1,943 & 4,832 & 2,088 & 2,648 \\
\hline Flywheel Mileage Up (MW) & 64,169 & 15,358 & 33,704 & 11,939 & 21,306 \\
\hline Flywheel Mileage Down (MW) & 64,161 & 15,342 & 33,704 & 11,958 & 21,314 \\
\hline
\end{tabular}




\subsection{Economic Analysis}

Breakeven cost analyses were developed to evaluate the cost of the flywheel regulation services, which are paid-by-capacity ${ }^{12}$.

Assume that within the flywheel's rated power output, $P_{\text {rated }}$, the flywheel is capable of ramping up and ramping down to any power output in 6 seconds without shortening its life. The life-time capacity $P_{\text {life }}$ provided by the flywheel is calculated as:

$$
P_{\text {life }}=L_{y} \times 24 \times 365 \times P_{\text {rated }}
$$

where $L_{y}$ is the flywheel lifetime. The breakeven cost assumes that the annualized cost of capital provides an adequate rate of return to the investor. Thus, an $8 \%$ rate of return is usually comparable to a nominal $10 \%$ to $11 \%$ rate of return before taxes. The discount rate is usually representative of the entity's weighted cost of capital. Breakeven costs include the annualized cost of capital plus the annual operations and maintenance costs.

The annualized cost of capital, including profit before taxes, is as follows

$$
\begin{aligned}
& C_{\text {install }}=E_{\text {rated }} \times \$ 5000 / \mathrm{kWh}=5000 \mathrm{kWh} \times \$ 5000 / \mathrm{kWh}=\$ 25 \mathrm{M} \\
& C_{\text {cap }}=\frac{C_{\text {install }} \times(1+i)^{n} \times i}{(1+i)^{n}-1}
\end{aligned}
$$

where $C_{\text {cap }}$ is the annualized cost of capital, $C_{\text {install }}$ is the installed capital cost including sales taxes, $i$ is the discount rate, and $n$ is the life of the asset.

$$
C_{O \& M}=k_{o p} \times C_{i n s t a l l}+(1-\eta) \times B
$$

where

$$
\begin{aligned}
& \begin{aligned}
& C_{O \& M}=\text { annual operation and maintenance cost } \\
& C_{\text {install }}=\text { installed capital cost } \\
& k_{o p}=\text { percent of the installed capital associated with the annual O\&M cost } \\
& B=\text { price of energy in } \$ / \mathrm{kW} \text {. } \\
& \qquad B_{B E}=\frac{C_{c a p}+C_{O \& M}}{P_{\text {life }}}
\end{aligned}
\end{aligned}
$$

where $B_{B E}$ is the breakeven price in $\$ / \mathrm{kW}$.

\footnotetext{
${ }^{12}$ Pay-by-capacity means that a unit is paid by the capacity bid into the regulation market regardless of the actual energy that it provides to the grid.
} 
The input parameters considered in the economic analysis are listed in Table 11. Please refer to [15] for detailed assumptions made in selecting parameters for the economic analysis. Note that the operations and maintenance $(O \& M)$ costs were estimated at $3 \%$ of the capital costs.

Table 11: The inputs of the model.

\begin{tabular}{|l|l|c|}
\hline \multicolumn{2}{|c|}{ Flywheel Characteristics } & Assumptions \\
\hline Flywheel Capacity (MWh) & 5 \\
\hline Flywheel Power (MW) & 20 \\
\hline Flywheel Life (year) & $10,15,20$ \\
\hline \multirow{4}{*}{ General } & Self Discharging & None \\
\cline { 2 - 3 } & Lifetime (cycles at 100\% DOD) & 150,000 \\
\cline { 2 - 3 } & One-way Efficiency & $90 \%$ \\
\hline \multirow{4}{*}{ Cost } & Capital Cost (\$/kWh) & 5,000 \\
\cline { 2 - 3 } & Start-up Cost (\$) & Not included in the study \\
\cline { 2 - 3 } & Shut-down Cost (\$) & 0.0825 \\
\cline { 2 - 3 } & Sales Tax & 0.08 \\
\cline { 2 - 3 } & Discount Rate & 3\% of the capital cost \\
\cline { 2 - 3 } & Operation Cost (\$) & \\
\hline
\end{tabular}

The current assessment of the flywheel lifetime is based on a theoretical analysis rather than on the experimental data. We varied the lifetime scenarios to evaluate their influence on the breakeven costs. Assuming fixed flywheel lifetimes at 10, 15, and 20 years, the breakeven prices are calculated when the 5-MWh, 20-MW flywheel is run at different DODs at an anticipated power output. This study is a cost-based analysis designed to show, for a fixed lifetime at an average DOD, how much capacity it can provide to the grid during its lifetime and at what cost the flywheel owner can break it even. Note that, in this calculation, we do not consider the cost of the energy lost in the charging and discharging processes. Therefore, the O\&M cost is calculated by letting $\eta=1$ :

$$
C_{O \& M}=k_{o p} \times C_{\text {install }}+(1-\eta) \times B=k_{o p} \times C_{\text {install }}
$$

The breakeven prices are shown in Table 12.

Table 12: Modeling results of the fixed flywheel lifetimes.

\begin{tabular}{|c|c|c|}
\hline $\begin{array}{c}L_{y} \\
\text { Life Time(year) }\end{array}$ & $\begin{array}{c}P_{\text {life }} \\
\text { Life time Capacity }( \pm \mathrm{MW})\end{array}$ & $\begin{array}{c}B \\
(\$ / \pm \mathrm{MW})\end{array}$ \\
\hline $\mathbf{1 0}$ & $1,752,000$ & 27.65 \\
\hline $\mathbf{1 5}$ & $2,628,000$ & 22.68 \\
\hline $\mathbf{2 0}$ & $3,504,000$ & 20.37 \\
\hline
\end{tabular}


Below are a few observations and comments:

- The longer the life of the flywheel is, the lower the breakeven price will be. When the flywheel responds to regulation signals, it normally runs at an average DOD from $20 \%$. When flywheels supply the real regulation signals (e.g., CAISO and ISO-NE ACE signals), they rarely run more than 12 to 15 full DOD cycles daily. Therefore, the flywheel designed for 150,000 cycles can run for 20-year. The breakeven regulation price, $B^{f w}=B_{u p}^{f w}+B_{d o w n}^{f w}$, for $\pm 1 \mathrm{MW}$ flywheel with 20-year designed lifetime, is $\$ 20.37$, as shown in Table 12 .

- Because flywheel storage can either absorb or discharge energy to the grid, it can provide bi-directional regulation service ${ }^{13}$ and bid into both the regulation-up and regulation-down service markets. Therefore, the breakeven price, $B^{f w}$, is for providing $1 \mathrm{MW}$ regulation-up and $1 \mathrm{MW}$ regulation-down services. For example, if in a electricity market, the regulation-up price is $\$ 10 / \mathrm{MW}$ and regulation-down price is $\$ 12 / \mathrm{MW}$, then a $1 \mathrm{MW}$ flywheel would receive $\$ 22$ for providing $\pm 1 \mathrm{MW}$ regulation services in both directions. Because $\$ 22$ is greater than $\$ 20.37$ (See Table 12), the flywheel storage would make profit in this market.

- The evaluation of the breakeven price for the hydro regulation service is not in the scope of this project; therefore, the price was not calculated. Based on the average regulation prices published at the CAISO website (see [21]), the lowest prices are approximately $\$ 2 / \mathrm{MW}$ for regulation-up and $\$ 2 / \mathrm{MW}$ for regulation-down service. Therefore, the bi-directional service is paid $\$ 4 / \pm M W$. Thus, for the combined regulation service provided by the flywheel-hydro hybrid energy storage, the weighted breakeven price for the regulation-up and regulation-down services are calculated as:

$$
\begin{aligned}
& B_{u p}^{f w-h y d}=\frac{\left(B_{u p}^{f w}+B_{u p}^{h y d}\right)}{2}=(10.18+2) / 2=6.09 \$ / \mathrm{MW} \\
& B_{\text {down }}^{f w-h y d}=\frac{\left(B_{\text {down }}^{f w}+B_{\text {down }}^{\text {hyd }}\right)}{2}=(10.18+2) / 2=6.09 \$ / \mathrm{MW}
\end{aligned}
$$

The weighted breakeven price for the bi-directional service is calculated as:

$$
B_{f w-h y d}=\frac{\left(B_{u p}^{f w}+B_{d o w n}^{f w}+B_{u p}^{h y d}+B_{d o w n}^{h y d}\right)}{2}=\frac{(20.37+4)}{2}=12.19 \$ / \pm \mathrm{MW}
$$

\footnotetext{
${ }^{13}$ The bi-directional regulation service of \pm 1 MW includes 1 MW regulation-up and 1 MW regulation-down.
} 
In the BPA balancing authority, the average regulation price in 2010 is $\$ 6.75 / \mathrm{kW}$-month [22][24] for $\pm 1 \mathrm{~kW}$ bi-directional regulation service. The payment for $1 \mathrm{MW}$ bi-directional regulation service is calculated as

$$
6.75 \times 1000 /(30 \times 24)=9.38 \$ / \pm M W
$$

In the CAISO balancing authority (Region CAISO_EXP), the average day-ahead regulation price [21] from January to July 2010 is $\$ 5.38 / \mathrm{MW}$ for regulation-down and $\$ 6.57 / \mathrm{MW}$ for regulation-up, as shown in Table 13 . The payment of $1 \mathrm{MW}$ bi-directional regulation service is calculated as

$$
5.38+6.57=11.95 \$ / \pm \mathrm{MW} .
$$

Table 13: The 2010 CAISO regulation prices (Region CAISO_EXP)

\begin{tabular}{|l|c|c|c|}
\hline 2010 & $\begin{array}{c}\text { Average } \\
\text { Regulation-down } \\
(\mathbf{1} \mathbf{~ M W})\end{array}$ & $\begin{array}{c}\text { Average } \\
\text { Regulation-up } \\
(\mathbf{1} \mathbf{M W})\end{array}$ & $\begin{array}{c}\text { Average } \\
\text { Bi-directional Regulation } \\
( \pm 1 \mathrm{MW})\end{array}$ \\
\hline Jan & $\$ 4.38$ & $\$ 4.99$ & $\$ 9.37$ \\
\hline Feb & $\$ 4.27$ & $\$ 4.75$ & $\$ 9.02$ \\
\hline March & $\$ 4.39$ & $\$ 5.00$ & $\$ 9.39$ \\
\hline April & $\$ 3.90$ & $\$ 5.22$ & $\$ 9.12$ \\
\hline May & $\$ 5.71$ & $\$ 8.33$ & $\$ 14.04$ \\
\hline June & $\$ 9.16$ & $\$ 11.60$ & $\$ 20.76$ \\
\hline July & $\$ 5.83$ & $\$ 6.10$ & $\$ 11.93$ \\
\hline Average & $\$ 5.38$ & $\$ 6.57$ & $\$ 11.95$ \\
\hline
\end{tabular}

The breakeven price for flywheel energy storage to provide bi-directional service (1 MW regulation-up and $1 \mathrm{MW}$ regulation-down) is $\$ 20.37 / \pm \mathrm{MW}$. Because the average bi-directional regulation price of the CAISO balancing authority is $\$ 11.95 / \pm \mathrm{MW}$ (Jan.-July, 2010) and that of the BPA balancing authority is $\$ 9.38 / \pm$ MW (2010), regulation service provided by a standalone flywheel energy storage will not be economical unless the regulation price will be increased or the fast regulation service will be paid at a higher rate.

Assuming that the minimum regulation price of regulation provided a hydro power plant is $\$ 4 / \pm \mathrm{MW}$, the breakeven price of the combined flywheel-hydro regulation service would be $\$ 12.19 / \pm \mathrm{MW}$; therefore, the flywheel-hydro regulation service breakeven price is found to be slightly higher than the average CAISO (\$11.95/ $\pm \mathrm{MW})$ and BPA (\$9.38/ $\pm \mathrm{MW})$ regulation prices. Because regulation prices are increasing when more renewable generation resources are integrated into the power grids, the flywheel-hydro regulation service is expected to become economical in the CAISO and BPA balancing authorities soon. 


\subsection{Conclusions}

The main findings can be summarized as follows:

- The flywheel followed the regulation signal with a 6-second response delay.

- The proposed WAEMS algorithm successfully allocated the fast component of the regulation signal to the flywheel and the slow one to the hydro power plant.

- The WAEMS combined service had the same fast-response characteristic as that provided by the flywheel storage alone.

- The WAEMS combined service was not strictly constrained by energy storage limits because the hydro plant supported the desired flywheels' energy level.

- The WAEMS control algorithm provided higher utilization rates and minimized fade time.

- The WAEMS control algorithm reduced wear and tear on the hydro unit and allows it to operate closer to its preferred operating point. (A reduction in response or lesser mileage means less wear and tear for the hydro unit.)

- The breakeven price for flywheel energy storage to provide bi-directional service (1 MW regulation-up and 1 MW regulation-down) is $\$ 20.37 / \pm \mathrm{MW}$. Because the average bi-directional regulation price of the CAISO balancing authority is $\$ 11.95 / \pm$ MW (Jan.-July, 2010) and that of the BPA balancing authority is $\$ 9.38 / \pm$ MW (2010), regulation service provided by a stand-alone flywheel energy storage will not be economical unless the regulation price will be increased or the fast regulation service will be paid at a higher rate.

- Assuming that the minimum regulation price of regulation provided a hydro power plant is $\$ 4 / \pm \mathrm{MW}$, the breakeven price of the combined flywheel-hydro regulation service would be $\$ 12.19 / \pm \mathrm{MW}$; therefore, the flywheel-hydro regulation service breakeven price is found to be slightly higher than the average CAISO $(\$ 11.95 / \pm$ $\mathrm{MW})$ and $\mathrm{BPA}(\$ 9.38 / \pm \mathrm{MW})$ regulation prices. Because regulation prices are increasing when more renewable generation resources are integrated into the power grids, the flywheel-hydro regulation service is expected to become economical in the CAISO and BPA balancing authorities soon.

Note that the flywheel energy storage can be operated in one of two ways to mitigate the flywheels' finite energy capacity: 1) receive a specially generated well-balanced regulation signal from the ISO, or 2) use an energy management system, such as the WAEMS, so it can respond to the same regulation signal as that sent to conventional generators. 
The New York ISO (NYISO) [25] and the Midwest ISO [26] implemented the Approach 1, which is a stand-alone application for the flywheel energy storage. The proposed WAEMS belongs to the second approach, which is a more flexible, effective, and economical operating scheme. By operating the flywheel energy storage combined with a hydro plant or some other generation resource, the combined service takes advantage of both. This not only reduces the wear and tear of the conventional regulating resources, but also helps the flywheel energy storage to stay within its energy limits. As shown in the main findings, the initial results have demonstrated an improved flywheel performance in terms of the utilization and the breakeven price.

To summarize, we conclude that a combined regulation service provided by a hydro power plant and a flywheel energy storage creates the following important benefits:

- providing additional means of mitigating the variability introduced by renewable resources,

- reducing the wear and tear of the hydro units,

- reducing the regulation requirements for BPA and CAISO balancing authorities by sharing the regulation services between them,

- providing combined service that has the same fast-response characteristic as that provided by the flywheel energy storage alone, and

- maintaining desired energy levels at the energy storage devices. 


\subsection{Recommendations and Future Works}

\subsection{Recommendations}

From Phase I and II results, we concluded that the opportunities for flywheels or other energy storage devices lie in the following areas:

- To avoid performance problems associated with their finite energy storage capacity, provide regulation services for system operators which would agree to manage the flywheels' energy level, or participate in alternative schemes helping to co-optimize fast acting storage devices and conventional generators to provide high-quality combined regulation services.

- Operate energy storage devices in conjunction with conventional generators to improve their response time, reduce their wear and tear, and provide compatible services that do not require modifications of the existing automatic generation control and market systems.

- To increase the capacity payment, explore opportunities for sharing regulation services among two or more balancing authorities.

- Investigate methods and tariff changes so that the fast responsive and flexible resources can be compensated for additional services such as frequency response, fast ramping, voltage and reactive power support, or damping of transmission line oscillations to prevent grid angular instability.

\subsection{Future Works}

During Phase 2 of the Wide Area Storage and Management System (WAEMS) project

- a standalone sodium sulfur battery storage for regulation and load-following services was demonstrated to be not economical;

- the performance of a prototype WAEMS controller that operates a flywheel energy storage system in conjunction with a hydropower plant for regulation service was demonstrated to be satisfactory by field tests using actual Bonneville Power Administration (BPA) and California Independent System Operator (CAISO) regulation signals; and

- the breakeven price of the WAEMS regulation service was calculated to be slightly higher than the current average price for regulation in the CAISO market. 
Based on these results, it is recommended that the next phase of the WAEMS project focus on research leading to (1) practical deployment of the WAEMS that provides balancing services (including both load-following and regulation services) to the CAISO and BPA balancing authorities and (2) commercialization of the control algorithms developed in Phases 1 and 2 of the WAEMS project.

A near-term goal should be commercialization of a shared storage system between CAISO and BPA. A longer term goal should be development of methodologies for operating both fast and slow resources and sharing these resources over multiple control areas to facilitate the renewable integration and operate the power grids reliably and economically.

The next steps are to

- enhance the WAEMS controller so that it is more robust and can provide load following services;

- field test more energy storage technology options, such as Li-ion battery energy storage; and

- assist BPA and CAISO to deploy a WAEMS system between BPA (offer a hydropower plant) and CAISO (offer an energy storage device).

Another potential area of future research is the development of an energy storage evaluation toolbox that incorporates the models, algorithms, methodologies, and standardized testing signals developed or obtained in previous WAEMS tasks. This toolbox would help users find optimal configurations and assess the performance and economics of different energy storage solutions, enabling them to answer the following questions:

- Are the selected ESDs capable of providing the required services as expected?

- How much fast-regulating ESD capacity is needed for a given regulation/loadfollowing signal?

- What is the cost of the service?

This research will provide information for power grid operators to make decisions on building an energy storage portfolio that best meets the wind-integration requirements and is most economical to implement. 


\subsection{References}

[1] Y.V. Makarov, P. Nyeng, B. Yang, J. Ma, J.G. DeSteese, D.J. Hammerstrom, S. Lu, V.V. Viswanathan, and C.H. Miller, Wide-Area Energy Storage and Management System to Balance Intermittent Resources in the Bonneville Power Administration and California ISO Control Areas. PNNL-17574. Pacific Northwest National Laboratory, Richland, WA, 2008.

[2] Y.V. Makarov, C. Loutan, J. Ma, and P. de Mello, “Operational impacts of wind generation in California power system," IEEE Trans. on Power Systems. 24(2): 1039-1050, 2009.

[3] Y.V. Makarov, J. Ma, S. Lu, and T.B. Nguyen, "Assessing the Value of Regulation Resources Based On Their Time Response Characteristics", PNNL Project Report PNNL17632, Prepared for CERTS and California Energy Commission, June 2008.

[4] Y. V. Makarov, B. Yang, J. G. DeSteese, P. Nyeng, C. H. Miller, J. Ma, S. Lu, V. V. Viswanathan, D. J. Hammerstrom, B. McManus, J. H. Pease, C. Loutan, and G. Rosenblum "Wide-Area Energy Storage and Management System to Balance Intermittent Resources in the Bonneville Power Administration and California ISO Control Areas," Proc. 8th International Workshop on Large-Scale Integration of Wind Power into Power Systems, Bremen, Germany, October 14-15, 2009, pp. 488-495.

[5] B. Yang, Y. Makarov, J. DeSteese, V. Viswanathan, P. Nyeng, B. McManus, and J. Pease, "On the Use of Energy Storage Technologies for Regulation Services in Electric Power Systems with Significant Penetration of Wind Energy", Proc. 5th International Conference on the European Electricity Market - EEM08, Paper \#328, Lisbon, Portugal, May 28-30, 2008.

[6] Beacon Power Flywheel Fact Sheet. Available online: www.beaconpower.com/files/Flywheel FR-Fact-Sheet.pdf.

[7] Taku Oshima, Masaharu Kajita, and Akiyasu Okuno, "Development of Sodium-Sulfur Batteries," Int. J. Appl. Ceram. Technol., 1 [3] 269-76 (2004).

[8] A. Bito, "Overview of the sodium-sulfur battery for the IEEE Stationary Battery Committee," Proc. of the 2005 PES general meeting, pp. 1232-1235, vol. 2, June 2005.

[9] Wikipedia. 2009. Net present value. Available online: http://en.wikipedia.org/wiki/Net_present_value.

[10] R. Walawalkar and J. Apt, Market Analysis of Emerging Electric Storage Systems. DOE/NETL-2008/1330, U.S. Department of Energy, National Energy Technology Laboratory, Morgantown, WV, 2008.

[11] Alan Ruddell, Investigation on Storage Technologies for Intermittent Renewable Energies:Evaluation and recommended R\&D strategy: Storage Technology Report ST6: Flywheel. WP-ST6 Flywheel. Chilton, Didcot, UK, 2003. Available online: http://en.wikipedia.org/wiki/Flywheel_energy_storage.

[12] Ed Douglas, Next-gen Of Flywheel Energy Storage. Product Design \& Development, March, 2009. Available online: http://www.pddnet.com/article-next-gen-of-flywheel-energy-storage/. 
[13] C.T. Horngren, G.L. Sundem, and W.O. Stratton. Introduction to Management Accounting, Prentice Hall, 2002.

[14] P. Nyeng, Bo Yang, Jian Ma, Y. V. Makarov, J. H. Pease, D. Hawkins, and C. Loutan, "Coordinated multi-objective control of regulating resources in multi-area power systems with large penetration of wind power generation", Proc. 7th International Workshop on Large-Scale Integration of Wind Power into Power Systems, Paper \#53, Madrid, Spain, May 26-27, 2008.

[15] N. Lu, M.R. Weimar, Y.V. Makarov, J. Ma, and V.V. Viswanathan, The Wide-Area Energy Storage and Management System - Battery Storage Evaluation. PNNL-18679, Pacific Northwest National Laboratory, Richland, WA, 2009.

[16] CAISO Real-Time Daily Market Watch, Available online: http://www.caiso.com/23a1/23a1c85b274b0.html

[17] CAISO Market Performance Report for April 2009. Available online: http://www.caiso.com/17ed/17ed90c231ac0.html

[18] The BPA total load, total wind generation, and ACE signal (April 13-18, 2010). Available online: http://www.transmission.bpa.gov/Business/Operations/Wind/default.aspx

[19] Shuai Lu and Yuri V. Makarov, Prediction of Within-Hour Balancing Requirements with Integration of Large Scale Wind. PNNL Project Report 18123, Prepared for the Bonneville Power Administration under Contract 51028, Pacific Northwest National Laboratory, Richland, WA, 2008.

[20] Yuri V. Makarov, Shuai Lu, Bart McManus and John Pease, The Future Impact of Wind on BPA Power System Ancillary Services. IEEE Transmission and Distribution Conference 2008, Chicago, April 2008.

[21] CAISO Regulation Prices. Available online: http://oasis.caiso.com.

[22] The BPA Generation Inputs Study (WP-10-FS-BPA-08). Available online: http://www.bpa.gov/corporate/ratecase/2008/2010 BPA Rate Case/wp-10.cfm

[23] Bonneville Power Administration Transmission Services 2010 Transmission and Ancillary Service Rate Schedules. 2010. Available online: http://www.transmission.bpa.gov/Business/Rates/documents/2010_Rate_Schedules_10_01 _09.pdf).

[24] 2010 Transmission and Ancillary Service Rate Schedules. Available online: http://www.transmission.bpa.gov/Business/Rates

[25] New York ISO current tariff. Available online: https://www.nyiso.com/public/webdocs/documents/tariffs/market_services/services_tariff. pdf.

[26] Midwest ISO current tariff. Available online: http://www.midwestiso.org/publish/Document/1d44c3 11e1d03fcc5 7cf90a48324a/Modules.pdf?action=download\& property=Attachment. 


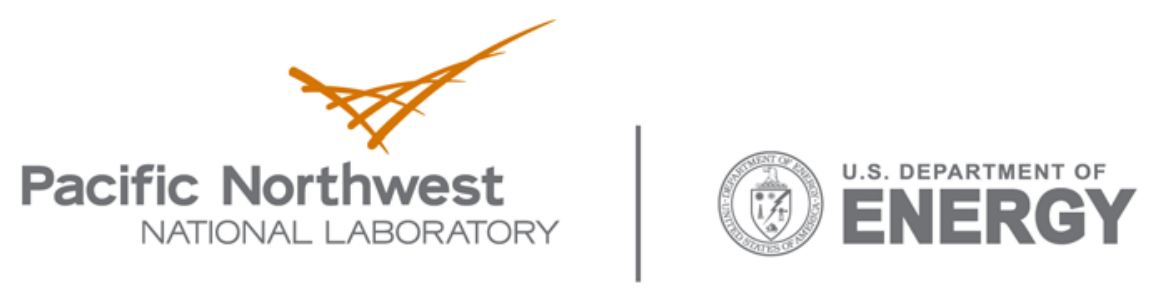

902 Battelle Boulevard

P.O. Box 999

Richland, WA 99352

1-888-375-PNNL (7665)

www.pnl.gov 